ALINE MASSABNI MOMENTI

\title{
MOVIMENTOS INDUZIDOS PELO ESCOAMENTO AO REDOR DE CILINDROS COM ALTERAÇÕES DE GEOMETRIA NA EXTREMIDADE LIVRE
}




\section{ALINE MASSABNI MOMENTI}

\section{MOVIMENTOS INDUZIDOS PELO ESCOAMENTO AO REDOR DE CILINDROS COM ALTERAÇÕES DE GEOMETRIA NA EXTREMIDADE LIVRE}

Dissertação apresentada à Escola Politécnica da Universidade de São Paulo para a obtenção do título de Mestre em Ciências. 


\section{MOVIMENTOS INDUZIDOS PELO ESCOAMENTO AO REDOR DE CILINDROS COM ALTERAÇÕES DE GEOMETRIA NA EXTREMIDADE LIVRE}

Dissertação apresentada à Escola Politécnica da Universidade de São Paulo para a obtenção do título de Mestre em Ciências

Área de Concentração:

Engenharia Naval e Oceânica

Orientador:

Prof. Dr. André Luís Condino Fujarra

São Paulo

2019 
Autorizo a reprodução e divulgação total ou parcial deste trabalho, por qualquer meio convencional ou eletrônico, para fins de estudo e pesquisa, desde que citada a fonte.

Este exemplar foi revisado e corrigido em relação à versão original, sob responsabilidade única do autor e com a anuência de seu orientador.

São Paulo, 26 de morgo de 2019

Assinatura do autor:

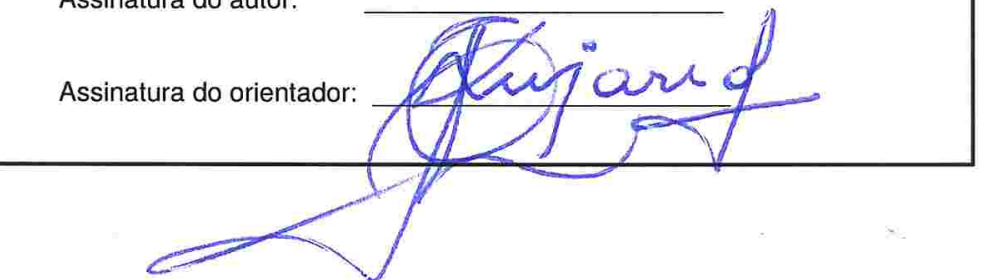

Catalogação-na-publicação

Momenti, Aline

Movimentos induzidos pelo escoamento ao redor de cilindros com alterações na geometria na extremidade livre. / A. Momenti -- versão corr. -- São Paulo, 2018.

$104 \mathrm{p}$.

Dissertação (Mestrado) - Escola Politécnica da Universidade de São Paulo. Departamento de Engenharia Naval e Oceânica.

1.Vibrações Induzidas pelo Escoamento 2.Vibrações Induzidas por Vórtices 3.Cilindros com baixa razão de aspecto I.Universidade de São Paulo. Escola Politécnica. Departamento de Engenharia Naval e Oceânica II.t. 


\section{Dedicatória}

Aos meus pais Luiz e Uadia, que me deram amor, carinho e educação para lutar e realizar meus sonhos. 



\section{Agradecimentos}

A Deus pelo presente da vida e que iluminou meu caminho durante estes anos; Aos meus pais, Luiz e Uadia, meu irmão Leonardo que sempre me deram todo o suporte para que eu ultrapassasse todos os obstáculos e conseguisse a conclusão das mais variadas tarefas em todos os âmbitos da vida pessoal e profissional;

À Rafaela, minha sobrinha, por me alegrar, renovar e ressignificar muitas concepções e entendimentos em minha vida;

Ao Diogo, por me incentivar a ser melhor que eu posso a cada dia, por sempre ter uma palavra de apoio, por se fazer presente mesmo que distante, com seu amor e cumplicidade.

As minhas companheiras de vida e lar: Amanda, Vivian, Ana, Luisa, Letícia e Bruna. Obrigada pelas refeições prontas, chás, conversas e desabafos, tornando nossa casa um lugar incrível e harmônico, ainda que com tantas diferenças;

Aos queridos Lota, Maria, Carol, tio Ban, tia Lu, Khal e Rapha: gratidão pela acolhida ao lar de vocês, nos momentos que mais precisei;

A todas as pessoas que estiveram comigo neste período e que, de alguma forma, contribuíram com amor e paciência para que eu chegasse ao final desta etapa;

Ao Departamento de Engenharia Naval e Oceânica da Escola Politécnica da Universidade de São Paulo, especialmente à Lânia Camilo;

Aos profissionais do Tanque de Provas Numérico, também da Universidade de São Paulo, por proporcionar um grande conhecimento e desenvolvimento em pesquisas científicas;

À equipe do Instituto de Pesquisas Tecnológicas do Estado de São Paulo, pela disponibilização do tanque de reboque para a realização dos ensaios e todo suporte técnico que foi necessário para a realização dos mesmos - especialmente para os técnicos: 'Seu' Mário, David, Bruno e Fidel;

Aos meus queridos amigos de pós-graduação: Maria Eduarda Chame e Pedro Paludetto: pela parceria em projetos e momentos de discussão, não somente sobre as pesquisas, mas pela amizade e por proporcionar um ambiente agradável na sala;

Ao Prof. Dr. André Luís Condino Fujarra, pela orientação, pela paciência e pelo constante estímulo transmitido durante todo o trabalho, pelo seu empenho profissional, pela amizade, calma e serenidade nos momentos mais difíceis;

E por fim, mas nem por isso menos importante, ao Prof. Dr. Rodolfo Gonçalves, que nunca deixou de acreditar em mim, pelas oportunidades, por me incentivar e chamar a atenção nos momentos necessários, sempre com o propósito de me ajudar a atingir excelência como profissional e principalmente, como pessoa. Gratidão por nossas 
infinitas conversas e inspirações ao longo destes anos de amizade. 
Talvez não tenha conseguido fazer o melhor, mas lutei para que o melhor fosse feito. Não sou o que deveria ser, mas graças a Deus não sou o que era antes.

(Marthin Luther King) 



\section{Resumo}

O desenvolvimento da indústria offshore fez com que a demanda por unidades flutuantes para operações em águas ultraprofundas aumentasse e, com isso, surgiu um maior interesse nos fenômenos decorrentes de vibrações induzidas pelo escoamento em plataformas do tipo spar, TLP e semissubmersível, além de torres para produção de energia eólica (instaladas no mar). Para ampliar o conhecimento nesta área, experimentos foram realizados com cilindros flutuantes com baixa razão de aspecto $(L / D=2)$ e com diferentes geometrias na extremidade livre. Experimentos com a vibração induzida pelo escoamento em cilindros de seção quadrada e cilindros de seção quadrada e arestas arredondadas com baixa razão de aspecto foram realizados em um tanque de reboque. Estas diferentes geometrias de cilindros foram testadas e suportadas elasticamente por um conjunto de molas lineares. Dois ângulos de incidência diferentes foram testados: 0 e 45 graus. Os resultados de amplitude na direção transversal para modelos submetidos à incidência de 0 graus mostraram ser maiores. Além disso, as oscilações em yaw se mostraram importantes em todos os caso analisados. O efeito das arestas se mostrou importante, particularmente na incidência de 45 graus, para velocidades reduzidas maiores que 8 .

Palavras-chave: Vibração Induzida por Vórtices (VIV), baixa razão de aspecto, cilindro de seção quadrada. 



\section{Abstract}

The development of the offshore industry has meant that the demand for ultradeep water floating units has increased, and with this, a greater interest in the phenomena arising from FIV in spar, TLP and semi-submersible platforms has arisen. In order to increase the area knowledge, experiments were performed with floating cylinders with different geometries, with low aspect ratio $(L / D=2)$. Experiments of flow-induced vibration in cylinders with sharp aokokoknd rounded square section with low aspect ratio were performed in a towing tank. These geometries have been tested and elastically supported by a set of linear springs to provide low structural damping to the system. Two different incidence angles were tested: 0 and 45 degrees. The transverse response amplitudes for the 0-degree flow incidence were found to be larger. Moreover, yaw oscillations are important for all the cases analyzed. The rounded effect on the cylinders of square section were important, particularly for the the 45-degree incidence at reduced velocities higher than 8 .

Keywords: Vortex-Induced vibration (VIV), low aspect ratio, square-section cylinder. 



\section{Lista de Figuras}

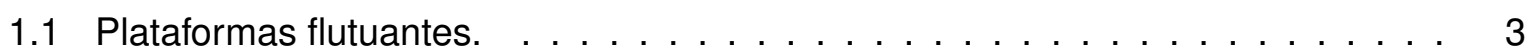

1.2 Um esboço do problema estudado: um cilindro transversal, de seção quadrada, com ângulo variável de ataque. . . . . . . . . . . . . . .

1.3 Um esboço do problema estudado: um cilindro transversal de seção quadrada e arestas arredondadas, com ângulo variável de ataque. . . . . . . . . . . . .

2.1 Esquema e visualizações do escoamento ao redor de um corpo afilado e um corpo rombudo, respectivamente. Imagens reproduzidas por Assi (2005), adaptadas de van Dyke (1982). . . . . . . . . . . . . . . . . . . .

2.2 Regiões de escoamento perturbado pela presença do corpo rombudo. Extraído de Assi (2005). . . . . . . . . . . . . . . . . . . . 10

2.3 Estágios da separação do escoamento e formação de bolhas de recirculação próxima a esteira. Extraído de Assi (2005), adaptado de van Dyke (1982). . . . 10

2.4 Início da instabilidade da esteira em regime laminar. Imagens extraídas de Batchelor (1967) e adaptado por Assi (2005). . . . . . . . . . . . . . . . . 11

2.5 Esteira de vórtices de Von Kármán para dois regimes de escoamento: laminar $(R e=140)$ e turbulento $\left(R e=10^{4}\right)$. Extraído de Van Dyke (1982) e adaptado por Assi (2005). . . . . . . . . . . . . . . . . . . . . . . . . 12

2.6 Esquema da formação da esteira de vórtices de um cilindro circular. Extraído de Gerrard (1966) e adaptado por Korkischko (2011).

2.7 Variação do número de Strouhal pelo número de Reynolds. Extraído de NORBERG (2000). . . . . . . . . . . . . . . . . . . . . .

2.8 Comportamentos dos coeficientes de pressão comparados com os regimes do escoamento e configurações de esteira. Curvas de $C x R e$ adaptadas de Zdravkovich (1997) por Assi (2005). . . . . . . . . . . . . . . . . . . . . . . 17

2.9 (a) Amplitudes transversal do VIV, em função da velocidade reduzida. Os pontos quadrados cheios foram obtidos por Khalak (1997), para $m^{*}=2,4$, e os pontos diamantes foram obtidos por Feng (1968), para $m^{*} \approx 250 \ldots \ldots \ldots \ldots .19$ 
2.10 Frequência de resposta adimensional em função da velocidade reduzida. Extraído de Khalak e Williamson (1997) . . . . . . . . . . . . . . . . . . . . 21

2.11 Lock-in. Extraído de Blevins (1990) adaptado por Santos (2011) . . . . . . . . . . 22

2.12 Padrão $2 P$ emitido de um cilindro com oscilação forçada. Extraído de Williamson \& Roshko (1988) . . . . . . . . . . . . . . . . . . . . 25

2.13 Padrão $2 P$ emitido de um cilindro com oscilação forçada. Extraído de Williamson e Govardhan (2004) . . . . . . . . . . . . . . . . . . . . . . . . . . . . 26

2.14 (a) Imagens ilustram o padrão $2 S$ e (b) ilustra o padrão $P+S$. Imagens superiores extraídas de Williamson e Govardhan (2004) e inferiores extraídas de Meneghini e Bearman (1995). . . . . . . . . . . . . . . . . .

2.15 (a) Modo $2 S$ e; (b) Modo $2 P$ em cilindro livre para oscilar. Figura extraída de Flemming e Williamson (2005) e adaptado por Freire (2015). . . . . . . . . . . . 27

2.16 Modo A $(R e=200$ e B $R e=270$. Extraído de Williamson (1996b). . . . . . . .

2.17 Amplitude adimensional transversal, $A_{y} / D$, como função da velocidade reduzida $V_{r}$, para cilindros flutuantes com razão de massa $m^{*}=1$ e diferentes razões de aspecto. Extraído de Gonçalves (2013). . . . . . . . . . . . . . . . . . . . . .

2.18 Comparação entre sistemas massa-mola livres para oscilar com 1GL e 2GL. Adaptado de Jauvtis e Williamson (2004), extraído de Gongalves (2013). . . . . 29

2.19 Sistema com um cilindro oscilando em $1 G L \ldots \ldots \ldots$. . . . . . . . 30

2.20 Escoamento ao redor de cilindros fixos com baixa razão de aspecto. A esquerda $L / D>\left(L / D_{c} r\right)$ e a direita $L / D<\left(L / D_{c} r\right) \ldots \ldots \ldots \ldots$

2.21 Cilindro fixo em uma placa plana e imerso a um escoamento. Extraído de Gambarine (2017) e adaptado de Sumner (2004). . . . . . . . . . . . . . . . . . .

2.22 Fluxo visualizado em torno da extremidade livre no plano vertical XZ em $Y / D=$ 0: (a) ponta plana; (b) ponta chanfrada; c) ponta arredondada; d) ponta hemisférica. Extraído de Park \& Lee -2004 . . . . . . . . . . . . . . . . . . .

2.23 Distribuições espaciais de velocidade média e intensidade de turbulência $(Y / D=$ 0; plano XZ): (a) ponta plana; (b) ponta chanfrada; c) ponta radiante; e (d) ponta

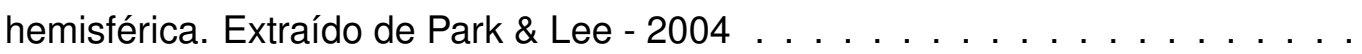

2.24 Distribuições espaciais de velocidade média e intensidade de turbulência $(Y / D=$ 0; plano XZ): (a) ponta plana; (b) ponta chanfrada; c) ponta radiante; e (d) ponta hemisférica. Extraído de Park \& Lee - 2004 . . . . . . . . . . . . . . . . . .

2.25 Desenho esquemático mostrando a emissão de vórtices ao redor de um cilindro com efeito da extremidade livre. Adaptado de Someya, 2010. Extraído de Gonçalves, 2013. . . . . . . . . . . . . . . . . . . . . . . . . . . . . . . 35 
2.26 Campo de velocidade adimensional na direção longitudinal do escoamento, no plano vertical central do cilindro, e respectivas linhas de corrente, para diferentes razões de aspecto e número de Reynolds. Extraído de Gonçalves, 2013. . . . . . 37

2.27 Mapa da resposta FIV de um cilindro quadrado com variação no ângulo de ataque e velocidade reduzida, $U^{*}$. As regiões são rotuladas de acordo com o tipo de resposta.O tamanho relativo dos símbolos denota a energia relativa das frequências dominantes no sistema. Extraído de Nemes, 2012.

2.28 Esboço do problema estudado: um cilindro transversal com ângulo de ataque variável, restrito para oscilar pelo fluxo. Extraído de Zhao, 2014. . . . . . . . . . . .

2.29 A amplitude (a) e a resposta de frequência (b) - (e) como função de $U^{*}$ com $m^{*}=2.64$ em $\alpha=20 \check{r}$, mostrando duas regiões de ressonância sombreadas cinza escuro. Extraído de Zhao, 2014. . . . . . . . . . . . . . . . . . . . . . . . . 40

2.30 Representações da interação entre VIV e Galloping. Extraído de AMATO (2010). 43

3.1 Foto do carro dinamométrico do tanque de reboque no IPT. . . . . . . . . . . 45

3.2 Foto carro secundário acoplado ao carro dinamométrico do tanque de reboque.

3.3 Ilustração do aparato experimental montado no carro secundário. A esquerda: vista superior. A direita: vista lateral. . . . . . . . . . . . . . . . . . . . .

3.4 A esquerda, configuração das câmeras usadas no ensaio. A direita, detalhes de uma dessas câmeras. . . . . . . . . . . . . . . . . . . . . . . . . . .

3.5 Foto dos cilindros utilizados para os experimentos estudado. . . . . . . . . . 48

3.6 Principais parâmetros geométricos dos cilindros estudado.

4.1 Exemplos de registros temporais de deslocamento adimensional nas direções longitudinal, transversal e vertical do modelo SSE-00 (modelo com arestas vivas e incidência $0^{\circ}$ ) em $V_{r}=7,34$.

4.2 Comparação entre as amplitudes e frequências de resposta transversal ao escoamento para os quatro modelos ensaiados: marcadores quadrados referem-se à incidência $0^{\circ} \mathrm{e}$, com o interior preenchido, aos modelos com arestas arredondadas SRE.

4.3 Comparação entre as amplitudes e frequências de resposta longitudinal ao escoamento para os quatro modelos ensaiados: marcadores quadrados referemse à incidência $0^{\circ} \mathrm{e}$, com o interior preenchido, aos modelos com arestas arredondadas SRE.

4.4 Comparação entre as amplitudes e frequências de resposta em yaw para os quatro modelos ensaiados: marcadores quadrados referem-se à incidência $0^{\circ}$ e, com o interior preenchido, aos modelos com arestas arredondadas SRE. . . . 
4.5 Amplitudes e frequências adimensionais de resposta na direção transversal ao escoamento para o modelo SRE-00, arestas arredondadas e incidência $0^{\circ}$. . . 56

4.6 Amplitudes e frequências adimensionais de resposta na direção transversal ao escoamento para o modelo SRE-45, arestas arredondadas e incidência $45^{\circ}$. . . 57

4.7 Amplitudes e frequências adimensionais de resposta na direção transversal ao escoamento para o modelo SSE-00, arestas vivas e incidência $0^{\circ} \ldots \ldots$. . . . . 58

4.8 Amplitudes e frequências adimensionais de resposta na direção transversal ao escoamento para o modelo SSE-45, arestas vivas e incidência $45^{\circ}$. . . . . . . . 59

4.9 Amplitudes e frequências adimensionais de resposta na direção longitudinal ao escoamento para o modelo SRE-00, arestas arredondadas e incidência $0^{\circ}$. . . 60

4.10 Amplitudes e frequências adimensionais de resposta na direção longitudinal ao escoamento para o modelo SRE-45, arestas arredondadas e incidência $45^{\circ}$. . . 61

4.11 Amplitudes e frequências adimensionais de resposta na direção longitudinal ao escoamento para o modelo SSE-00, arestas vivas e incidência $0^{\circ}$. . . . . . . . 62

4.12 Amplitudes e frequências adimensionais de resposta na direção longitudinal ao escoamento para o modelo SSE-45, arestas vivas e incidência $45^{\circ}$. . . . . . 63

4.13 Amplitudes e frequências adimensionais de resposta em yaw para o modelo SRE-00, arestas arredondadas e incidência $0^{\circ} \ldots \ldots \ldots$. . . . . . . . . . 64

4.14 Amplitudes e frequências adimensionais de resposta em yaw para o modelo

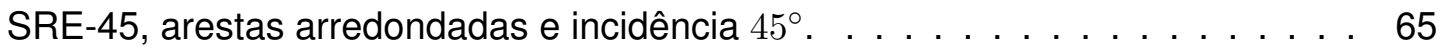

4.15 Amplitudes e frequências adimensionais de resposta em yaw para o modelo SSE-00, arestas vivas e incidência $0^{\circ} \ldots \ldots \ldots 66$

4.16 Exemplos de registros temporais de rotação (roll, pitch e yaw) do modelo SSE00 (modelo com arestas vivas e incidência $0^{\circ}$ ) em $V_{r}=7,34 \ldots \ldots 7$

4.17 Amplitudes e frequências adimensionais de resposta em yaw para o modelo SSE-45, arestas vivas e incidência $45^{\circ}$. 


\section{Lista de Tabelas}

3.1 Características geométricas das molas utilizadas. . . . . . . . . . . . . 46

3.2 Principais características das câmeras Qualisys ${ }^{\circledR}$. . . . . . . . . . . . . . . 47

3.3 Parâmetros dimensionais dos cilindros. . . . . . . . . . . . . . . . . . . . . . 48

3.4 Parâmetros dos testes para cada condição. . . . . . . . . . . . . . . . 50 



\title{
Lista de Símbolos
}

\author{
$\rho \quad$ Densidade do fluido \\ $v$ Viscosidade cinemática do fluido \\ $\zeta$ Coeficiente de amortecimento \\ $A$ Lado da seção quadrada dos modelos \\ $C_{D} \quad$ Coeficiente de arrasto \\ $C_{L} \quad$ Coeficiente de sustentação \\ d Diâmetro do arame das espiras das molas \\ $D$ Dimensão característica dos cilindros quadrados \\ $D_{0} \quad$ Diâmetro das espiras das molas \\ $f_{a q} \quad$ Frequência de aquisição dos sinais experimentais \\ $f_{n y} \quad$ Frequência natural na direção transversal \\ $f_{s} \quad$ Frequência de emissão de vórtices \\ $f_{x} \quad$ Frequência de oscilação na direção longitudinal \\ $f_{y} \quad$ Frequência de oscilação na direção transversal \\ $f_{w} \quad$ Frequência de oscilação em yaw \\ $F_{D} \quad$ Força de arrasto \\ $F_{L} \quad$ Força de sustentação \\ $k$ Constante elástica das molas \\ $L \quad$ Calado do modelo \\ $L_{O} \quad$ Comprimento inicial das molas \\ $L / D$ Razão de aspecto \\ $m^{*} \quad$ Razão de massa ou massa reduzida \\ Re Número de Reynolds \\ St Número de Strouhal \\ $U$ Velocidade do fluido \\ $U_{\text {med }}$ Velocidade média do fluido \\ $V_{c r} \quad$ Velocidade crítica do VIV \\ $V_{r} \quad$ Velocidade reduzida \\ $V_{0} \quad$ Velocidade de deflagração do galloping
}


$X^{r m s} / D \quad$ Amplitude rms adimensional na direção longitudinal

$Y^{r m s} / D \quad$ Amplitude rms adimensional na direção transversal

$Z^{r m s} / D$ Amplitude rms adimensional na direção vertical

$\Omega_{x}^{r m s} \quad$ Amplitude rms de rotação entorno da direção longitudinal

$\Omega_{y}^{r m s}$ Amplitude rms de rotação entorno da direção transversal

$\Omega_{z}^{r m s} \quad$ Amplitude rms de rotação entorno da direção vertical 


\title{
Lista de Abreviações
}

\author{
FIV Flow-Induced Vibration \\ IPT Instituto de Pesquisas Tecnológicas do Estado de São Paulo \\ rms root mean square \\ $S R E$ Cilindro de seção quadrada e arestas arredondadas \\ $S S E \quad$ Cilindro de seção quadrada e arestas vivas \\ TLP Tension Leg Platform \\ $T P N \quad$ Tanque de Provas Numérico \\ $V I V \quad$ Vortex-Induced Vibration
}





\section{APRESENTAÇÃO}

Este trabalho trata de uma investigação experimental acerca de mudanças na geometria das arestas de cilindros quadrados, resultando no aprofundamento do conhecimento a respeito dos fenômenos de Vibrações Induzidas pelo Escoamento, comumente conhecidas por FIV - seu acrônimo em língua inglesa para Flow-Induced Vibrations. Para facilitar a leitura e organização, o texto foi dividido nas seções a seguir.

O capítulo 1 faz uma breve introdução e contextualização do problema de Vibração Induzida por vórtices, ou simplesmente VIV no âmbito da Engenharia Oceânica, um dos vários tipos de FIV. No capítulo 2 apresenta uma extensa fundamentação teórica com base em três temas distintos e complementares: o estudo da fenomenologia do VIV e do Galloping, outro tipo de FIV; assim como o efeito da geometria na aresta.

Já no capítulo 3, o leitor encontra a metodologia e materiais utilizados para o estudo experimental desenvolvido. Também são descritos os modelos construídos e suas principais características. Os resultados e as discussões principais dos ensaios são apresentados no capítulo 4. E por fim, no capítulo 5 discorrerá sobre as conclusões e perspectivas que puderam ser sintetizadas a partir do que foi estudado e dos resultados obtidos. 


\section{Capítulo 1}

\section{INTRODUÇÃO}

\subsection{Cenário atual da indústria offshore}

Aproveitar os recentes avanços tecnológicos para descobrir um novo jeito de trabalhar é uma ideia que circula em todos os ramos da engenharia. Na área naval, sendo a engenharia oceânica uma área consideravelmente nova, a busca por fontes de energia é um dos maiores desafios atuais.

O petróleo é um recurso mineral de grande relevância, seja como fonte de energia ou matéria-prima industrial. No Brasil, a indústria petrolífera se tornou estratégica para a autonomia e desenvolvimento na nação. A exploração iniciou-se há mais de 40 anos e hoje mais de $90 \%$ da produção vem do mar. Esses fatos colocaram o Brasilcomo referência mundial em tecnologia de exploração deste tipo de reserva.

Contudo, encontrou também grandes dificuldades técnicas e econômicas, principalmente no que se refere à exploração em águas profundas e ultraprofundas (na camada présal, recentemente), tendo como consequência o desenvolvimento no estudo das plataformas flutuantes, isto é, sistemas na superfície livre fixados por intermédio de amarrações ao leito oceânico.

Pelo menos até o momento, a exploração em alto mar ainda tem se mostrado uma ótima solução e tem sido intensamente praticada desde então, aumentando a demanda por projetos de pesquisa neste segmento.

Neste cenário, CLAUSS (2007) definiu que, em grande parte, os desafios relacionados com a produção de petróleo e gás está relacionado a agentes ambientais agindo de forma severa, como ondas, correntezas e ventos. Além das embarcações de apoio, são necessárias as unidades de produção, que podem apresentar diversas formas e tipos, utilizadas conforme as necessidades e características da área de operação. Dentre os principais tipos de plataformas existentes, destacam-se as fixas, as auto-elevatórias e as flutuantes. Este último tipo apresenta grande diversidade de formas e capacidade.

Este trabalho se concentrará em geometrias de colunas normalmente encontradas em 
plataformas do tipo semissubmersível, TLP ou Spar e até mesmo em turbinas eólicas, mostradas na Figura 1.1.

Figura 1.1: Plataformas flutuantes.

(a) SEMI-SUBMERSÍVEL

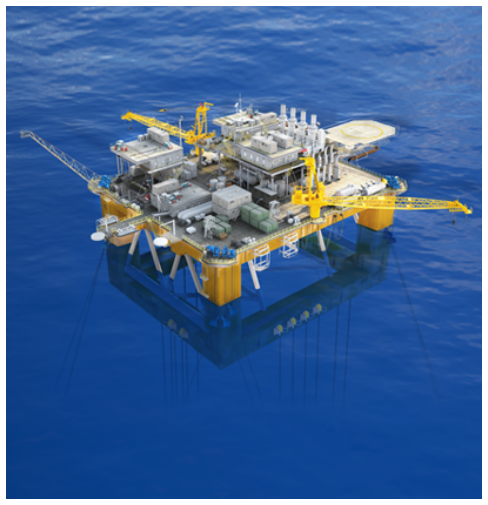

(c) SPAR

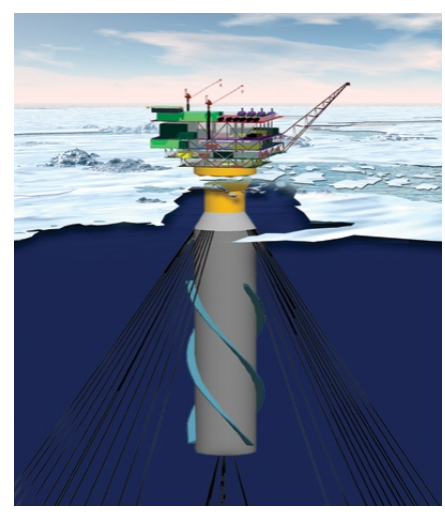

(b) TLP

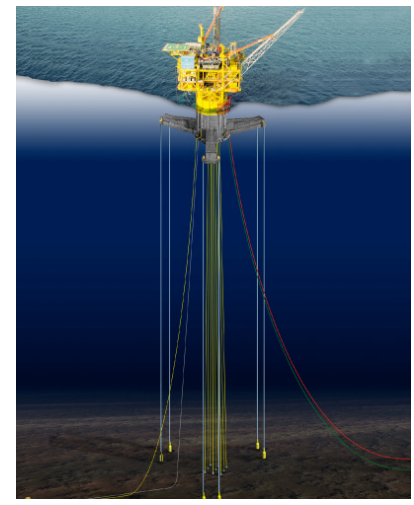

(d) TURBINA EÓLICA

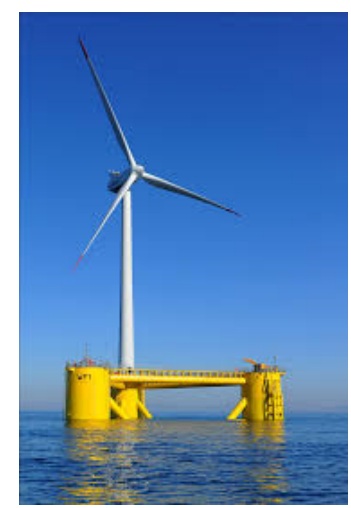

Independente do segmento da engenharia onde ocorra, o fenômeno de VIV tem sido intensamente investigado por conta das inúmeras aplicações, além da grande variedade de parâmetros geométricos. Portanto, é neste contexto que a presente pesquisa se insere, buscando reposta para um aspecto fundamental que pode melhorar a compreensão do VIV em plataformas flutuantes. A próxima seção traz detalhes dessa motivação 


\subsection{Motivação}

Em grande parte, os desafios relacionados com a produção de petróleo no mar geralmente são atividades bem complexas devido ao ambiente adverso. Um dos principais efeitos relacionados à ação da correnteza sobre a plataforma flutuante é a geração das Vibrações Induzidas por Vórtices. O VIV é caracterizado por oscilações em estruturas sob escoamento fluido que podem preocupar pela ordem de grandeza das amplitudes de movimento alcançadas (próximo de uma dimensão característica, o diâmetro no caso de estruturas cilíndricas de seção circular), podendo afetar a integridade estrutural.

Em linhas gerais, o VIV consiste em um fenômeno não linear de caráter auto-excitado e auto-limitado, com amplitudes máximas restritas a valores da ordem da dimensão característica da seção transversal da estrutura.

A ideia básica das plataformas flutuantes é possuir baixos níveis de movimentos para as condições de mar onde serão instaladas. Consequentemente, para quebrar as barreiras tecnológicas impostas por uma atividade altamente complexa, é necessário o entendimento profundo dos fenômenos físicos a que estão submetidos estas plataformas.

Neste contexto, o objetivo é compreender melhor a interação fluido-estrutural, devido aos problemas de vibrações observados e que podem levar essas estruturas a um eventual colapso por fadiga.

Figura 1.2: Um esboço do problema estudado: um cilindro transversal, de seção quadrada, com ângulo variável de ataque.

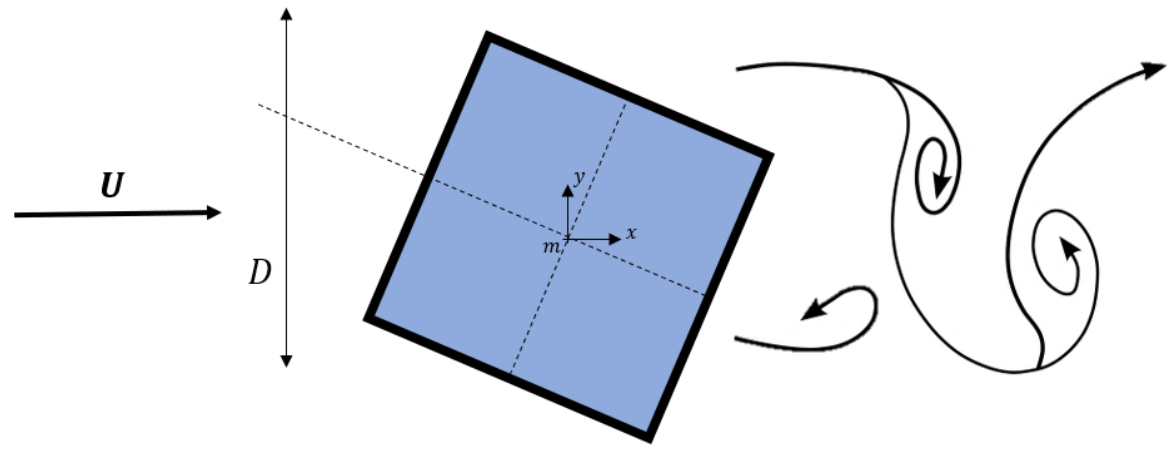

O presente trabalho foi motivado pelos estudos em uma única coluna de plataformas semissubmersíveis típicas, com o objetivo de entender os efeitos das arestas arredondadas nos cilindros de seção quadrada e com diferentes ângulos de incidência. O grande desafio está no estudo do escoamento ao redor do cilindro de seção quadrada, pois este é capaz de exibir dois fenômenos diferentes: o VIV e/ou o Galloping. As Figuras 1.2 e 1.3 mostram desenhos esquemáticos dos mecanismos fluidos propostos, mais adiante descritos com profundidade. 
Figura 1.3: Um esboço do problema estudado: um cilindro transversal de seção quadrada e arestas arredondadas, com ângulo variável de ataque.

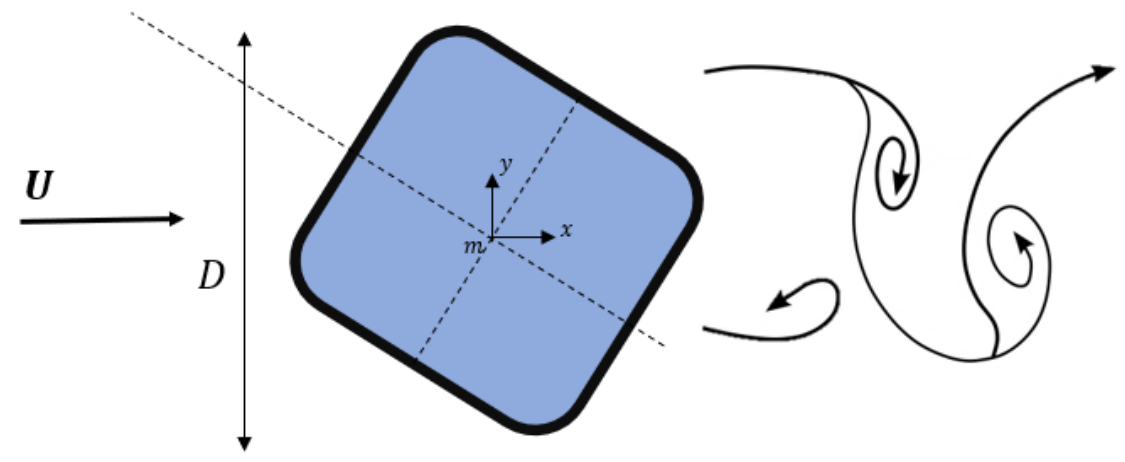

\subsection{Objetivos}

Isto posto, o foco deste trabalho é, portanto, analisar a ordem de grandeza dos movimentos resultantes dos mecanismos de desprendimento de vórtices, a capacidade de se descrever a variação da amplitude de vibração em função da velocidade reduzida em diferentes ângulos de incidência, haja vista que, dependendo deste ângulo, o cilindro de seção quadrada está sujeito a dois fenômenos decorrentes do FIV: o VIV e/ou o galloping.

Para tanto, como primeiro objetivo específico será necessária a concepção e construção de dois modelos flutuantes para os ensaios experimentais: dois cilindros de seção quadrada e arestas vivas e outros dois de seção quadrada com arestas arredondadas.

Como objetivo específico seguinte, estes cilindros são conectados a molas lineares e submetidos a um escoamento uniforme, com diferentes combinações de velocidade e ângulo de incidência. 


\section{Capítulo 2}

\section{Revisão Bibliográfica}

A seguir, faz-se uma breve descrição do fenômeno de desprendimento de vórtices. Na sequência são dados detalhes acerca dos fenômenos de VIV e Galloping.

Esses tópicos são apresentados com a finalidade de contextualizar as atividades experimentais desenvolvidas neste texto. Para leituras mais detalhadas sobre o assunto, sugere-se consulta ao livro BLEVINS (2001) e aos artigos de revisão SARPKAYA (2004) e WILLIAMSON (2004).

\subsection{Escoamento ao redor de corpos rombudos}

Autores na extensa literatura atual definem as regiões de escoamento perturbado como aquelas que possuem características do fluxo original, no entanto, alteradas pela presença de um corpo, cuja geometria, por sua vez, pode caracterizá-lo como afilado ou rombudo.

Corpos afilados são aqueles que conseguem ficar imersos no escoamento sem causar grandes pertubações, ou seja, o fluido apresenta gradiente de velocidade apenas em pontos próximos à parede da estrutura e, portanto, suas linhas de corrente são paralelas à mesma, como mostra a Figura 2.1.

Em seu artigo, BEARMAN, 1984, define que um corpo rombudo é aquele que, quando imerso em uma corrente de fluido, gera separação do escoamento e esta, por sua vez, ocorre em uma porção considerável da superfície de contato com o próprio corpo.

A caracterização de um corpo rombudo não depende apenas de sua geometria, mas também dos parâmetros associados ao escoamento, tais como orientação da estrutura em relação ao escoamento, velocidade deste, viscosidade e densidade do fluido.

Ainda em BEARMAN (1984), evidencia-se que quando corpos rombudos são submetidos a uma corrente fluida no sentindo transversal, gera-se instabilidades no escoamento na região a jusante dos mesmos, sendo o desprendimento alternado de vórtices fenômeno que naturalmente emerge dessa condição.

Esses vórtices, por sua vez, interagem com a estrutura por intermédio da formação 
Figura 2.1: Esquema e visualizações do escoamento ao redor de um corpo afilado e um corpo rombudo, respectivamente. Imagens reproduzidas por Assi (2005), adaptadas de van Dyke (1982).
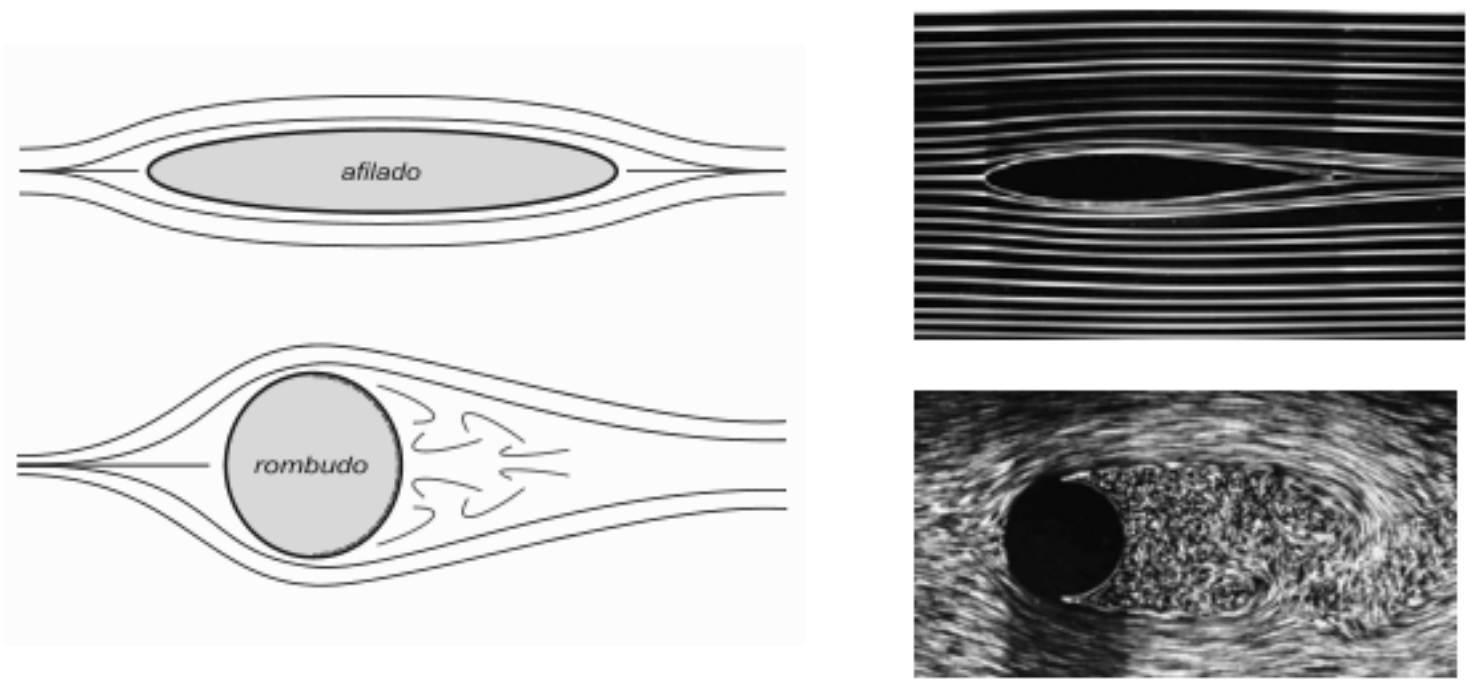

de campos de pressão cíclicos. As forças resultantes podem, então, levar ao surgimento de oscilações do corpo que são capazes de excitar de forma simultânea diferentes modos naturais destes elementos, podendo em casos extremos levar à fadiga e ao colapso da estrutura.

Dentre os corpos rombudos, destacam-se os cilíndricos. Sua geometria simples, de fácil construção, permite que sejam utilizados em diversas aplicações industriais e particularmente, na engenharia oceânica, onde está presente em plataformas, risers, entre outras estruturas.

Não por acaso, o cilindro é também a geometria mais extensamente estudada, cujos padrões de escoamento são melhor conhecidos. Baseando-se neste contexto, justifica-se uma revisão aprofundada do escoamento nesse tipo de geometria. 


\subsection{Escoamento ao redor de um cilindro fixo}

Baseando-se nos trabalhos de FUJARRA (2013), SARPKAYA (2004) e ASSI (2005), que descrevem de maneira muito didática o fenômeno de VIV, sabe-se que um corpo rombudo imerso em um fluido em movimento lança vórtices e estes, por sua vez, criam um campo de distribuição de pressão sobre o corpo que pode induzi-lo a uma resposta vibracional em certas velocidades. Ou seja, devido a geometria que este corpo possui, ocorre a separação do escoamento e o surgimento de duas camadas cisalhantes na região a jusante do corpo.

De acordo com GERRAD (1966), a interação entre as camadas cisalhantes é o principal fator para a geração e emissão de vórtices no escoamento ao redor de corpos rombudos, pois, segundo MENEGHINI (1993), essas duas camadas cisalhantes possuem vorticidade de sinais opostos, o que resulta em um sistema instável quando pequenas perturbações estão presentes e certas condições são satisfeitas. A interação destas duas camadas cisalhantes de fluido são não-lineares e são a causa principal da formação e desprendimento de vórtices.

De modo geral, todo fluido escoando ao redor de corpos rombudos apresenta regiões perturbadas, classificadas segundo ZDRAVOVICH (1987) como ilustrado na Figura 2.2.

A região 1 representa a faixa de escoamento incidente a montante do ponto de estagnação frontal do corpo. A região 2 , por sua vez, apresenta a camada limite aderida a superfície do corpo. Quando o gradiente de pressão passa a ser desfavorável para a aderência destas camadas limites, elas se separam e formam as referidas camadas cisalhantes livres que delimitam a esteira.

A região 3, então, é composta por escoamento deslocado e acelerado pela presença do corpo, na qual a velocidade média do escoamento é maior que a do escoamento incidente. Por fim, a região 4 é a parte do escoamento perturbado, chamada de esteira, que apresenta uma característica totalmente separada e com a velocidade média menor que a do escoamento ao longe.

O fenômeno de separação da camada limite, bem como os demais fenômenos derivados do escoamento separado, são governados pelo número de Reynolds, Re, definido em termos da velocidade do escoamento incidente $U$, da dimensão característica do corpo $D$ e da viscosidade cinemática do fluido $\nu$. O valor de Reynolds é utilizado como referência para o entendimento dos regimes de escoamento laminar e turbulento. A Equação 2.1 mostra essa relação que caracteriza o número de Reynolds.

$$
R e=\frac{\rho U D}{\mu}=\frac{U \cdot D}{\nu}
$$

Quando o número de Reynolds é muito baixo, diz-se que o escoamento é altamente dominado pelos efeitos viscosos, pois as forças inerciais não têm magnitude suficiente para vencer as forças viscosas do fluido, de modo que o escoamento não se separa da parede. Porém, a medida que Reynolds aumenta, verifica-se crescimento de bolhas de recirculação 
Figura 2.2: Regiões de escoamento perturbado pela presença do corpo rombudo. Extraído de Assi (2005).

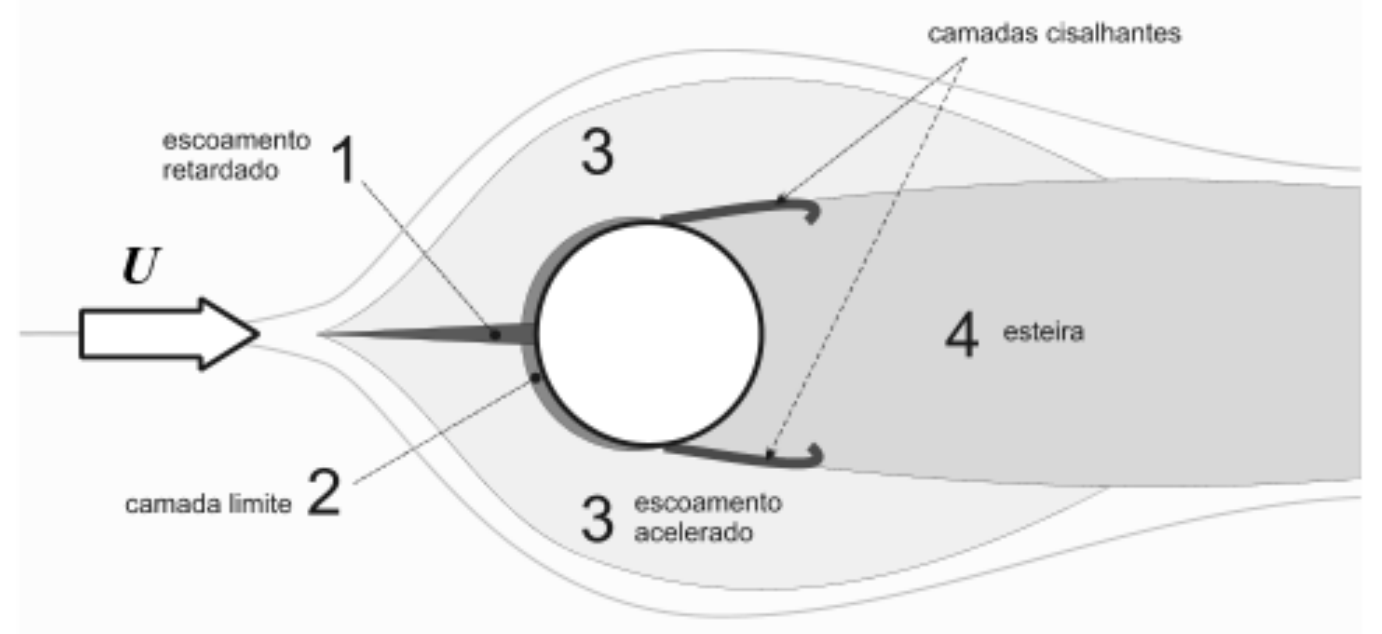

na região imediatamente após o corpo.

Figura 2.3: Estágios da separação do escoamento e formação de bolhas de recirculação próxima a esteira. Extraído de Assi (2005), adaptado de van Dyke (1982).

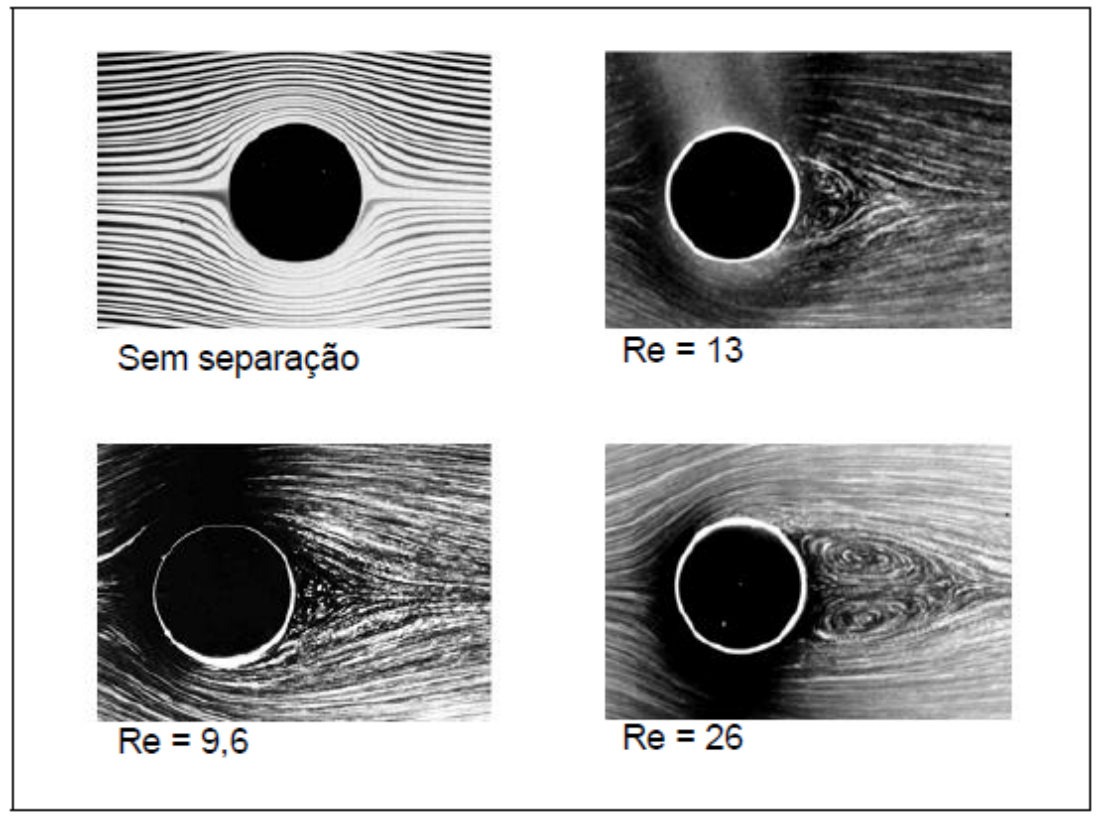

Enquanto o escoamento mantém velocidades baixas, estas bolhas permanecem estáveis e próximas à parede do corpo, em uma configuração simétrica. Esta sequência do efeito na esteira devido ao aumento do número de Reynolds é vista na Figura 2.3. 
Figura 2.4: Início da instabilidade da esteira em regime laminar. Imagens extraídas de Batchelor (1967) e adaptado por Assi (2005).

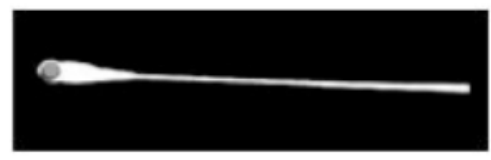

$\mathrm{Re}=32$

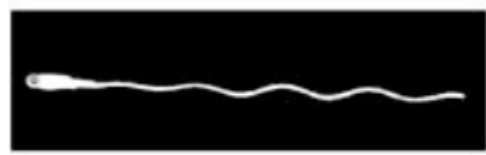

$\mathrm{Re}=55$

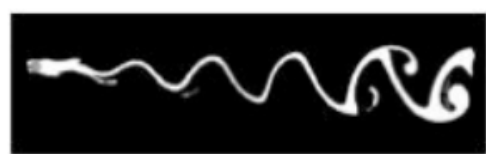

$\mathrm{Re}=65$

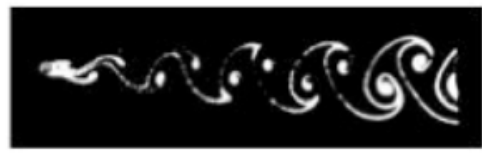

$\mathrm{Re}=73$

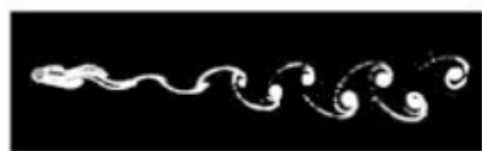

$\operatorname{Re}=102$

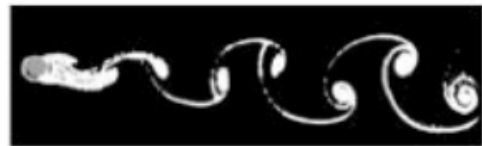

$\operatorname{Re}=161$

A esteira formada é ilustrada na Figura 2.4, recebendo o nome de esteira de von Kármán. Esta é uma região de baixa pressão, para onde o escoamento presente na região externa é atraído, gerando instabilidades na fronteira que os separa.

Além disso, a Figura 2.4 também mostra seis faixas distintas de $R e$. Quando $R e=32$, as bolhas de recirculação se mantêm na esteira, sem perturbá-la. A partir de $R e=55$, observase que a esteira já apresenta sinais de instabilidade. Em $R e=65$, o comportamento instável da esteira é nítido e, portanto, a medida que $R e$ aumenta, verifica-se um crescimentos nas bolhas de recirculação próximo a esteira, requerendo cuidados adicionais na preparação de experimentos, pois há extrema dificuldade de reprodução deste número em laboratório.

A característica alternada responde pelas flutuações periódicas da força de sustentação, com frequência praticamente igual a frequência de emissão, $f_{s}$, também conhecida como frequência de desprendimento de vórtices. Este parâmetro será melhor explicado mais adiante.

Contudo, quando o Re ultrapassa um certo valor crítico, estas bolhas não mais permanecem próximas a região da esteira, mas tornam o regime instável. A Figura 2.5 ilustra duas condições de esteiras: para o regime laminar e para o regime turbulento. A partir de $R e=180$, essas instabilidades começam a gerar uma tridimensionalidade no escoamento até então inexistentes.

Entre a faixa de $R e=400$ até um limite de $R e=10^{5}$, a transição ocorre nas camadas cisalhantes livres com a camada limite permanecendo laminar durante este período. Valores de Reynolds acima de $10^{5}$, promovem a ocorrência do estágio de transição na camada limite, ou seja, é neste momento que ocorre uma brusca diminuição da força de arrasto sobre o cilindro, mas conhecida como a crise do arrasto. É necessário um melhor entendimento deste fenômeno de transição devido aos padrões de escoamento que irão se formar na região da esteira, que é a região mais estudada pelos autores, pois as flutuações que acontecem na 
Figura 2.5: Esteira de vórtices de Von Kármán para dois regimes de escoamento: laminar $(R e=140)$ e turbulento $\left(R e=10^{4}\right)$. Extraído de Van Dyke (1982) e adaptado por Assi (2005).
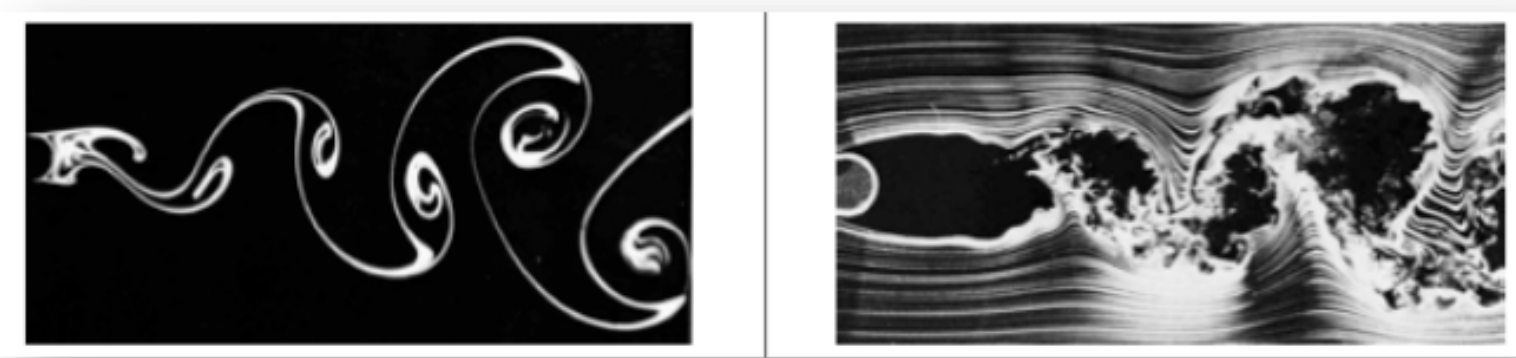

esteira irão refletir diretamente na superfície do corpo e, portanto, são responsáveis por causar as vibrações que serão estudadas no decorrer deste trabalho. 


\subsection{Geração e desprendimento de vórtices}

Um grande avanço na compreensão do fenômeno de geração e emissão de vórtices foi alcançado pelos estudos de vários pesquisadores na área de engenharia oceânica. O modelo físico explica os fenômenos que ocorrem na camada limite, camadas cisalhantes, formação de vórtices na esteira a jusante e seu desprendimento para a esteira, conforme visto anteriormente.

Em linhas gerais, a região da esteira é formada por vórtices gerados na superfície do cilindro que são convectados pelo escoamento.

Para compreender melhor como estes vórtices são formados, é necessário definir brevemente o conceito de vorticidade, isto é, uma grandeza vetorial que representa a tendência à rotação de uma partícula de fluido dentro de um escoamento.

A representação matemática da vorticidade é baseada no rotacional do campo de velocidades. Em um escoamento ao longe, sem perturbações, esta grandeza inexiste, pois o campo de velocidade é uniforme. Entretanto, ao se chegar na região próxima à parede, temse $o$ inerente perfil de velocidades da camada limite.

O mecanismo de formação dos vórtices é descrito de maneira extremamente prática, como ilustrado na Figura 2.6, retirada de KORKISCHKO (2011), que adapta a versão original encontrada em GERRAD (1966).

Figura 2.6: Esquema da formação da esteira de vórtices de um cilindro circular. Extraído de Gerrard (1966) e adaptado por Korkischko (2011).

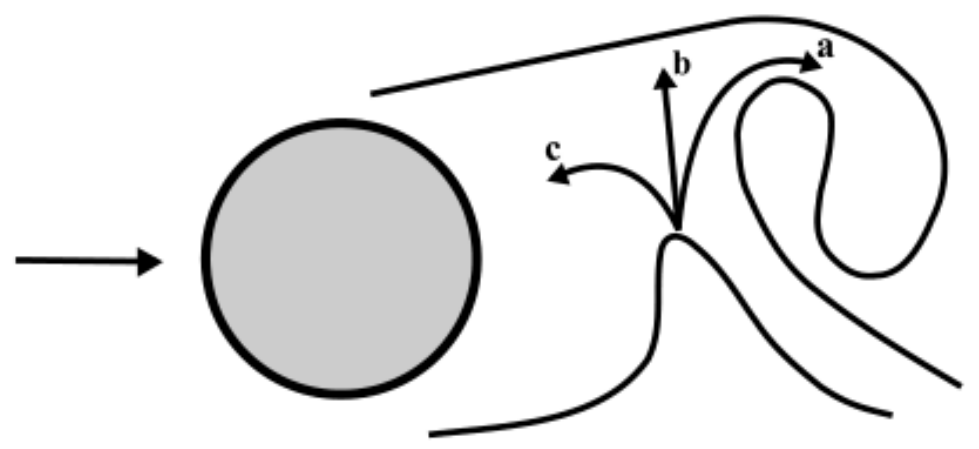

É notório que após os pontos de separação, a camada limite desprendida está livre na esteira próxima na forma de camadas cisalhantes. Como não há mais a presença da parede do corpo, esta região rotacional enrola-se, formando uma espécie de núcleo, que vem a ser um novo vórtice. O fluido arrastado em (a) é convectado pelo vórtice crescente, enquanto a porção de fluido em (b) abre caminho e interrompe a alimentação do vórtice (a), de modo que ele desliga-se do filamento liberado na região de separação e é convectado pela esteira. A região de baixa pressão logo atrás do corpo oscila e atrai o fluido (c) formando um novo vórtice, porém com vorticidade oposta ao recentemente liberado. Este novo vórtice formado 
será interrompido da mesma forma, devido á interação com a camada cisalhante oposta e este processo se repete indefinidamente.

A já mencionada frequência de emissão de vórtices, $f_{s}$, depende da distância entre as camadas cisalhantes. Quanto mais próximas elas estiverem, mais rapidamente elas interagem entre si e maior essa frequência.

A distância entre as camadas está associadas à dimensão característica do cilindro (diâmetro se a seção transversão for circular) e à velocidade do escoamento. Portanto, podese dizer que a frequência de emissão de vórtices também é associada ao número de Reynolds do escoamento e ao ponto de separação, discutidos na sessão anterior.

Em seu estudo sobre a geração de vórtices, ROSHKO (1954) estima de $43 \%$ da circulação gerada permanecem na esteira após a formação dos vórtices. BEARMAN (1984) afirma ainda que a geração e desprendimento de vórtices é um fenômeno dependente apenas da interação entre as camadas cisalhantes e não da geometria do corpo, que apenas modifica a interferência da esteira a jusante com os pontos de separação. 


\subsection{Número de Strouhal e Forças Fluidodinâmicas}

Por sua vez, a frequência de emissão de vórtices é inversamente proporcional a razão entre o diâmetro do cilindro e a velocidade do escoamento, decorrendo daí a definição do número de Strouhal, demonstrada na Equação 2.2.

$$
S t=\frac{f_{s} \cdot D}{U}
$$

A Figura 2.7 mostra como esse parâmetro varia ao longo da faixa de Reynolds. Observase que no intervalo $10^{2}<R e>10^{5}$, o número de Strouhal gira em torno de 0.2 , valor que na prática é comumente adotado em análises que necessitam de uma estimativa para a frequência de emissão de vórtices de uma geometria cilíndrica.

Figura 2.7: Variação do número de Strouhal pelo número de Reynolds. Extraído de NORBERG (2000).

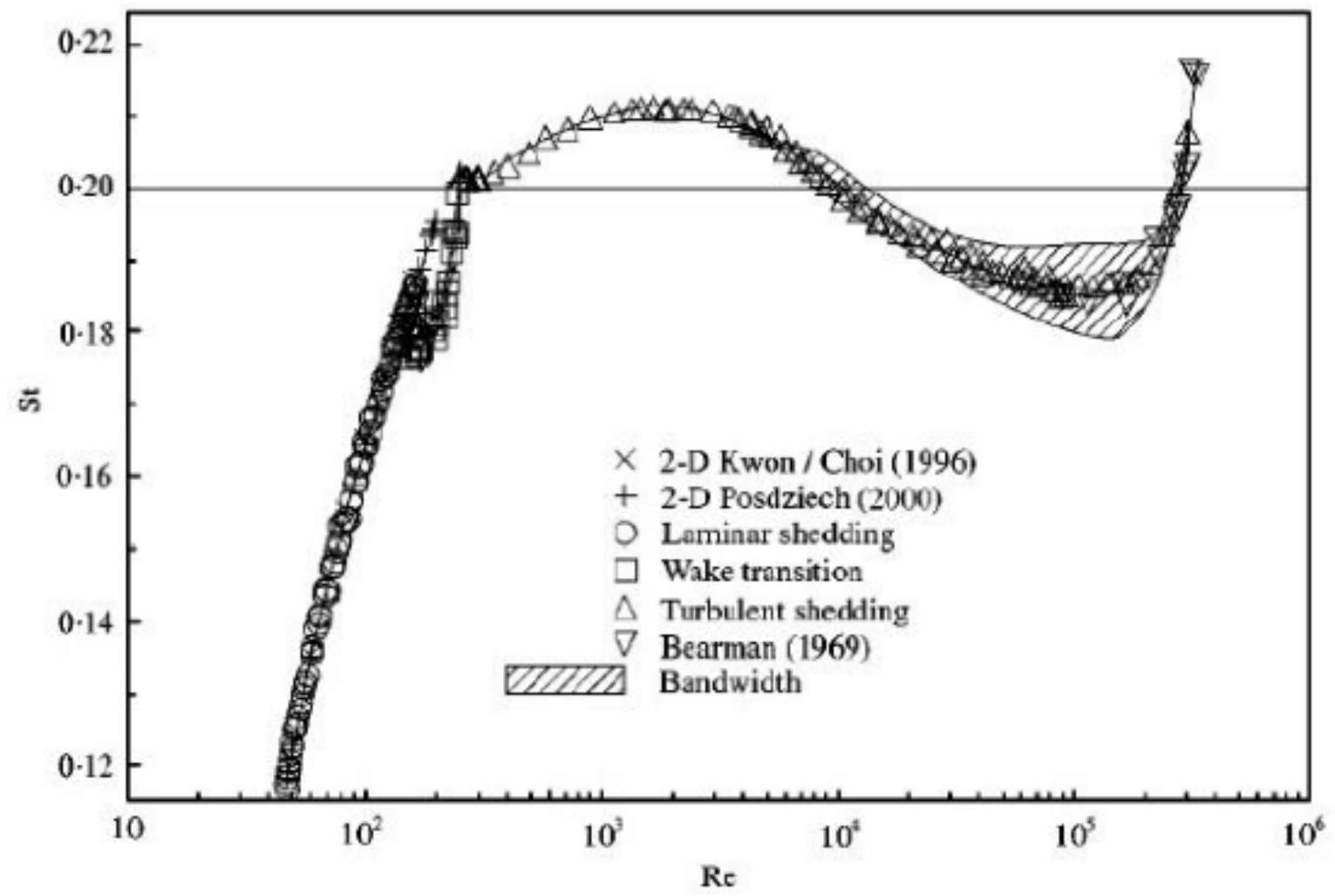

As pequenas variações no número de Strouhal se devem ao fato da esteira de vórtices responder de maneira diferente com relação ao regime de escoamento, resultando na mudanças nos coeficientes de forças atuante no cilindro. Uma boa descrição da região entre os regimes de escoamento e os coeficientes de forças transversais e longitudinais nos cilindros fixos pode ser encontrados em ASSI (2005).

A força resultante da interação entre o escoamento e o cilindro pode ser decompostas 
em duas componentes:

- Força de arrasto $\left(F_{d}\right)$, que é a força projetada na direção das linhas de corrente do escoamento ao longe;

- Força de sustentação $\left(F_{l}\right)$, que é a componente perpendicular ao arrasto.

Se estas forças forem adimensionalizadas em termos da pressão dinâmica do fluido, encontram-se os coeficientes de arrasto $\left(C_{d}\right)$ e de sustentação $\left(C_{l}\right)$, dados pelas equações 2.3 e 2.4 .

$$
\begin{gathered}
C_{d}=\frac{F_{d}}{\frac{1}{2} \rho U_{\infty}^{2} D L}, \\
C_{l}=\frac{F_{l}}{\frac{1}{2} \rho U_{\infty}^{2} D L},
\end{gathered}
$$

onde $\left(F_{d}\right)$ e $\left(F_{l}\right)$ são as forças resultantes no cilindro nas respectivas direções longitudinal e transversal ao escoamento incidente, $\rho$ é a densidade ou massa específica do fluido, $U_{\infty}$ é a velocidade de corrente livre (fora da região perturbada) e $D L$ é o produto do diâmetro pelo comprimento do cilindro, resultando na área projetada na direção do escoamento.

Note como a esteira se modifica com o aumento do número de Reynolds, evoluindo de um arranjo simétrico em regime laminar para um regime de emissão alternada de vórtices, que se mantém até o regime turbulento, obviamente com alterações estruturais que impactam nos valores dos coeficientes de força.

Como a emissão de vórtices ocorre de forma dinâmica, tanto o coeficiente de arrasto quanto o de sustentação não são constantes no tempo e possuem valores médios $\left(\vec{C}_{d}, \vec{C}_{l}\right.$ e flutuantes $\left(C_{d}^{\prime}, C_{l}^{\prime}\right)$. O coeficiente de arrasto pode ser ainda dividido em duas parcelas, no qual o arrasto dado por efeito viscosos são separadas do arrasto causados pelos efeitos de diferença de pressão. A Figura 2.8 mostra o comportamento de tais coeficientes para a número de Reynolds que engloba todas as fases de transição na esteira. Como visto na seção anterior, observa-se que durante o regime laminar, os coeficientes de arrasto vão diminuindo quase que paralelamente até que na região de $R e=200$, os vórtices desprendidos criam uma zona de baixa pressão atrás do cilindro que diverge o arrasto de pressão do arrasto viscoso, mantendo sua predominância por toda faixa de Reynolds subsequente. 
Figura 2.8: Comportamentos dos coeficientes de pressão comparados com os regimes do escoamento e configurações de esteira. Curvas de $C x R e$ adaptadas de Zdravkovich (1997) por Assi (2005).

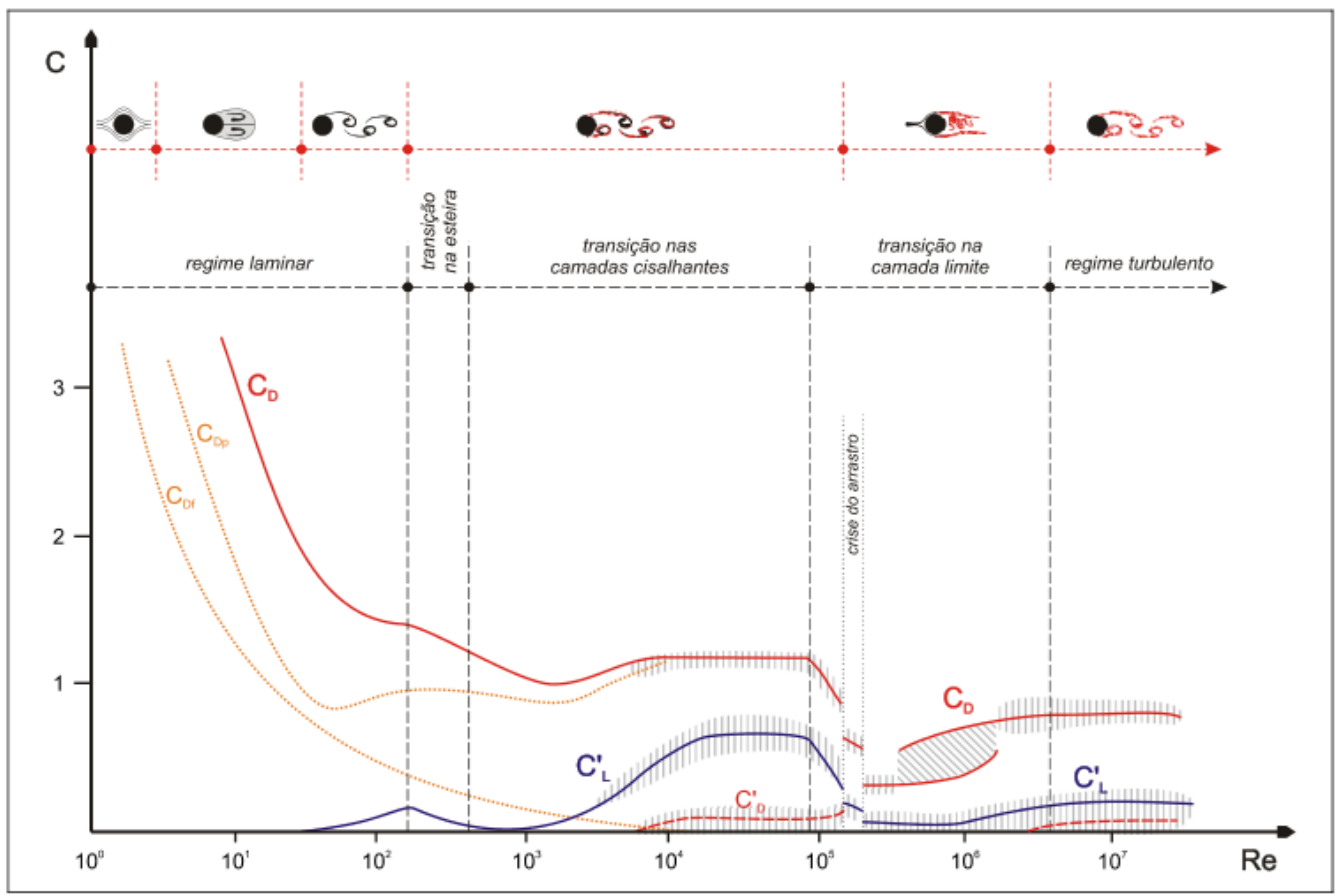




\subsection{VIV - Vibrações Induzidas por Vórtices}

Revisados os conceitos mais importantes, nesta seção são adicionados à teoria básica de dinâmica de corpos rígidos para formular e compreender o problema de VIV.

A maneira mais intuitiva de compreender este fenômeno é esboçar uma estrutura rombuda e elástica. Quando o cilindro possui liberdade de movimento, essas forças provocam considerável vibração do corpo que, por sua vez, altera o escoamento, iniciando um processo auto-alimentado. As amplitudes de vibração podem atingir valores significativos, da ordem do diâmetro do cilindro, principalmente quando a frequência de emissão de vórtices se aproxima de uma das frequências naturais do sistema.

As vibrações podem provocar danos severos à estrutura. As contribuições mais relevantes do estudo de VIV nas últimas décadas podem ser encontrados nos excelentes trabalhos de SARPKAYA (1979), BEARMAN (1984), KHALAK (1999), BLEVINS (2001) e WILLIAMSON (2004).

O estudo experimental de VIV em cilindros pode ser abordado em formas distintas, isto é, de acordo com o número de grau de liberdade do sistema, tipo do cilindro (rígidos ou flexíveis) e o tipo de oscilação (livre ou forçada).

Cada uma dessas frentes envolve diferentes mecanismos físicos e exige diferentes abordagens teóricas. Descrever todas elas foge ao escopo dessa dissertação, de modo que a partir desse ponto o enfoque será apenas em cilindros rígidos montados em base elástica, sujeitos à oscilação livre.

\subsubsection{Parâmetros adimensionais e conceitos fundamentais}

Até este ponto, foi estabelecido que o fenômeno de VIV ocorre devido à formação e desprendimento de vórtices e que este processo depende da velocidade do escoamento e das características geométricas do corpo rombudo. Além dessas informações, outros parâmetros são relevantes ao estudo de VIV. O objetivo desta subseção é definir os parâmetros adimensionais usados ao longo deste texto e apresentar a definição de alguns conceitos fundamentais.

\subsubsection{Definição de parâmetros adimensionais}

A Figura 2.9, extraída de KHALAK (1997), representa uma resposta clássica do fenômeno de VIV. O gráfico mostra a curva de amplitude amplitudes transversais como função da velocidade reduzida para dois valores de massa reduzida. Apenas observando este primeiro resultado, faz-se necessário definir os parâmetros de amplitude, velocidade reduzida e massa adimensional, bem como a razão de frequências de oscilação indiretamente. 
Figura 2.9: (a) Amplitudes transversal do VIV, em função da velocidade reduzida. Os pontos quadrados cheios foram obtidos por Khalak (1997), para $m^{*}=2,4$, e os pontos diamantes foram obtidos por Feng (1968), para $m^{*} \approx 250$.

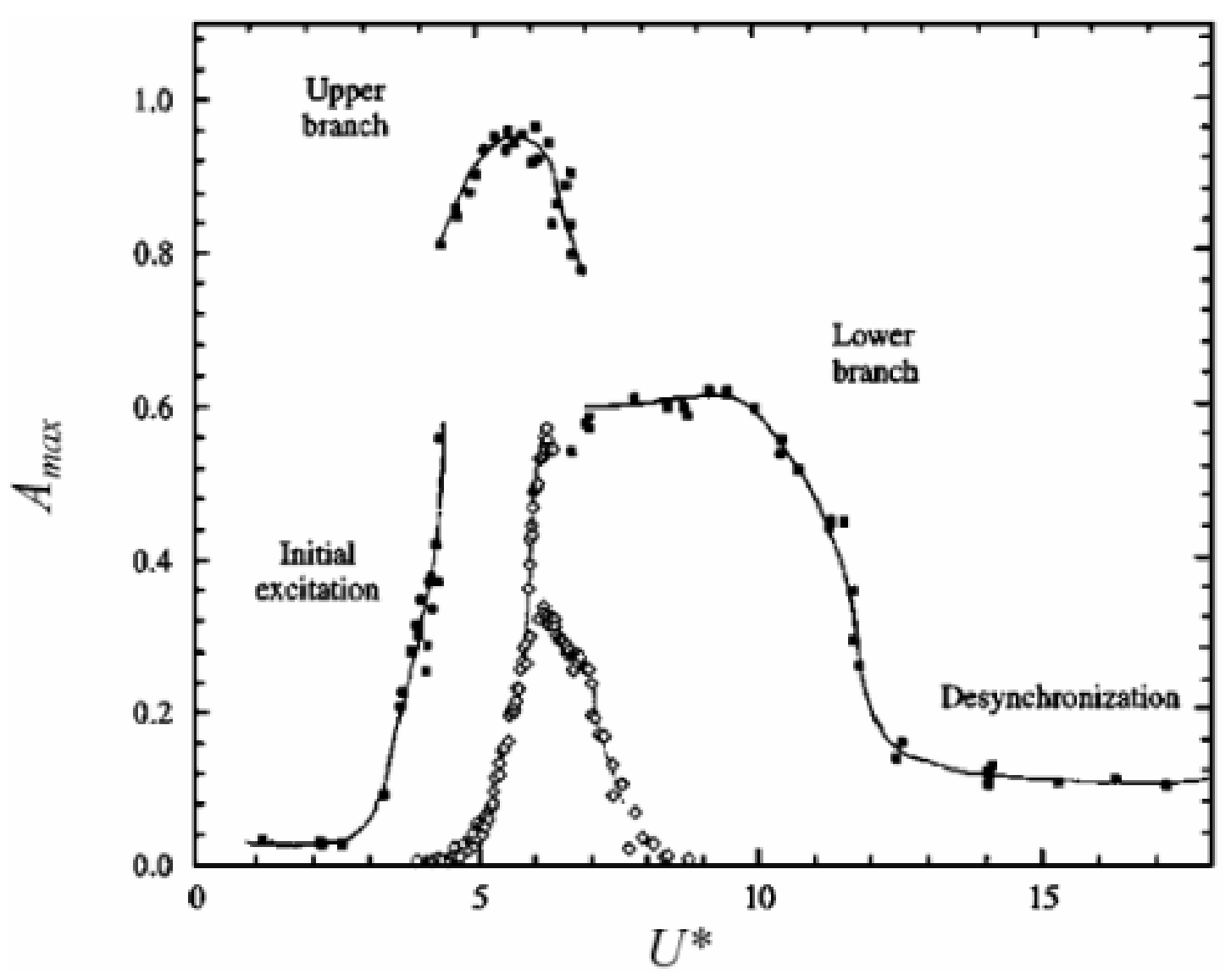

\subsubsection{Amplitude de resposta}

Este parâmetro relaciona a amplitude de oscilação medida $\hat{y}$ para determinada condição do fenômeno com o comprimento característico do corpo que oscila. Neste caso, considera-se que esse comprimento característico seja o diâmetro $D$ do cilindro de seção circular.

Vale lembrar que essa amplitude considera um valor representativo das oscilações na direção transversal ao escoamento. Entenda-se por valor representativo um valor que resume e simplifica determinada característica do fenômeno. Um sinal senoidal, por exemplo, apresenta uma única amplitude de oscilação.

O valor máximo de oscilação também pode ser considerado. Ao longo deste texto, as amplitudes são definidas como o $R M S$ nas séries temporais para cada direção.

Além disso, o gráfico representado na Figura 2.9 apresenta os nomes initial branch, upper branch, lower branch e decoherence, segundo terminologia inglesa. Estes nomes referemse a diferentes comportamentos do cilindro dentro do fenômeno de VIV.

Aos diferentes comportamentos de resposta, tanto em amplitude quanto em frequên- 
cia, foi dado o nome de ramos de resposta. A principal importância de se definir os ramos de resposta é simplificar e dividir o comportamento observado para o fenômeno de VIV.

\subsubsection{Frequência natural do sistema}

Quando sistemas mecânicos são excitados, eles costumam vibrar com determinada frequência. Esta frequência, que depende da massa e da rigidez do corpo é denominada como a frequência natural desse corpo. Por ter característica própria e constante dos sistemas, a frequência natural costuma ser usada como a frequência de referência no cálculo de outros parâmetros adimensionais, como por exemplo, a velocidade reduzida, explicada adiante.

Corpos rígidos montados em base elástica capaz de oscilar apenas em um grau de liberdade possuem uma única frequência natural.

A maneira mais simples de determinar a frequência natural do sistema é por intermédio do ensaio de decaimento. Nesse tipo de ensaio, descrito em detalhe no decorrer do texto, a estrutura é deslocada de sua posição de equilíbrio e, então, liberada para oscilar livremente. A partir da resposta apresentada, determina-se a frequência natural e o amortecimento atuante.

Experimentos de VIV realizados em ar, com o auxílio de túneis de vento, empregam o valor da frequência natural da estrutura também medida em ar $f_{n}$. Experimentos realizados em canais de água ou tanques de reboque, por outro lado, podem empregar as duas definições.

$\mathrm{Na}$ literatura de VIV, ambas as frequências naturais são consideradas. Neste estudo, foi adotada a frequência obtida em água. Existe uma linha de pesquisadores que adota a frequência natural em ar, dentre os quais, podem ser citados BEARMAN (1984) e SARPKAYA (2004). Outra linha de pesquisadores considera a frequência natural em água, como visto em KHALAK (1999), GOVARDHAN (2000) e ASSI (2010).

\subsubsection{Razões de Frequências}

A razão de frequências determina a relação entre a frequência dominante de oscilação em cada direção e a frequência natural da estrutura. No exemplo extraído de KHALAK (1997), Figura 2.10, a razão de frequência é calculada em função da frequência natural. Neste resultado, há duas retas que servem como referência.

A primeira reta, horizontal, representa a região no qual a frequência de vibração para um cilindro é igual a sua frequência natural em água $f_{y}=f_{n}$. A segunda reta, inclinada, ilustra a razão entre a frequência de desprendimento de vórtices para um cilindro fixo $f_{s}$ e $f_{n}$. Não pertence ao escopo dessa seção analisar todas as informações que podem ser extraídas deste gráfico. Neste momento, o objetivo é apenas definir as grandezas envolvidas.

Apresentar apenas a frequência dominante de oscilação é uma maneira simplificada de representar o fenômeno. Uma alternativa mais completa se dá com a apresentação dos mapas de frequência. Estes mapas apresentam, para cada velocidade reduzida, não apenas o valor dominante da frequência, mas sim todo o seu espectro e permitem avaliar a presença de 
Figura 2.10: Frequência de resposta adimensional em função da velocidade reduzida. Extraído de Khalak e Williamson (1997).

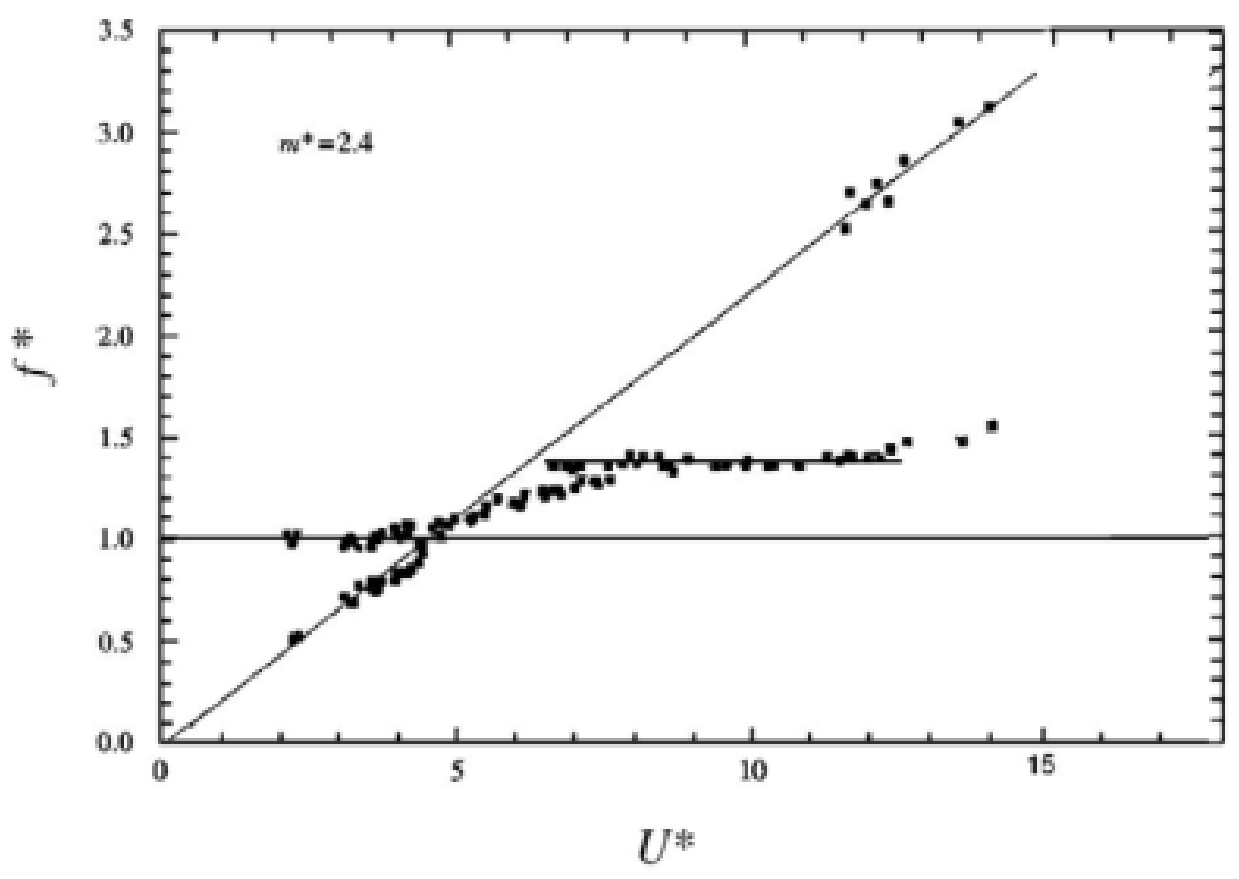

harmônicos na resposta ou, ainda, a presença de outras frequências que não sejam múltiplos de $f_{s}$ e $f_{y}$.

\subsubsection{Velocidade reduzida}

Outro parâmetro de importância fundamental para a ocorrência do VIV é a velocidade reduzida $V_{r}$, como mostra a Equação 2.5 .

$$
V_{r}=\frac{f \cdot D}{U}
$$

Se o corpo submetido ao escoamento incidente for livre para oscilar, poderá ter uma ou várias frequências naturais de oscilação $f_{n}$. Para adimensionalizar a velocidade reduzida é comum usar o diâmetro do cilindro $D$.

Assim, se ao aumentar a velocidade do escoamento, a frequência de desprendimento de vórtices se aproxima de uma destas frequências naturais, ocorre o fenômeno de sincronização lock - in representado usualmente em termos de velocidade reduzida $V_{r}$ e, segundo o qual, para uma faixa razoavelmente larga de $V_{r}$, a frequência de desprendimento $f_{s}$ se mantém aproximadamente igual a uma das frequências naturais do corpo $f_{n}$. 


\subsubsection{Região de sincronização e lock-in}

Como citado anteriormente, nos casos em que existe a liberdade para oscilar na direção transversal, sabe-se que o aumento gradativo da velocidade do escoamento eleva a frequência de emissão de vórtices até que esta atinja, aproximadamente, o valor da frequência natural do sistema $f_{s} \approx f_{n}$, colocando-o em oscilação. Tal comportamento é conhecido como lock-in ou sincronização, como mostra a figura 2.11.

Figura 2.11: Lock-in. Extraído de Blevins (1990) adaptado por Santos (2011).

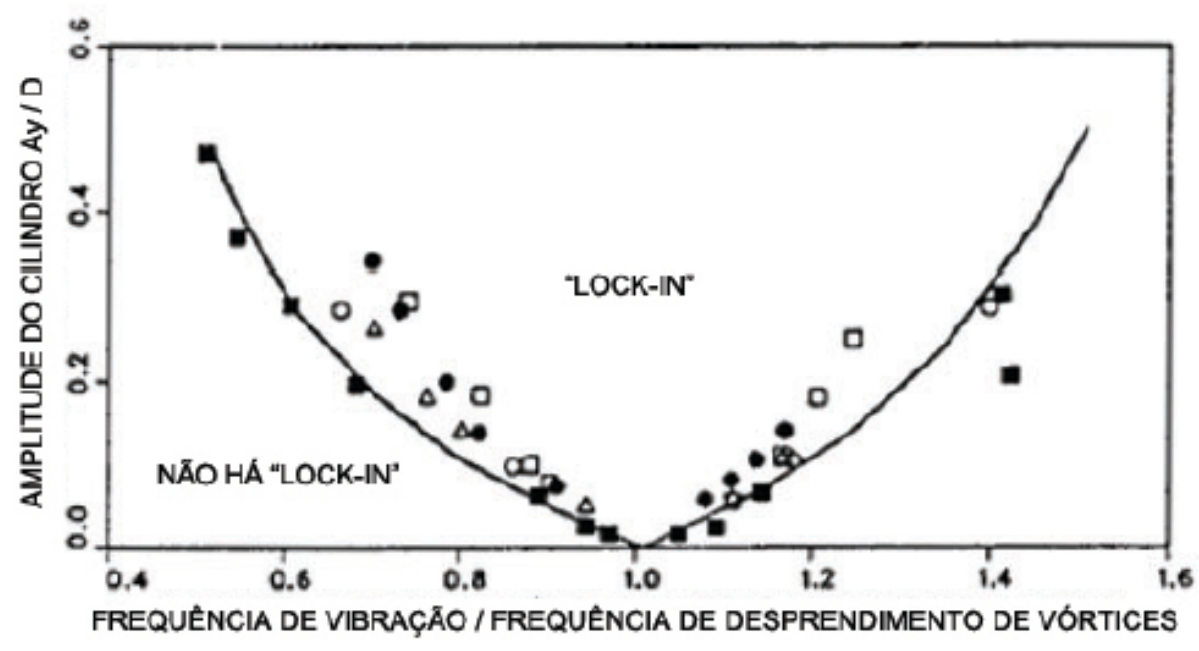

A região de sincronização é a faixa de velocidade reduzida $V_{r}$ na qual o movimento do cilindro e a resposta do fluido ocorrem de maneira sincronizada, ou seja, com mesma frequência dominante.

\subsubsection{Massa adicional}

Quando um corpo imerso num fluido acelera, é necessário que este corpo desloque certa massa de fluido que o rodeia para poder se movimentar. Por esse motivo, para acelerar um corpo a partir do repouso também é preciso acelerar a massa de fluido, aumentando assim a força e o trabalho necessário para causar a aceleração. A força adicional, oriunda da presença do fluido, pode ser entendida como consequência de uma massa adicional presa ao corpo.

É comum adimensionalizar a massa adicional em função da massa do fluido deslocado pelo corpo rombudo imerso no escoamento. O coeficiente adimensional resultante desse processo é denominado coeficiente de massa adicional, $C_{a}$ e é definido pela equação 2.6 abaixo.

$$
C_{a}=\frac{m_{a}}{m_{d}}
$$

Como apresentado em KHALAK (1999), a massa adicional efetiva, obtida experimentalmente, é definida como a parcela de força fluida que está em fase com a aceleração do 
cilindro.

Na maioria dos escoamentos de ar, a massa adicional de fluido pode ser desprezada, mas para cilindros de baixa razão de massa imersos em água, a massa do corpo pode ter a mesma ordem de grandeza da massa adicional. Deste modo, o parâmetro $m^{*}$ é bastante importante para a análise de VIV, conforme verificado por JAUVITIS (2004). 


\subsection{Escoamento ao redor de um cilindro oscilando}

Como foi apresentado neste texto, o fenômeno de geração e desprendimento de vórtices pode ser drasticamente alterado quando o corpo rombudo está oscilando ou, equivalentemente, quando estiver imerso em um escoamento oscilatório.

A forma como a oscilação do corpo afeta este fenômeno pode ser estudado de duas maneiras distintas:a primeira delas procura analisar a influência indireta através da aplicação de oscilações forçadas em um cilindro montado em um túnel de vento ou água. A segunda, procura investigar diretamente os efeitos da oscilação montando o cilindro em um sistema de base constituída por molas ajustáveis, proporcionando sua movimentação nas direções transversal e/ou longitudinal do escoamento incidente.

Existem prós e contras em cada uma destas formas de se atacar o problema. A utilização de um cilindro montado em base elástica permite obter evidências diretas das interações não-lineares que ocorrem entre excitação e resposta. O outro método, i.e. através de oscilações forçadas, faz com que os experimentos tenham um número inferior de parâmetros a serem medidos, além de algumas características observadas nos problemas práticos de VIV não são por ele reproduzidas. Aqui, será dada atenção às oscilações montadas em base elástica, por ser este o esquema a ser adotado para o ensaio experimental.

A importância prática do estudo de cilindros oscilatórios em virtude da geração e desprendimento de vórtices fez com que houvessem muitas pesquisas fundamentais sobre 0 assunto nas últimas décadas. Muitas destas pesquisas estudaram o fenômeno de VIV utilizando um cilindro montado em base elástica e livre para oscilar. Com este tipo de aparato, oscilações ocorrem somente para certos valores de velocidade reduzida, parâmetro adimensional e a frequência de desprendimento de vórtices; está próxima a frequência natural do sistema ou de um de seus múltiplos ou submúltiplos.

A esteira de vórtices de um cilindro isolado é alterada quando o corpo passa de uma configuração estática para um comportamento de oscilações transversais. Basicamente, os padrões de emissão de vórtices estão relacionados à amplitude e a frequência destas oscilações. Em um trabalho minucioso, WILLIAMSON (1988) mapearam os padrões de emissão de vórtices em função destes dois parâmetros.

A Figura 2.12 resume este trabalho e apresenta os modos de emissão encontrados para um cilindro com oscilação. A princípio, três padrões distintos foram verificados: o já conhecido $2 S$ (two single); o modo $2 P$ (two pairs); e o modo $P+S$ (pair+single). Como visto anteriormente, no modo $2 S$, dois vórtices isolados são desprendidos para cada ciclo de emissão. Já no modo $2 P$, dois pares de vórtices são desprendidos para a esteira em cada ciclo. E no modo $P+S$, uma composição de um vórtice isolado e um par de vórtices são desprendidos do cilindro em cada ciclo de emissão.

Além de métodos experimentais, algumas simulações numéricas foram realizadas para tentar prever e visualizar o comportamento destes padrões de emissão de vórtices. As próximas imagens mostram ilustrações de experimentos e de simulações publicadas na literatura, 
Figura 2.12: Padrão $2 P$ emitido de um cilindro com oscilação forçada. Extraído de Williamson \& Roshko (1988).

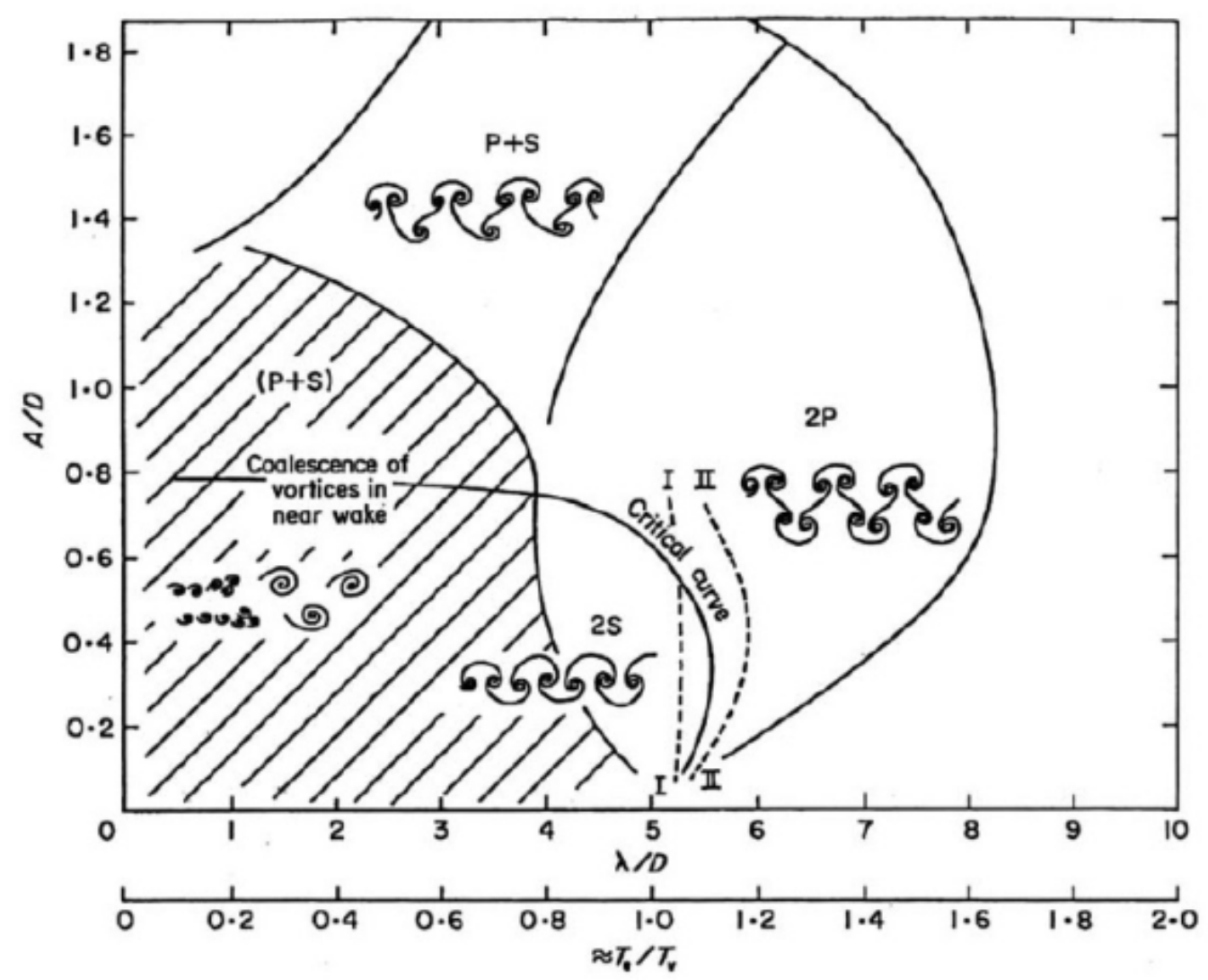

exemplificando os padrões discutidos anteriormente. A Figura 2.13 mostra a emissão do modo 2P por um experimento feito usando uma técnica de visualização por partículas de alumínio.

Já a Figura 2.14 mostra imagens comparativas entre os padrões $2 S$ e $P+S$, extraídos de um experimento com a técnica de tintura fluorescente e simulações numéricas. Vale ressaltar que os resultados de Meneghini e Bearman são obtidos via simulações numéricas, enquanto os resultados de Williamson e Govardhan foram obtidos experimentalmente.

É importante ressaltar que estes padrões de esteiras apresentados até agora apenas aparecem em vibrações forçadas. Para os casos onde há vibração livre na direção transversal do escoamento, são observados apenas os padrões $2 S$ e $2 P$.

A Figura 2.15 mostra imagens do experimento realizado com o cilindro vibrando livremente na direção transversal ao escoamento e os dois padrões de esteira resultantes.

Ainda no tocante à dimensão da esteira de emissão de vórtices, todas as considerações sobre este fenomenologia trataram apenas de escoamentos bidimensionais ao redor de cilindros.

No entanto, a formação da esteira de vórtices não é um fenômeno puramente bidimensional. A terceira dimensão do cilindro (seu comprimento $L$ ) fora do plano até agora observado é muito importante para o desenvolvimento da esteira. Os filamentos de vórtices não são es- 
Figura 2.13: Padrão $2 P$ emitido de um cilindro com oscilação forçada. Extraído de Williamson e Govardhan (2004).

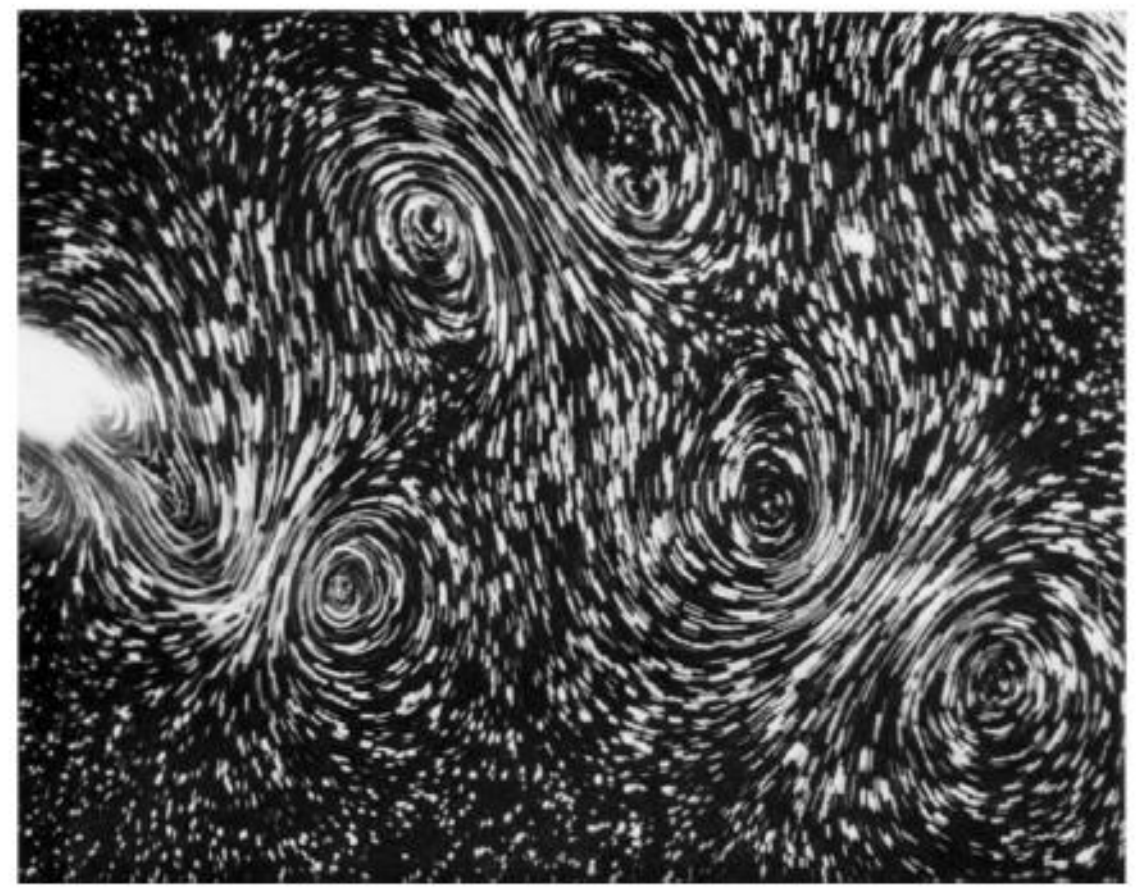

Figura 2.14: (a) Imagens ilustram o padrão $2 S$ e (b) ilustra o padrão $P+S$. Imagens superiores extraídas de Williamson e Govardhan (2004) e inferiores extraídas de Meneghini e Bearman (1995).
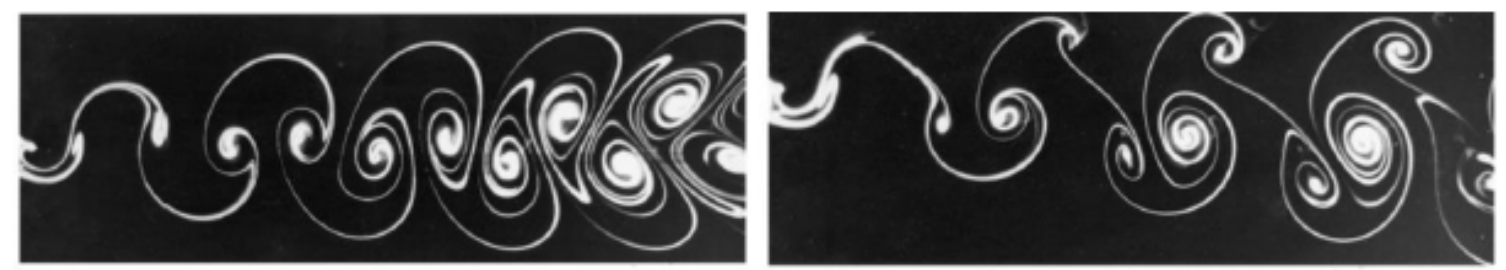

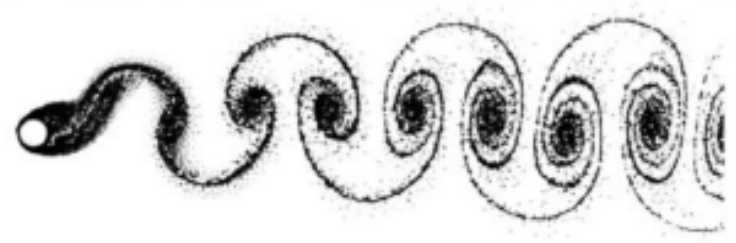

(a)

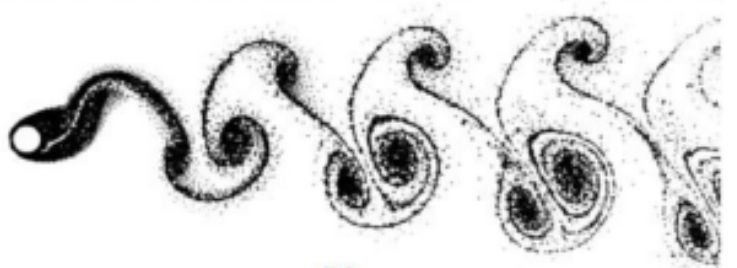

(b)

truturas bidimensionais, mas variam ao longo do comprimento do cilindro, dependendo de muitos parâmetros do escoamento, discutidos mais adiante.

ASSI, 2005, explica que, a priori, não se pode afirmar que todas as seções transversais ao longo do comprimento de um cilindro apresentarão fenômenos idênticos de emissão de vórtices sincronizados no tempo. A partir de $R e=180$, a esteira começa a apresentar as primeiras tridimensionalidades. 
Figura 2.15: (a) Modo $2 S$ e; (b) Modo $2 P$ em cilindro livre para oscilar. Figura extraída de Flemming e Williamson (2005) e adaptado por Freire (2015).

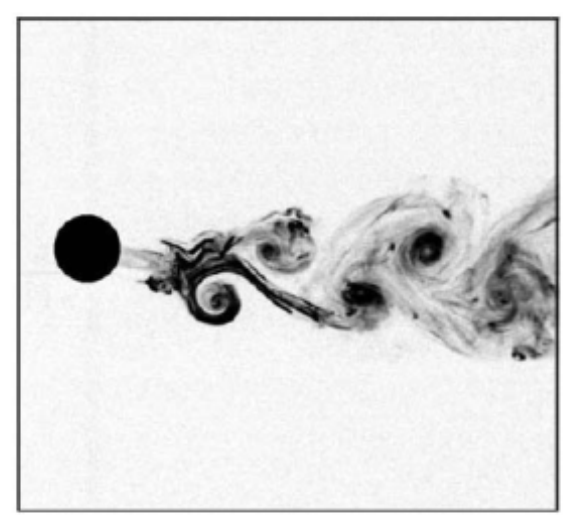

(a)

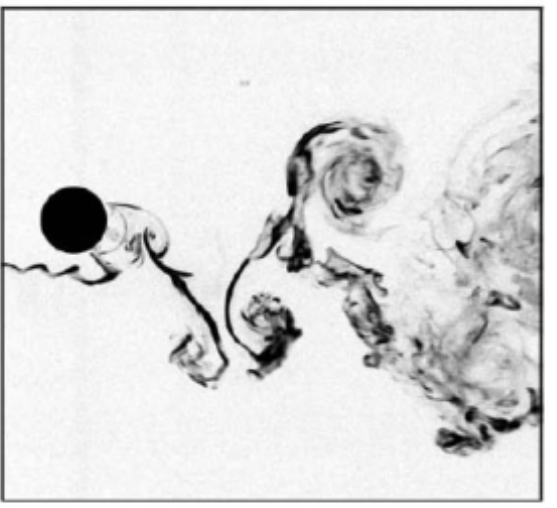

(b)

A Figura 2.16 possui imagens experimentais retiradas do trabalho de WILLIAMSON (1996), mostrando estas estruturas que perturbam a esteira, Nesta imagem, também é possível perceber que o Modo $A$, a distância entre os vórtices é de aproximadamente quatro diâmetros, enquanto que no modo $B$ estas estruturas se repetem com o mesmo espaçamento menor, em torno de um diâmetro.

Figura 2.16: Modo A ( $R e=200$ e B $R e=270$. Extraído de Williamson (1996b).

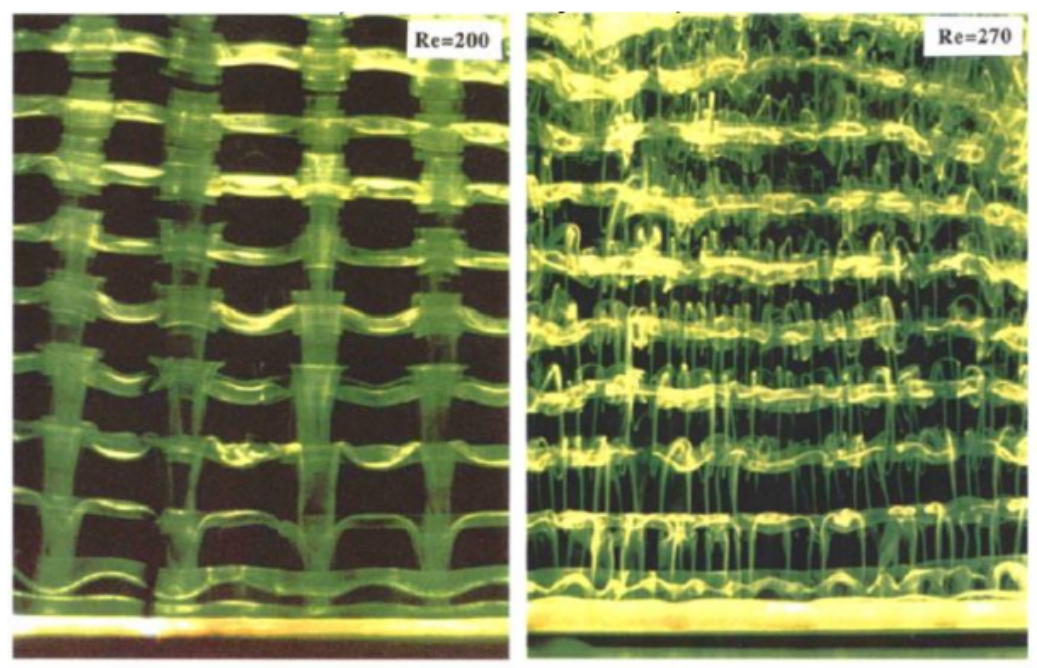


Até então no que se refere a fenomenologia do VIV, há que se considerar a razão de aspecto $L / D$, definida como a relação entre o comprimento e o diâmetro do cilindro. Este parâmetro tem papel fundamental na definição dos padrões de emissão de vórtices. Geralmente, para cilindros com alta razão de aspecto $(L / D>13)$, a emissão de vórtices ao longo do comprimento é bastante correlacionada com os efeitos tridimensionais da esteira.

Já para os cilindros com baixa razão de aspecto $(L / D<6)$, observa-se que a emissão de vórtices a partir da extremidade livre afetal parcial ou totalmente o padrão de emissão de vórtices ao longo do corpo; mecanismo este que será de maior relevância neste trabalho.

Figura 2.17: Amplitude adimensional transversal, $A_{y} / D$, como função da velocidade reduzida $V_{r}$, para cilindros flutuantes com razão de massa $m^{*}=1$ e diferentes razões de aspecto. Extraído de Gonçalves (2013).

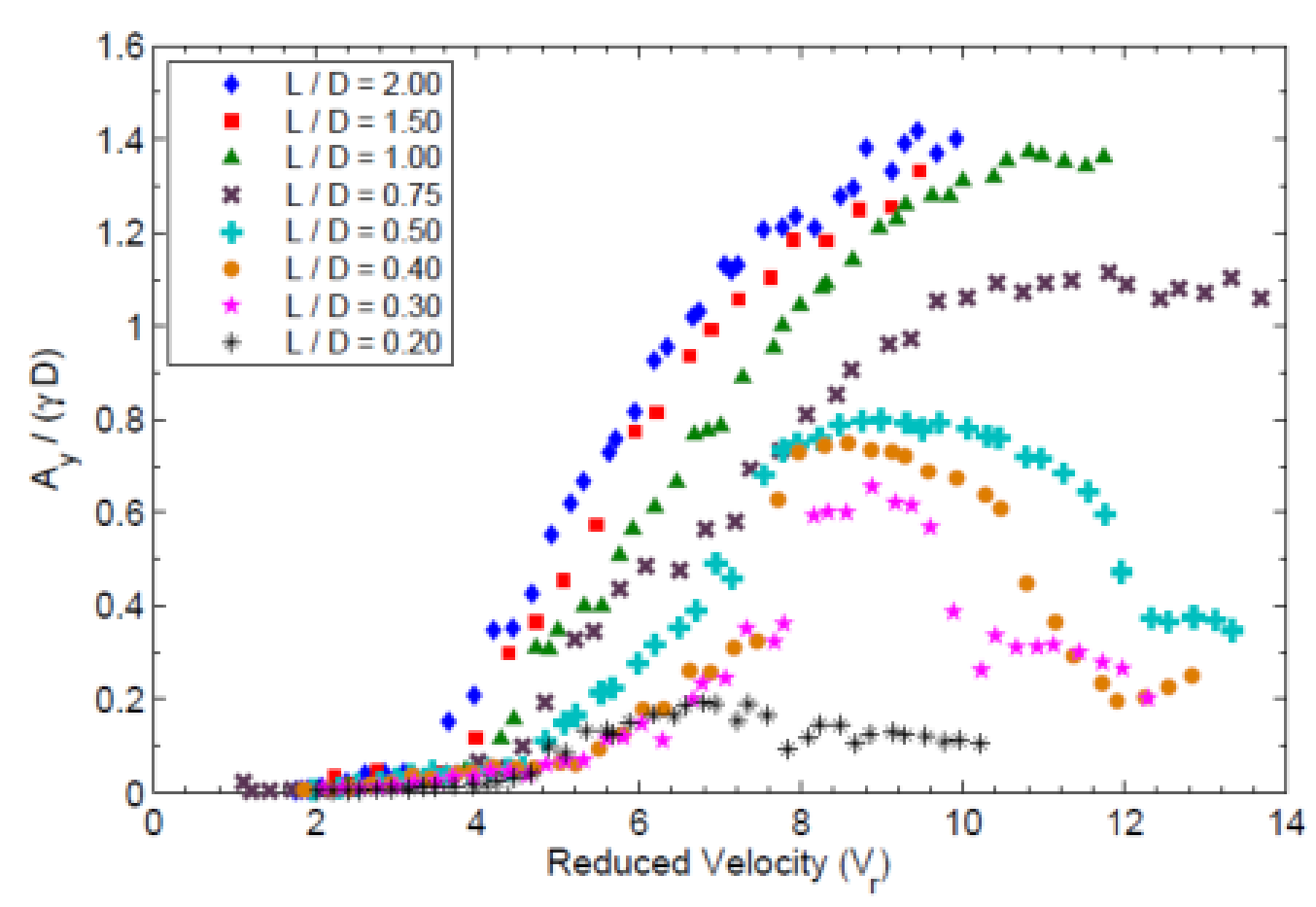




\subsection{Graus de liberdade}

Como demonstrado anteriormente, as primeiras observações do fenômeno de VIV levaram os engenheiros e pesquisadores a concluir que as principais oscilações de um corpo rombudo imerso em um fluido se davam na direção transversal ao escoamento, isto é, apenas com 1 grau de liberdade. Por esse motivo, o fenômeno passou a ser largamente estudado nessa direção.

Somente nas últimas décadas que o estudo VIV em cilindros montados e livres para oscilar em dois graus de liberdade ( $2 \mathrm{GL}$ ) ganhou maior interesse, muito por conta da alta demanda tecnológica suscitada, na engenharia oceânica, pela produção de petróleo e gás a lâminas d'águas cada vez mais profundas.

Porém, grande partes destes trabalhos dedica-se ao estudo de cilindros longos, ou seja, com alta razão de aspecto, que neste texto definiremos como a razão entre o comprimento da região imersa pelo diâmetro característico $L / D$. Com base na nomenclatura atual, cilindros considerados longos são aqueles que possuem $L / D>13$. Já cilindros com $L / D<6$ são considerados cilindros curtos e será a grande abordagem deste trabalho. Esta modalidade, especificamente, recebe o nome de Movimento Induzido por Vórtices, o VIM. No entanto, cabe ressaltar que uma visão mais ampla sobre as principais investigações do VIM em plataformas pode ser visto nos trabalhos de FUJARRA (2012) e GONÇALVES (2013a).

A Figura 2.18 apresenta os arranjos esquemáticos dos sistemas livres para oscilar com $1 \mathrm{GL}$ e $2 \mathrm{GL}$. De acordo com os estudo na área, descreve-se que a possibilidade de movimento em 2GL, ou seja, na direções transversal e longitudinal ao escoamento seja responsável por maiores amplitudes de movimento na direção transversal.

Figura 2.18: Comparação entre sistemas massa-mola livres para oscilar com 1GL e 2GL. Adaptado de Jauvtis e Williamson (2004), extraído de Gongalves (2013).
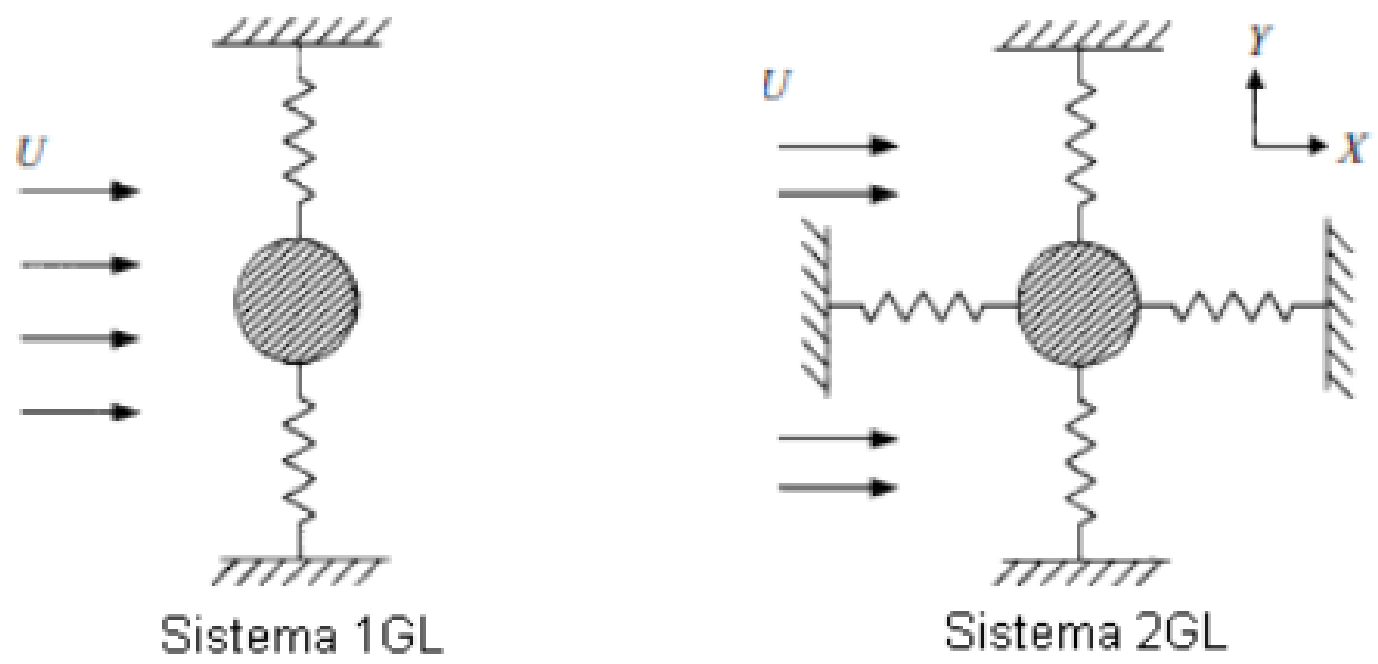

Sistema 2GL 
Um cilindro rígido e livre para oscilar colocado num escoamento uniforme e sujeito a VIV na direção transversal ao escoamento pode ser representado simplificadamente como um sistema massa-mola-amortecedor, como mostrado na Figura 2.19.

Figura 2.19: Sistema com um cilindro oscilando em $1 G L$.

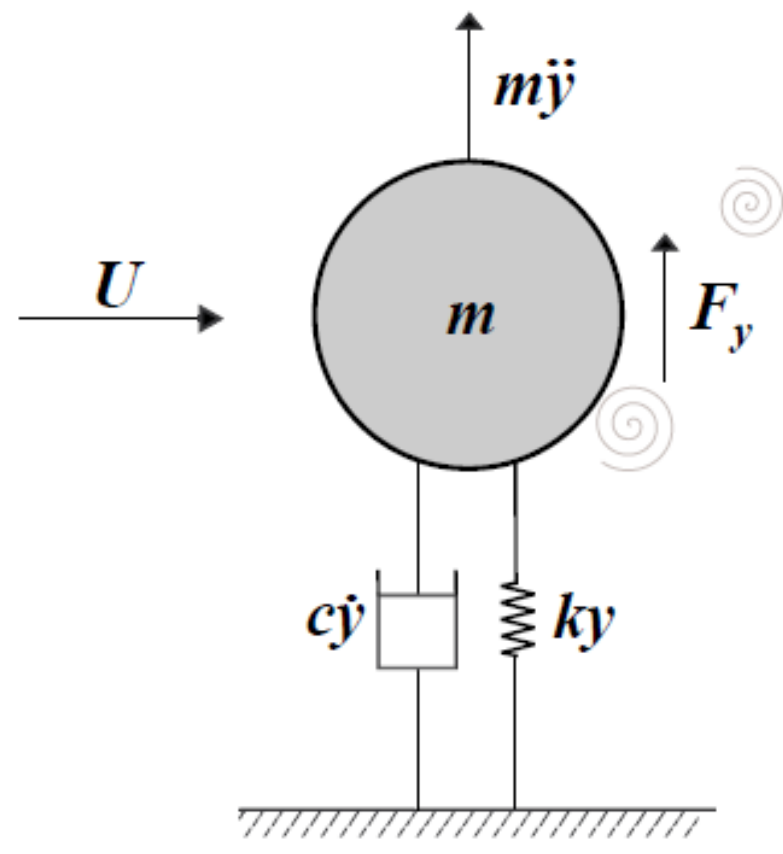

A equação 2.7 de movimento que governa tal sistema é escrita como:no qual y é o deslocamento do corpo de sua posição de equilíbrio, $m \ddot{y}$ é a força inercial, cy é a força de amortecimento viscoso proporcional a velocidade do corpo e associada com a estrutura, $k y$ é a força de restauração originada da rigidez da mola e, por fim, $F_{y}$ é a força fluida flutuante, ou seja, a força de sustentação.

$$
m \ddot{y}+c \dot{y}+k y=F_{y}
$$




\subsection{Diferenças na geometria das arestas}

Além de VIV em cilindros circulares, alguns estudos interessantes sobre este fenômeno em outras geometrias podem ser encontrados na literatura, sendo sintetizados nesta seção aqueles com maior interesse para os estudos mais adiante apresentado.

Um cilindro circular tem sido considerado um corpo que melhor representa os fenômenos descritos acima, devido à sua geometria simples e estrutura de vórtice coerente. Em contrapartida, o cilindro com seção não-circular permaneceu relativamente menos explorada pela literatura.

Como descrito na seção anterior, a esteira formada atrás de um corpo bidimensional, colocado em um fluxo uniforme, raramente permanece $2 D$, mesmo em números baixos de Reynolds, nos quais a esteira de vórtice é formada. A tridimensionalidade da esteira do cilindro tem sido frequentemente caracterizada por fenômenos de fluxos, tais como o desprendimento oblíquo, ondulação irregular e vórtices curvos. Estudos do autor SLAOUTI (1981) explicam melhor esses fenômenos.

Um dos primeiros estudos para o padrão de emissão de vórtices de cilindro com baixa razão de aspecto $(1 \leq L / D \leq 8)$ é apresentada em KAWAMURA (1984), baseada em experimentos com cilindros fixos. Um dos resultados apresentados foi a descrição de um par de vórtices emitidos a partir da aresta na extremidade livre do cilindro, denominados trailing vortices, que interferem diretamente na esteira de von Kármán.

A partir deste estudo, definiram uma razão de aspecto crítica, $L / D_{c} r \cong 2$, a partir da qual a esteira de von Kármán era completamente extinta. A Figura 2.20 ilustra dois cilindros de baixa razão de aspecto: um com valores maior que o valor crítico (suscetível ao padrão da esteira de von Kármán) e outro com valores menores (emissões da extremidade livre dominam a região próxima ao cilindro).

É importante salientar que o foco dos primeiros estudos com cilindros de baixa razão de aspecto era voltado para as grandes torres e chaminés em camada limite atmosférica e, portanto, a maioria das investigações neste quesito eram desenvolvidas com base em cilindros curtos fixos em uma superfície estacionária. A Figura 2.21 ilustra este arranjo experimental.

Com o avanço da tecnologia, novos procedimentos de ensaios permitiram a obtenção de resultados e visualizações melhores do escoamento junto aos cilindros.

Em PARK (2004) foi investigado experimentalmente o fluxo em torno de 1 cilindro com $L / D=6$, montado verticalmente numa placa plana longa, em túnel de vento; variando a forma de canto da extremidade livre. Os campos de velocidades próximos da extremidade livre foram medidos utilizando o método PIV (Particion Image Velocimetry) com $R e=7500$.

A figura 2.22 mostra o escoamento visualizado no plano $X Z$. A estrutura fluida ao redor dos cilindros estudados é notória diante a um cilindro circular. A estrutura da sequência $3 D$ parece ser induzida a partir de uma interação entre os fluidos arrastados de ambos os lados do cilindro. 
Figura 2.20: Escoamento ao redor de cilindros fixos com baixa razão de aspecto. A esquerda $L / D>\left(L / D_{c} r\right)$ e a direita $L / D<\left(L / D_{c} r\right)$
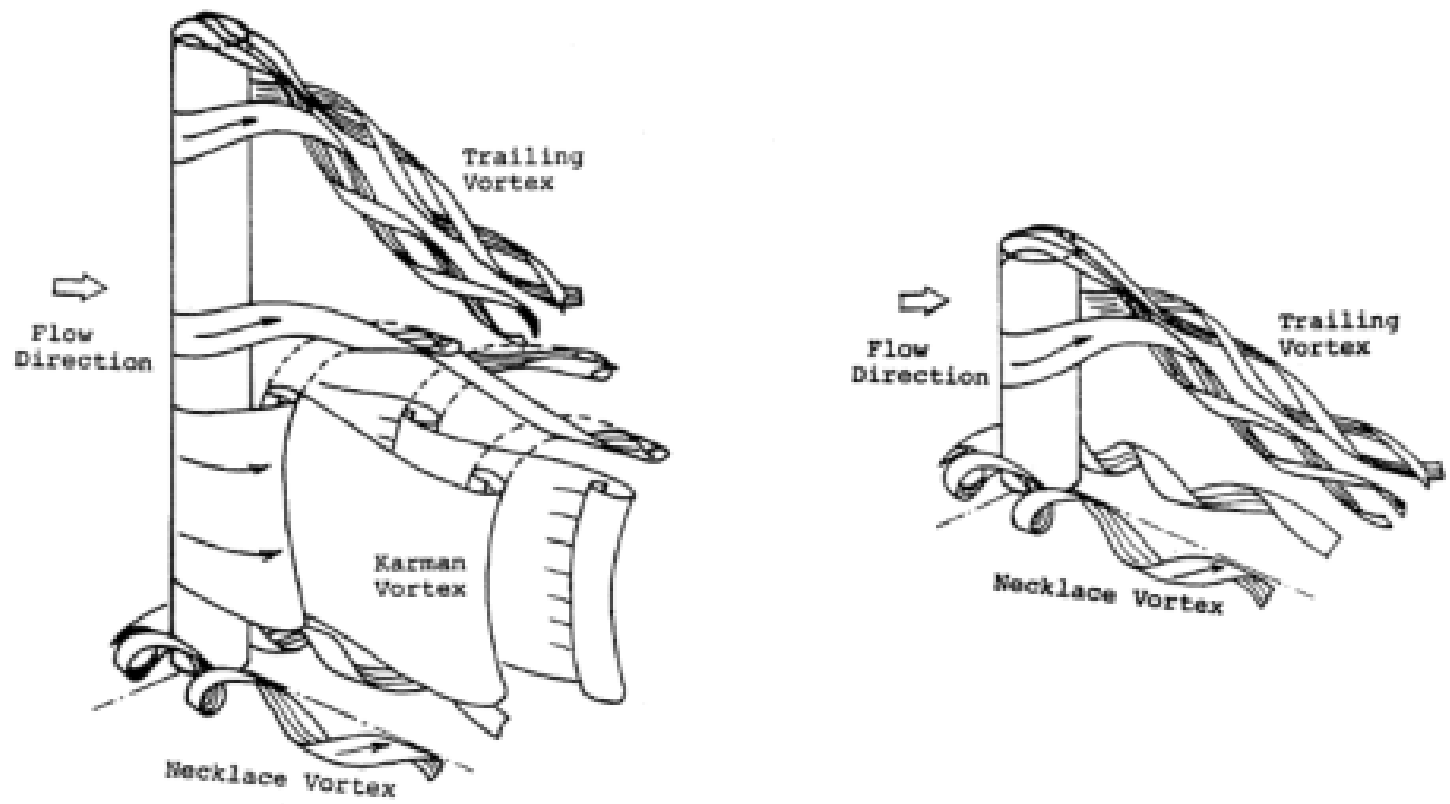

Figura 2.21: Cilindro fixo em uma placa plana e imerso a um escoamento. Extraído de Gambarine (2017) e adaptado de Sumner (2004).

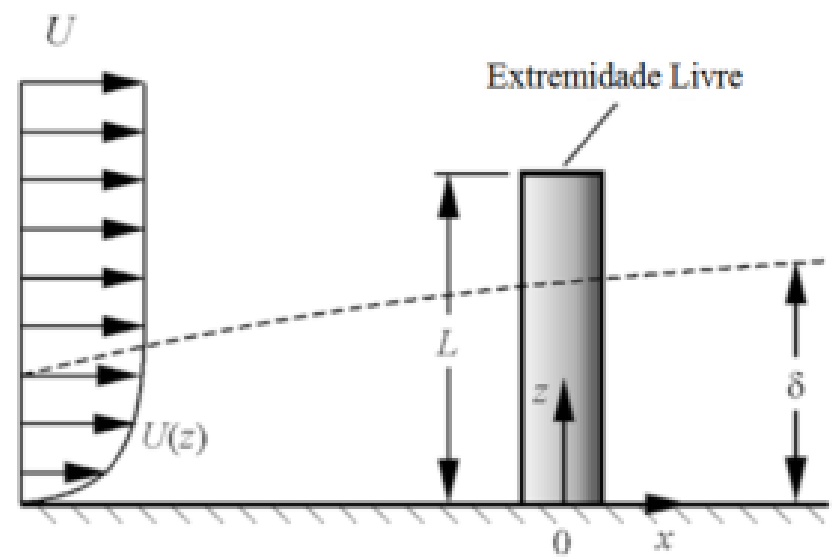

A bolha de recirculação formada acima da ponta e a largura da camada de cisalhamento separada atrás do corpo é reduzida. Um par de vórtices longitudinais de contra-rotação é formado na região traseira da ponta quadrada. Estes dois vórtices longitudinais são de tamanho similar e são quase simétricos em relação ao plano central da esteira. 
Figura 2.22: Fluxo visualizado em torno da extremidade livre no plano vertical $\mathrm{XZ}$ em $Y / D=0$ : (a) ponta plana; (b) ponta chanfrada; c) ponta arredondada; d) ponta hemisférica. Extraído de Park \& Lee - 2004
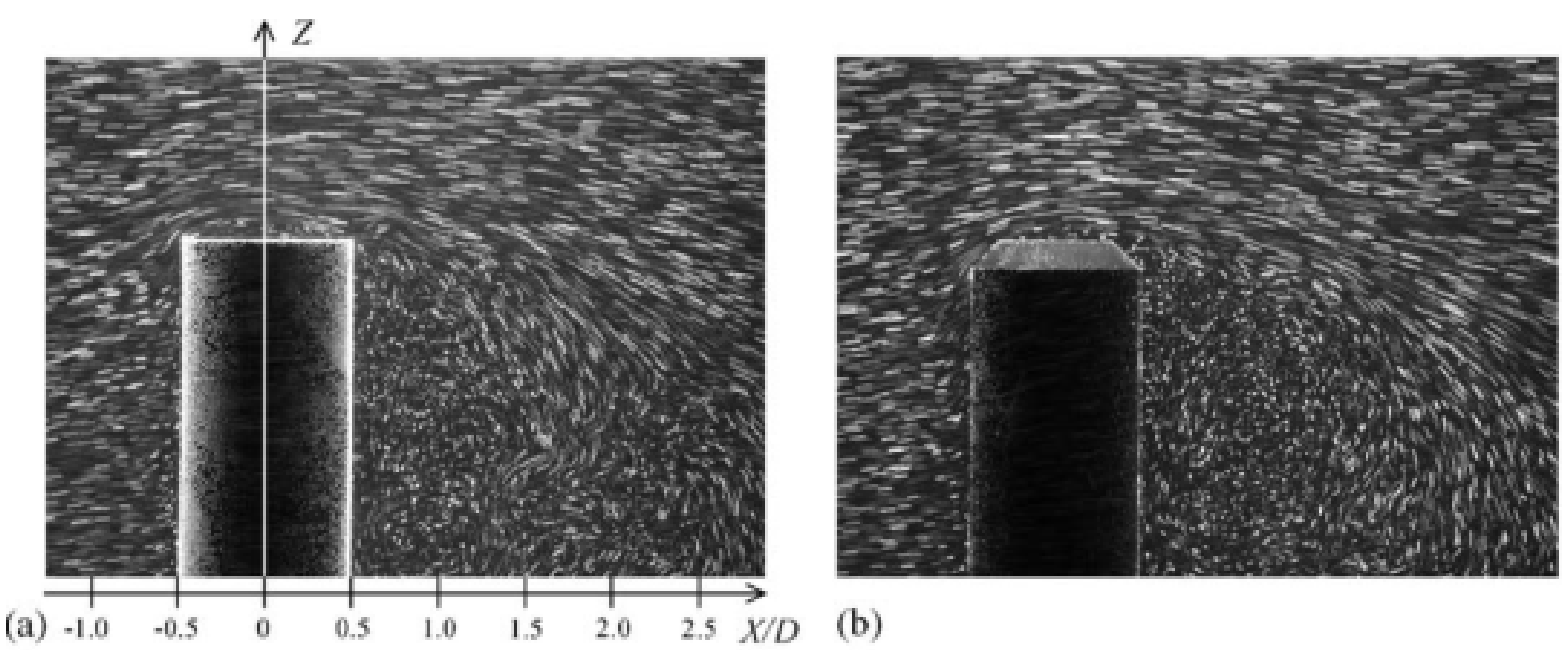

(b)
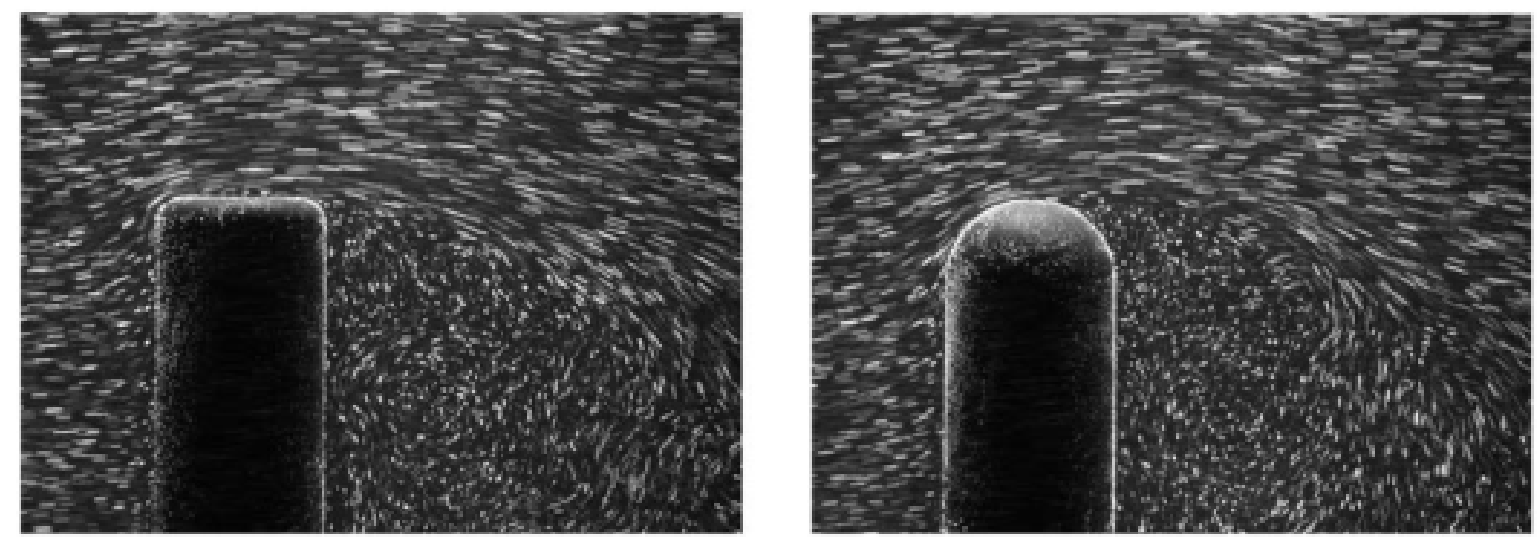

(c)

(d)

Quando o canto da ponta é alterado para a forma chanfrada ou arredondada, essa estrutura vorticial torna-se mais fraca e quase desaparece. A Figura ?? mostra esse efeito.

Ainda em PARK (2004), foi mostrada a densidade espectral de potência (PSD), ilustrado na Figura 2.24 para os quatro formatos de extremidade livre. As frequências de desprendimento de vórtices são menores $\left(f_{s}=66 \mathrm{~Hz}\right)$ na mesma velocidade de fluxo uniforme. Os autores concluíram o campo de escoamento turbulento induzido pelo fluxo de cisalhamento separado da extremidade livre também pode ser uma das principais causas da vibração no cilindro.

Em estudos anteriores, os autores mencionaram que as flutuações da força de arrasto foram aumentadas devido ao fluxo de recirculação altamente turbulento na região da esteira, devido a alteração da geometria da extremidade livre.

As primeiras análises com cilindros curtos livres para oscilar são encontrados há pouco tempo, em trabalhos como SOMEYA (2010). Neste estudo, o cilindro está livre para oscilar em $2 \mathrm{GL}$, no canal de água circulante. A metodologia de análise foi através da técnica de PIV. As velocidades e vibrações do cilindro foram medidas e mostraram que o número de Strouhal na 
Figura 2.23: Distribuições espaciais de velocidade média e intensidade de turbulência $(Y / D=$ 0; plano XZ): (a) ponta plana; (b) ponta chanfrada; c) ponta radiante; e (d) ponta hemisférica. Extraído de Park \& Lee - 2004
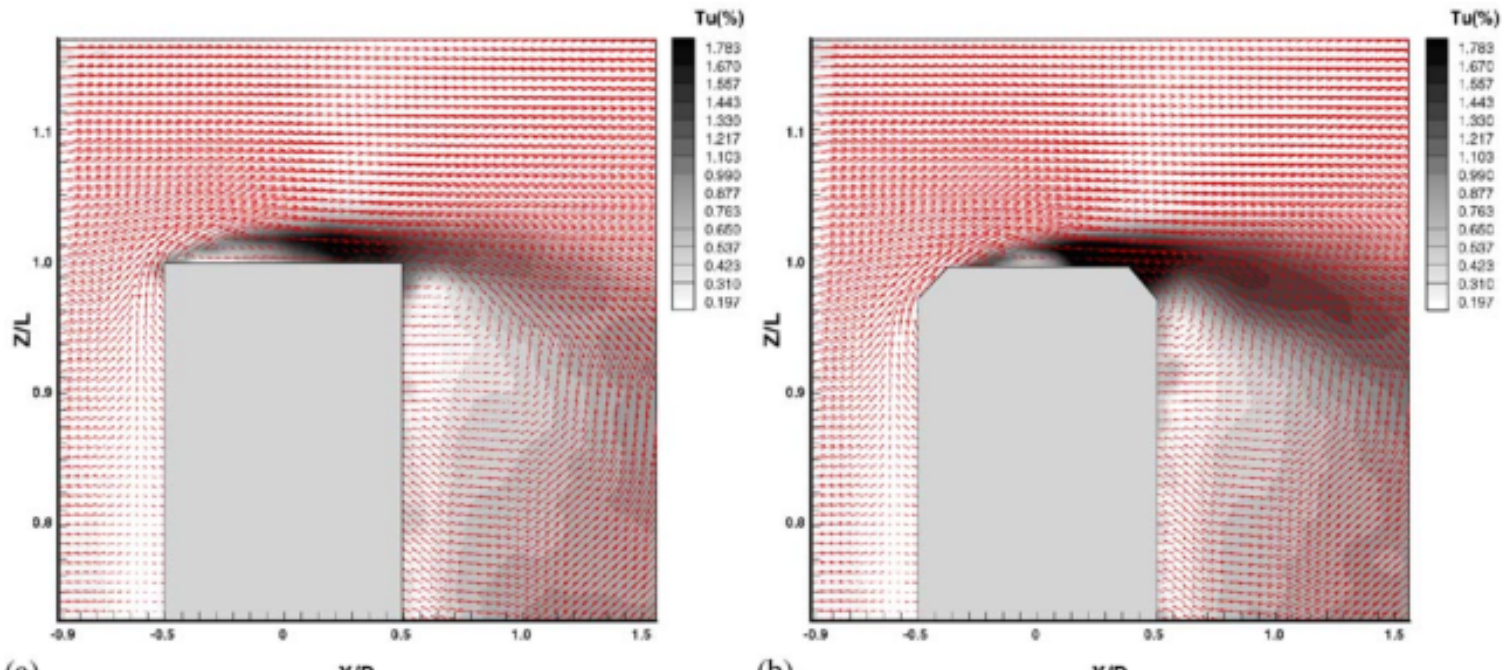

(a)

(b)

$\mathrm{X} / \mathrm{D}$
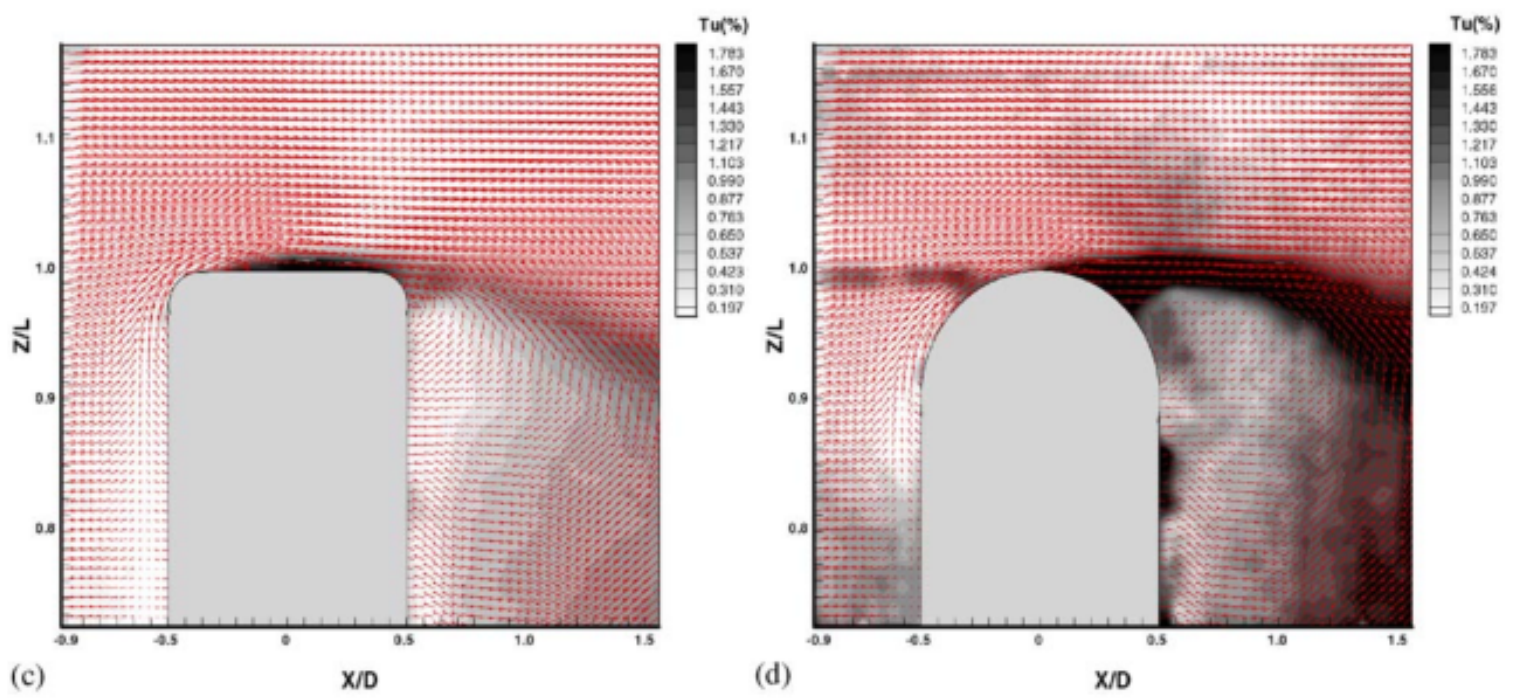

extremidade livre é significativamente maior que no restante do cilindro.

A maioria desses pesquisadores realizou experimentos em instalações de túneis de vento. Atualmente, existem apenas alguns estudos sobre os efeitos de $L / D$ que foram conduzidos em canais de água. Para alguns trabalhos mais recentes nesta linha, destacam-se os estudos de GONÇALVES (2012), GONÇALVES (2013a), GONÇALVES (2013b), GONÇALVES (2015) entre outros.

GONÇALVES (2013c) foi o primeiro que descreveu as amplitudes e frequências de reposta como função da velocidade reduzida $\left(1,5 \leq V_{r} \leq 14\right)$ e da razão de aspecto $(0,2 \leq$ $L / D \leq 2$ ), obtidas em experimentos em canal de água. Ainda neste trabalho, em modelos livres para oscilar em $2 \mathrm{GL}$, foi possível observar oscilações para cilindros com $L / D$ inferior a $L / D_{c} r$, além de apresentar um comportamento onde as amplitudes de oscilação diminuem conforme a redução da razão de aspecto. 
Figura 2.24: Distribuições espaciais de velocidade média e intensidade de turbulência $(Y / D=$ 0 ; plano $\mathrm{XZ}$ ): (a) ponta plana; (b) ponta chanfrada; c) ponta radiante; e (d) ponta hemisférica. Extraído de Park \& Lee - 2004

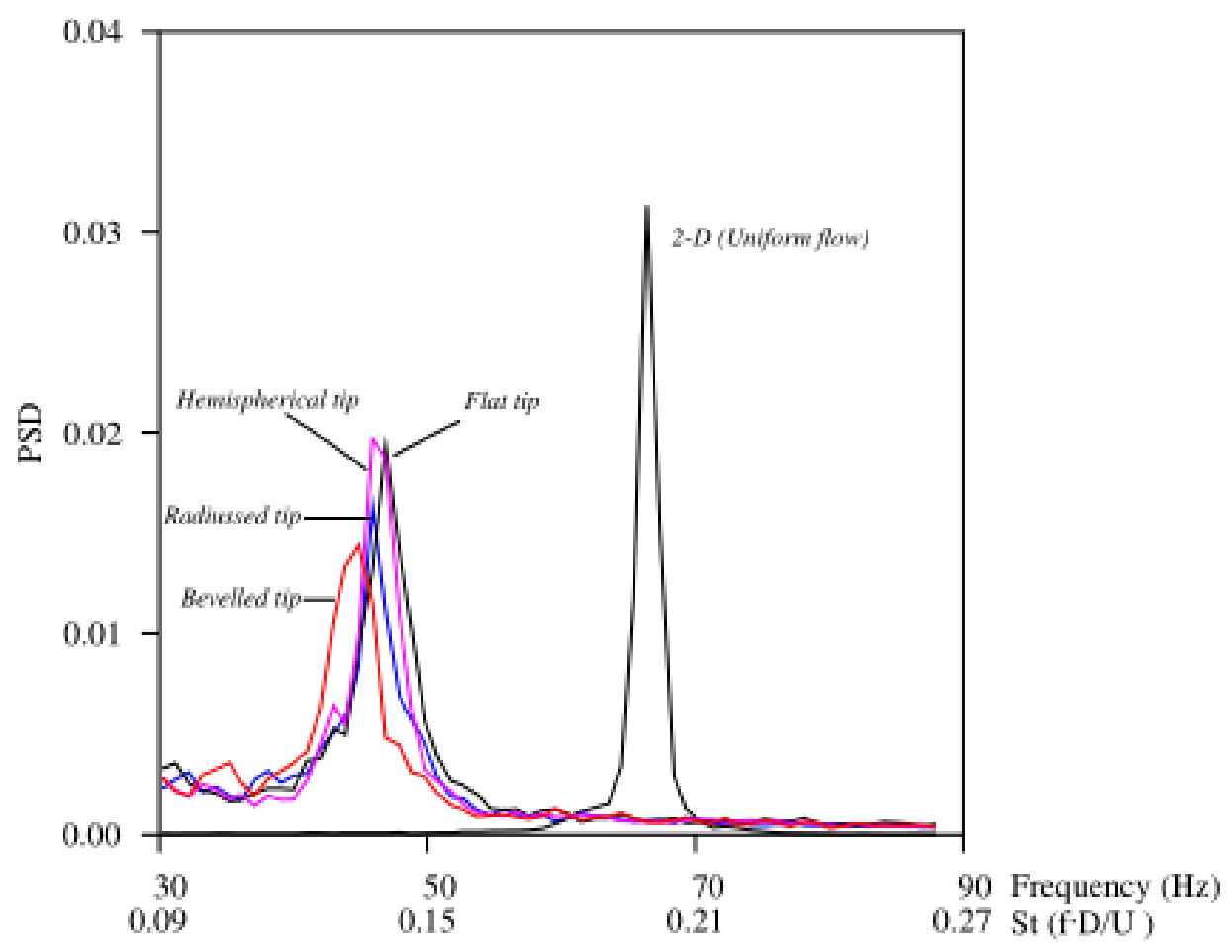

Figura 2.25: Desenho esquemático mostrando a emissão de vórtices ao redor de um cilindro com efeito da extremidade livre. Adaptado de Someya, 2010. Extraído de Gonçalves, 2013.

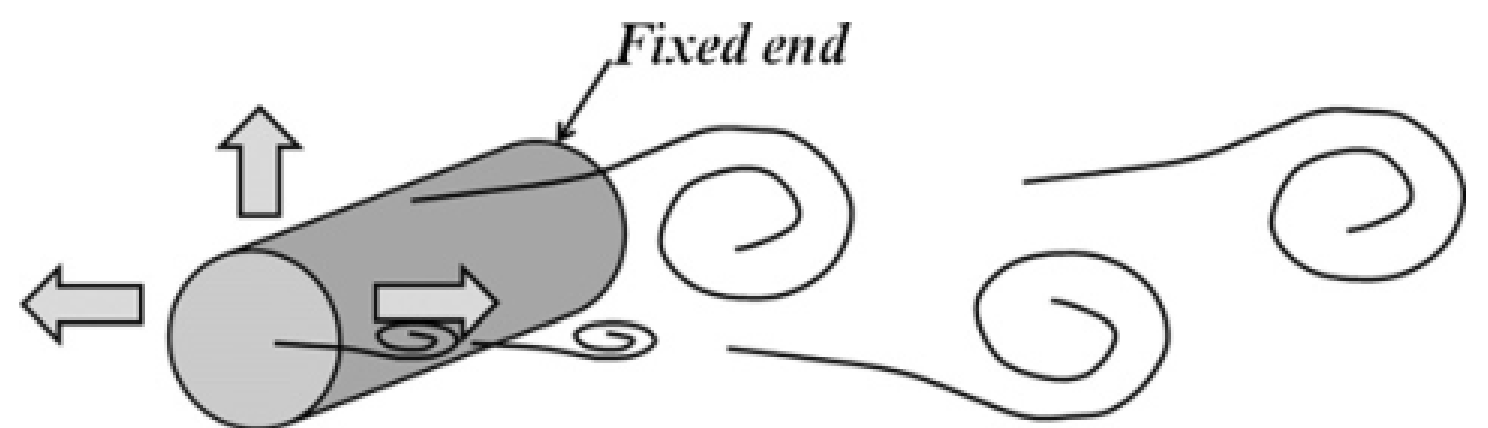

Free with $2 \mathrm{DoF}$

De acordo com o que foi descrito no início da seção, este comportamento pode estar relacionado aos efeitos causados pela aresta da superfície plana, visto que os vórtices emitidos por esta região tendem a ter maiores influências conforme a redução da razão de aspecto. 0 
trabalho apresentou imagens obtidas por PIV do escoamento ao redor do cilindro curto, no qual foi comprovado o aparecimento de vórtices na extremidade livre e sua interação com a esteira formada nas paredes do cilindro.

Na Figura 2.26 apresenta no plano vertical os contornos de velocidade média adimensional na direção longitudinal, $U_{x} / U$, no qual $U_{x}$ é a velocidade média adimensional na direção longitudinal, e $U$ é a velocidade do escoamento. Cada linha de gráfico corresponde a uma razão de aspecto (de baixo para cima: $L / D=0,3 ; 0,5 ; 1.0$ e 2,0 ) e cada coluna de gráficos a um regime distinto de escoamento (da esquerda para a direita: $R e=1 \times 10^{4}, 2,3 \times 10^{4} \mathrm{e}$ $\left.4,3 \times 10^{4}\right)$.

Verifica-se que o escoamento incidente move-se da extremidade livre em direção a superfície, após ocorrer uma separação junto ao vórtice anterior. A jusante de todos os casos, é observada uma grande região de recirculação no plano vertical longitudinal ao escoamento.

Como resultado da modificação de $L / D$, no entanto, nesta mesma região percebe-se uma variação na posição do ponto de recolamento do fluxo, junto a superfície livre. Importante destacar que o ponto de recolamento mencionado é definido como aquela posição próxima à superfície livre, onde as linhas de corrente passam a ter a mesma direção das linhas de corrente do escoamento ao longe, ou seja, caracterizando o final da região de recirculação a jusante do cilindro. Assim, a posição do ponto de recolamento distancia-se em relação ao centro do cilindro.

No entanto, estudos sobre o fluxo ao redor de cilindros com seção não circular ainda são bem escassos na literatura, ainda que sua relevância tenha aumentado nos últimos anos, principalmente na engenharia oceânica. NEMES (2012) examinou a influência do ângulo de ataque de um cilindro com seção quadrada, na direção transversal ao escoamento. Os experimentos mostraram que este corpo, com baixa razão de aspecto e massa, pode sofrer combinações de VIV e galloping.

Quando um corpo tem um ângulo de ataque que o torna simétrico ao fluxo, por exemplo, quando ele assume a orientação diamante (denominada pelo autor) os dois mecanismos permanecem independentes. No entanto, quando a simetria é perdida, encontra-se uma resposta 'mista', com um novo ramo de oscilações induzidas por vórtices, que excede as amplitudes resultantes dos dois fenômenos independentes. Quanto a amplitude de movimento, é mostrado que a transição entre o VIV e o galloping ocorre numa faixa estreita na variação do ângulo de incidência.

Apesar do rico conjunto de resultados mostrados, os modos de desprendimento de vórtices permanecem muito semelhantes aos encontrados anteriormente em VIV.

A Figura 2.27 fornece um mapa de como os cilindros com seção quadrada respondem como uma função do seu ângulo de ataque $\alpha$ e velocidade reduzida, $U$ *

O mapa de parâmetros destaca três tipos de fenômenos fluido-estrutural e suas regiões correspondentes. VIV (região clara) exibe respostas de frequência semelhantes às do diamante; galloping (região escura) com comportamento de frequência e amplitude associado ao quadrado, e uma região de resposta VIV que é referida como o ramo superior (ligado por 
Figura 2.26: Campo de velocidade adimensional na direção longitudinal do escoamento, no plano vertical central do cilindro, e respectivas linhas de corrente, para diferentes razões de aspecto e número de Reynolds. Extraído de Gonçalves, 2013.

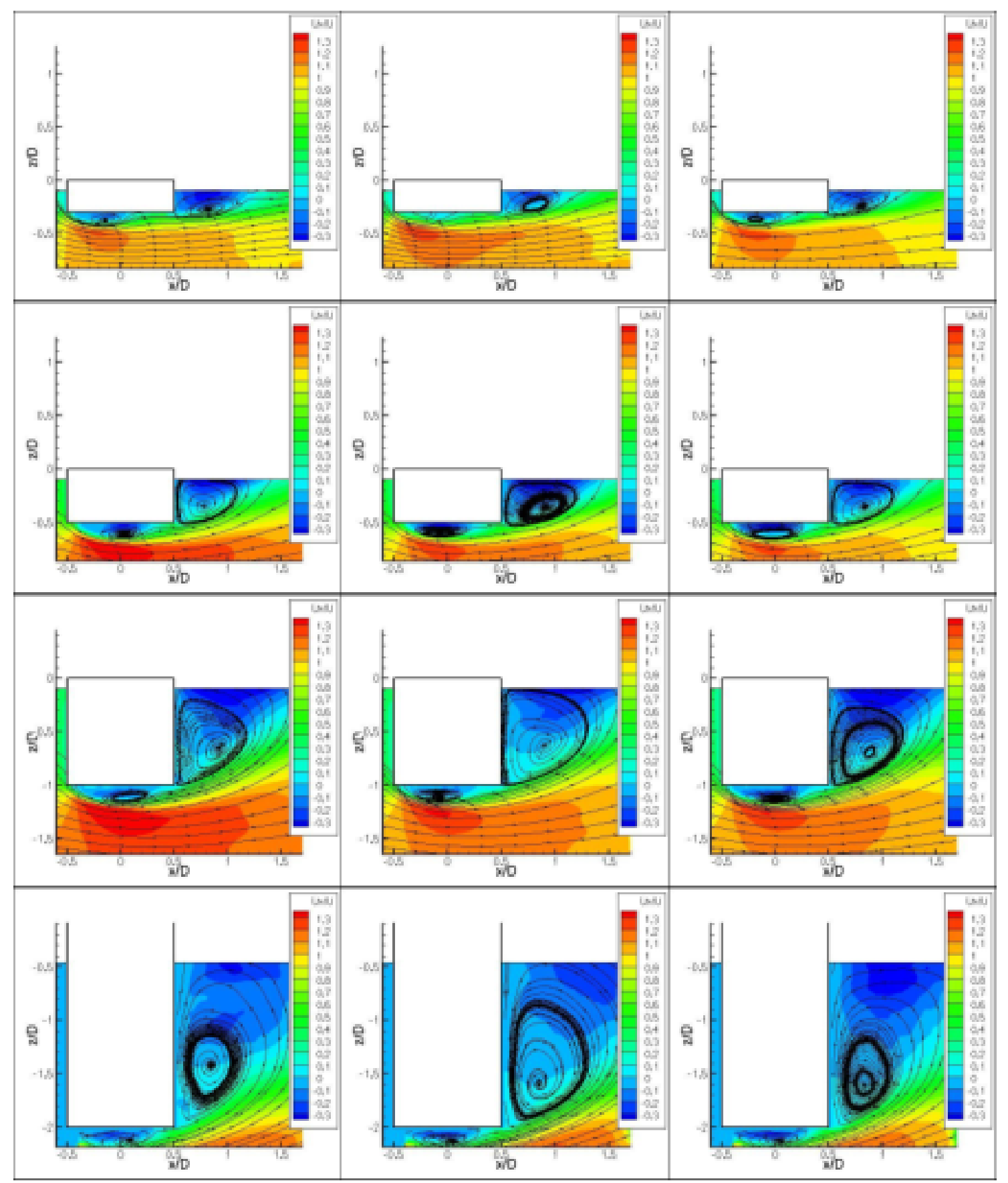

linha grossa).

As combinações ângulo-velocidade onde as medições de força e posição foram registradas são denotadas por símbolos associados aos comportamentos dominantes de FIV (círculo, VIV; quadrado, galloping / baixa frequência; triângulo, ramo mais alto). O tamanho relativo dos símbolos representa a potência CWT normalizada relativa do pico da frequência de 
Figura 2.27: Mapa da resposta FIV de um cilindro quadrado com variação no ângulo de ataque e velocidade reduzida, $U^{*}$. As regiões são rotuladas de acordo com o tipo de resposta.O tamanho relativo dos símbolos denota a energia relativa das frequências dominantes no sistema. Extraído de Nemes, 2012.

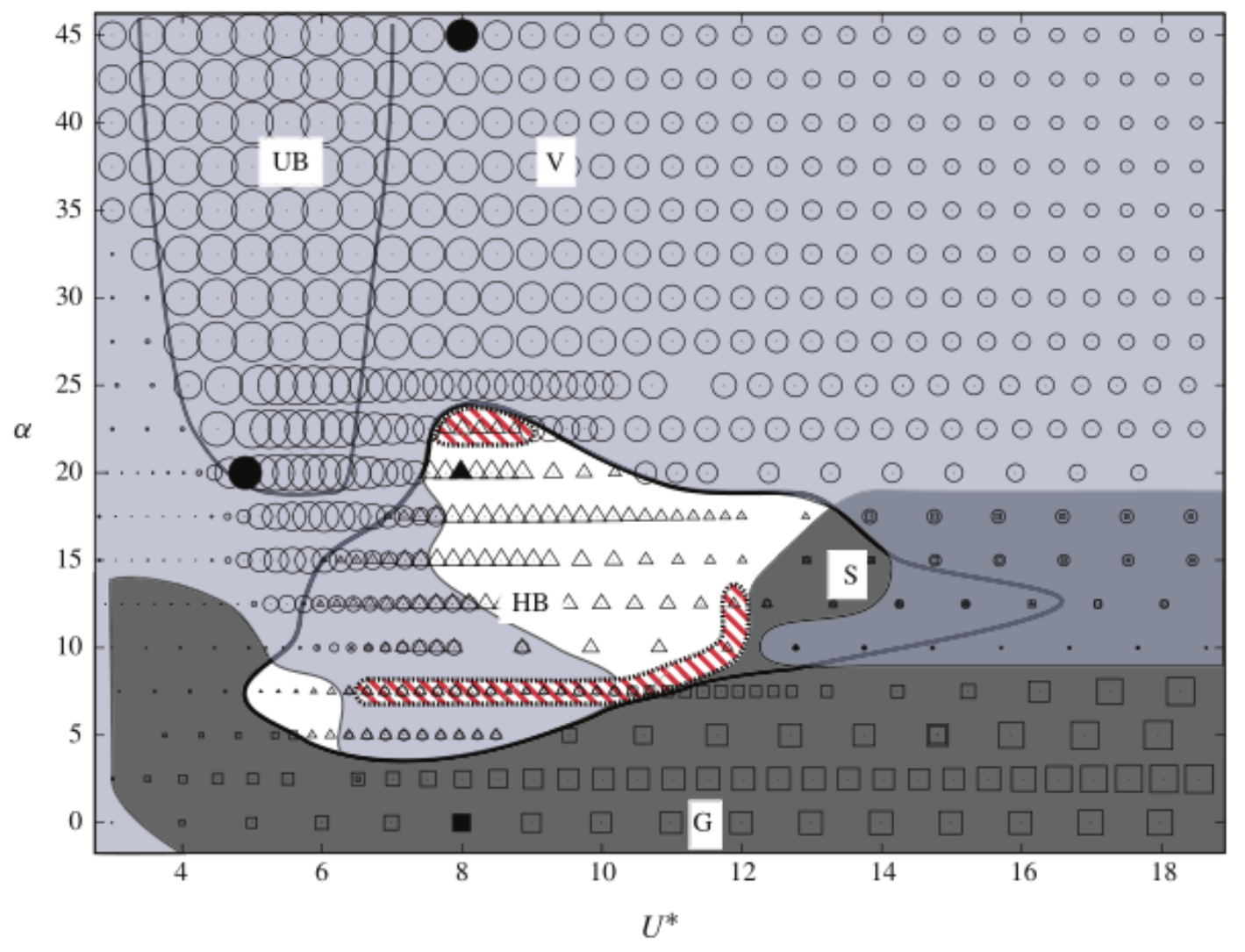

oscilação associada à resposta FIV. Onde dois símbolos são sobrepostos, existem dois modos na resposta de frequência, com seu tamanho de símbolo representando sua contribuição de potência relativa para a resposta de oscilação.

Ainda com relação a investigação da influência do ângulo de ataque no escoamento e influenciado pela área de transição encontrada nos estudos de NEMES (2012), ZHAO (2014) investiga a vibração na direção transversal de um cilindro com baixa razão de massa, montado numa base elástica, em três diferentes ângulos de incidência: $\alpha=0^{\circ}, 20^{\circ} \mathrm{e} 45^{\circ}$.

Esta configuração geométrica apresenta um cilindro com seção quadrada, como mostra a Figura 2.28. O foco é sobre estes três ângulos representativos, no qual $\alpha=0^{\circ}$ é reconhecido o fenômeno de galloping; $\alpha=45^{\circ}$ é reconhecido o fenômeno de VIV; e um valor intermediário $\alpha=20^{\circ}$, onde foi difícil de determinar o que ocorre.

Para o caso de $\alpha=0^{\circ}$, a amplitude de oscilação aumenta linearmente com a velocidade do fluxo, exceto para uma série de regimes que ocorrem quando a frequência natural está perto de um múltiplo ímpar inteiro da frequência de oscilação do galloping, e a frequência de desprendimento de vórtice sincroniza a este múltiplo ímpar da frequência natural. A Figura 
2.29 mostra este resultado.

Figura 2.28: Esboço do problema estudado: um cilindro transversal com ângulo de ataque variável, restrito para oscilar pelo fluxo. Extraído de Zhao, 2014.

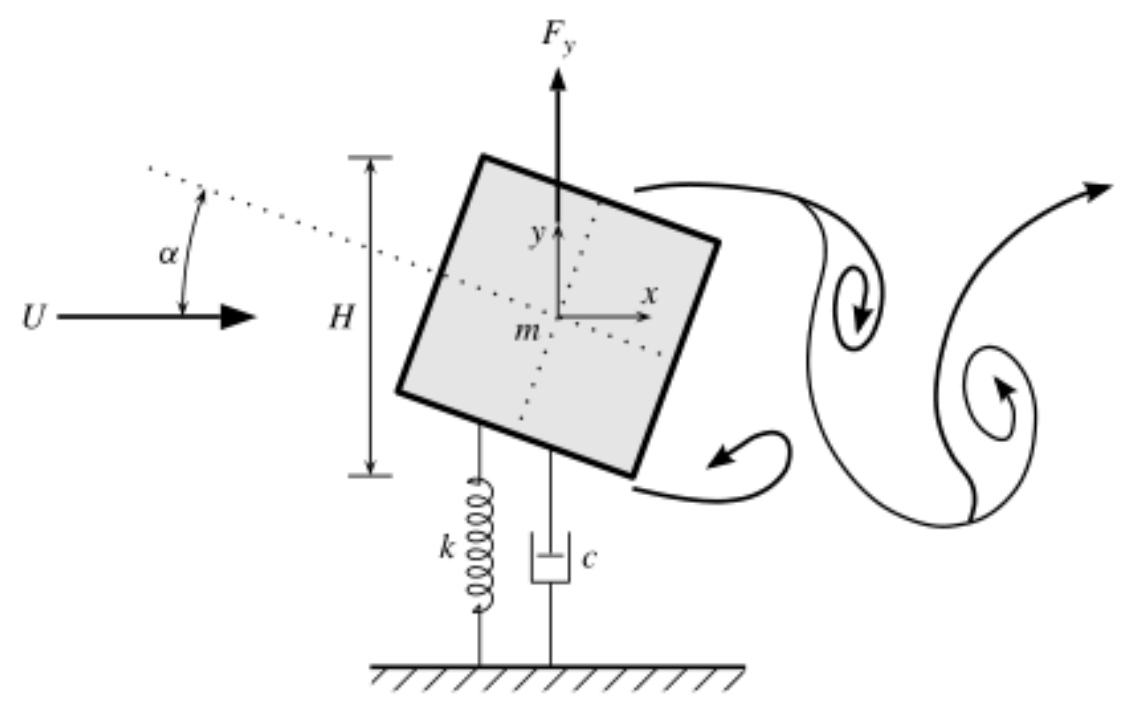


Figura 2.29: A amplitude (a) e a resposta de frequência (b) - (e) como função de $U^{*}$ com $m^{*}=2.64$ em $\alpha=20 \check{\text { r }}$, mostrando duas regiões de ressonância sombreadas cinza escuro. Extraído de Zhao, 2014.
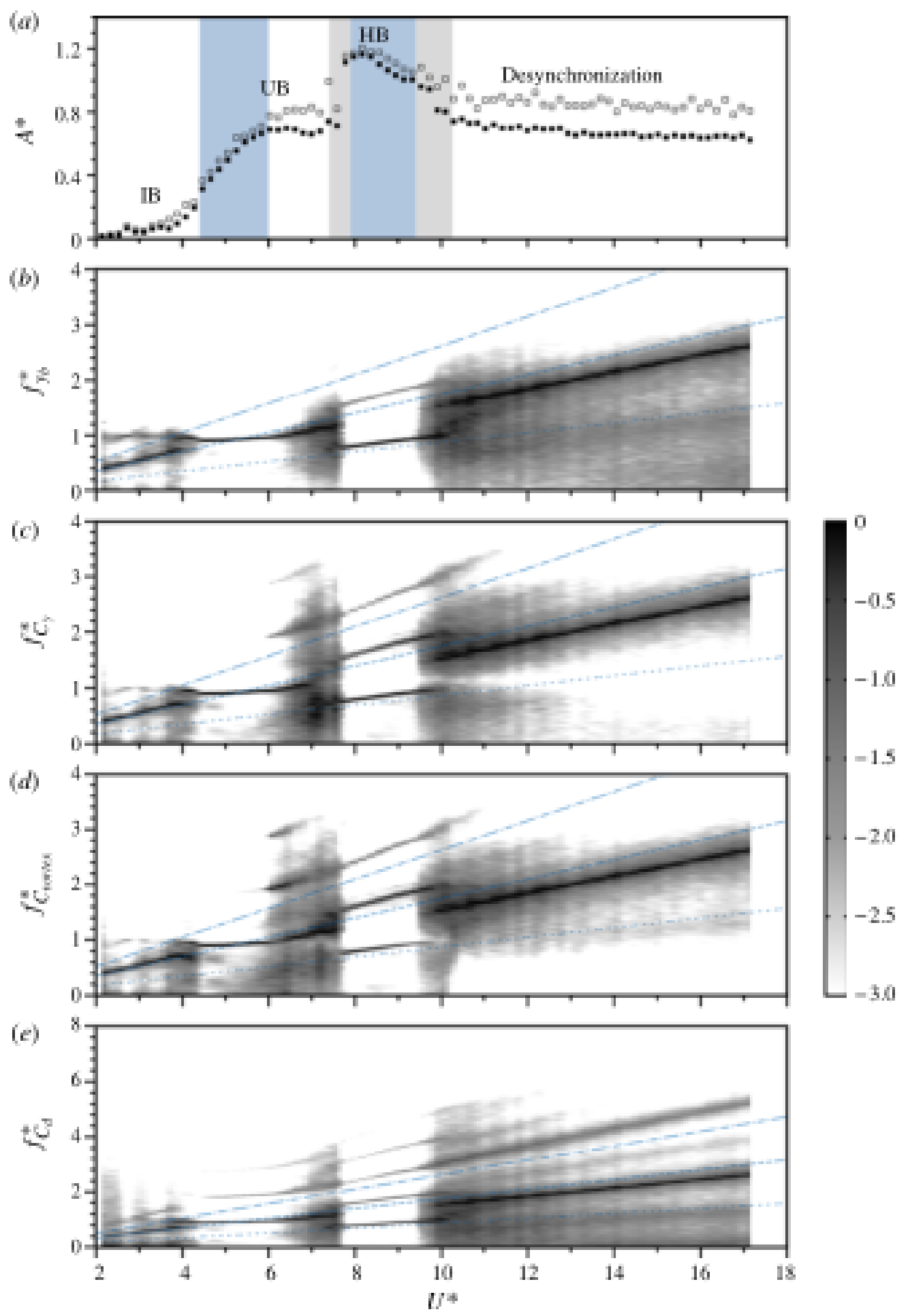
Para $\alpha=45^{\circ}$, a resposta de VIV consiste em um aumento sutil nos regimes, com 5 regimes de oscilações de alta amplitude, comparado a dois encontrados nos estudos clássicos de VIV em cilindro circular. Já para o caso intermediário $\alpha=20^{\circ}$, ocorre um ramo superior àquele encontrado no VIV típico, com amplitude muito grande.

O ramo mais alto é causado por uma sincronização sub-harmônica entre a desprendimento do vórtice e a frequência de oscilação do corpo, no qual dois ciclos de desprendimento de vórtices ocorrem ao longo de um ciclo de oscilação. Parece que esta sincronização subharmônica é um resultado direto da assimetria do corpo. A figura 2.29 mostra este resultado.

Os cilindros flutuantes de seção quadrada, com baixa razão de aspecto, te um período natural diferente de movimentos no plano horizontal, que varia o ângulo de incidência atual.

Neste contexto, GONÇALVES (2015) realizou experimentos em uma bacia oceânica, com o objetivo de entender a fenomenologia em torno dos cilindros flutuantes de seção quadrada, com razão de massa $m^{*}=1$ e com variação na razão de aspecto $(1,0 \leq L / D \leq 3,0)$ com o intuito de esclarecer ainda mais a influência do ângulo de ataque. Para efeito de comparação, usou-se os resultados prévios para cilindros circulares.

A Figura 2.30b mostra as amplitudes de movimento no sentindo transversal e longitudinal, respectivamente. Em geral, as amplitudes adimensionais na direção transversal e longitudinal foram maiores para os cilindros circulares, denominado CC pelo autor. A razão de aspecto permaneceu indiferente entre os cilindros na incidência de $45^{\circ}$ e teve efeitos leves para a incidência de $0^{\circ}$.

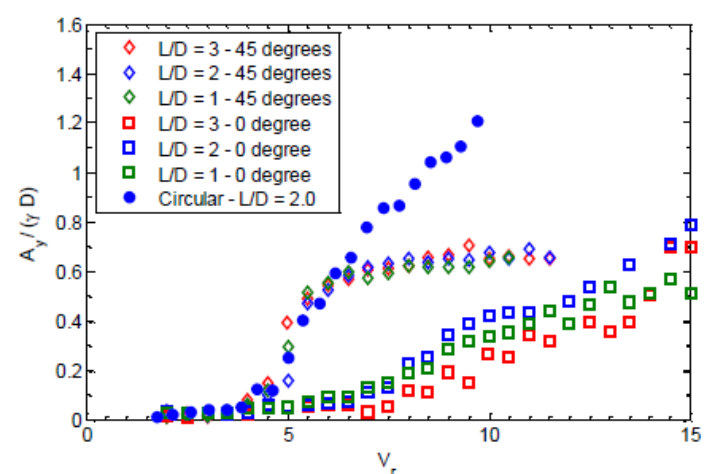

(a)

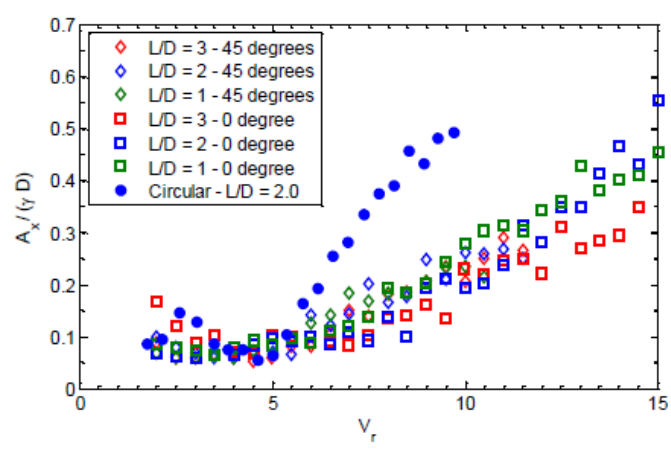

(b) 


\subsection{Galloping}

Esta seção apresenta a fenomenologia relacionada ao galloping. Este fenômeno tem sido observado há muito tempo e, em princípio, nas linhas de energia elétrica.

Quando acumulava-se gelo sobre tais linhas, sua seção transversal muda de geometria e, com isso, é mais suscetível a ocorrência deste fenômeno. Portanto, essa configuração é resultado de uma instabilidade aerodinâmica associada à geometria da seção transversal submetida ao escoamento, bem como ao seus coeficientes de sustentação e arrasto.

Isso pode ser explicado muito sucintamente da seguinte maneira. Se um obstáculo for colocado no escoamento fluido, vórtices podem ser formados a jusante deste obstáculo, liberados com uma dada periodicidade que depende da forma e dimensão da estrutura, assim como da velocidade do fluido, semelhante ao que acontece com o VIV.

Em suma, o galloping tem a sua causa explicada pela oscilação da força de sustentação resultante da variação do ângulo de ataque do escoamento em relação à estrutura. Este fenômeno é geralmente associado a sistemas com apenas um grau de liberdade (1GL).

Além de um eventual efeito de interferência a montante, outros fatores de importância nas análises do fenômeno de galloping são a própria característica do escoamento incidente e da forma geométrica da estrutura, bem como o efeito do amortecimento estrutural. Um cilindro circular, por exemplo, pode apresentar comportamento típico de VIV para uma velocidade reduzida na faixa de 5 a 10 , tipicamente, e pode apresentar comportamento de galloping para velocidades mais elevadas.

Diferente do VIV, no entanto, uma vez que o galloping se estabelece, suas amplitudes de oscilação aumentam indefinidamente à medida que ocorre o aumento da velocidade do escoamento,podendo ser iguais a dez vezes o valor da dimensão característica da seção transversal.

Apesar disso, o mecanismo físico do galloping isolado já bem compreendido no sentido de que sua ocorrência e seu nível de resposta podem ser previstos a partir do conhecimento das propriedades fluidodinâmicas da seção transversal. Por outro lado, nas VIV, estes parâmetros são mais difíceis de serem estabelecidos.

Quando as condições permitem a presença simultânea de galloping e VIV, introduz-se uma complexidade adicional ao problema da interação fluido-estrutura. Isso acontece quando a velocidade do escoamento $U$ é tal que a frequência de desprendimento de vórtices $f_{s}$ se assemelha à frequência natural do corpo $f_{n}$ e, simultaneamente, as forças fluidodinâmicas apresentam componente com magnitude suficiente e em contrafase com a velocidade, promovendo a mitigação do efeito dissipativo estrutural.

A Figura 2.30, extraída de AMATO (2010), ilustra o mecanismo de interação entre os fenômenos de VIV, com velocidade típica de desprendimento de vórtices $V_{c r}$ associada ao pico ressoante, e galloping, com velocidade de deflagração $V_{0}$.

As teorias fluidodinâmicas que analisam as excitações por galloping empregam a te- 
Figura 2.30: Representações da interação entre VIV e Galloping. Extraído de AMATO (2010).
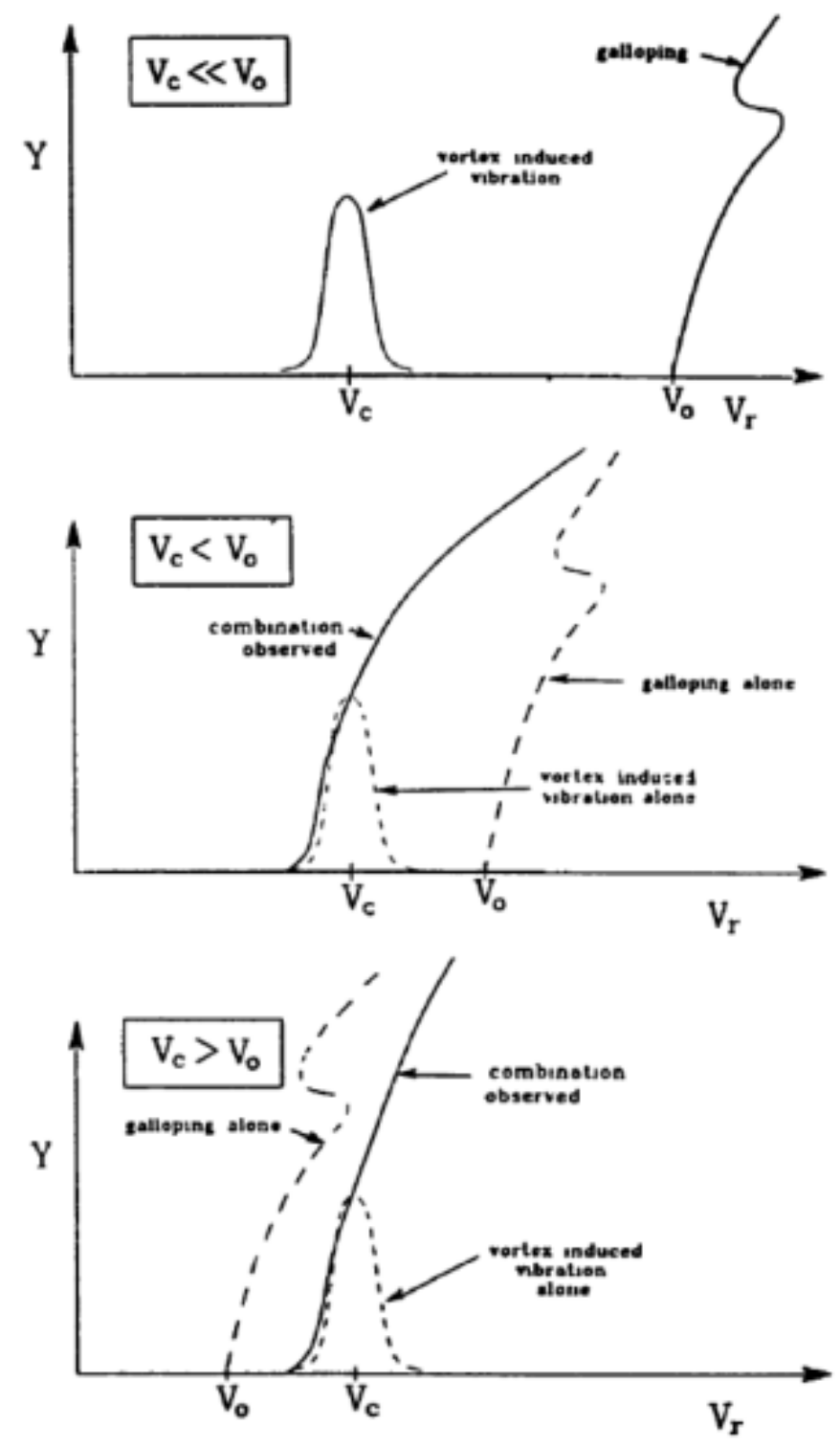

oria de fenômeno de quasi-steady, onde a força fluida resultante é determinada apenas pela velocidade relativa em um dado instante. Isto é, por hipótese, a força fluida (magnitude e direção) aplicada no corpo em qualquer posição que se encontre em um escoamento é a mesma que seria encontrada se o corpo estivesse estacionário naquela posição. A teoria quasi-steady é válida somente para casos em que a frequência de excitação da força fluida é muito maior que a frequência natural de oscilação do corpo. Verifica-se, portanto, que quando a velocidade de deflagração do galloping é próxima ou menor que a velocidade crítica do VIV, $V_{0} \lesssim V_{c r}$, uma resposta combinada aparece e as amplitudes aumentam consideravelmente a partir da velocidade de início do VIV. Naturalmente, esta teoria quasi-steady de combinação deixa de existir quando $V_{0} \gg V_{c r}$. 


\section{Capítulo 3}

\section{MATERIAIS E MÉTODOS}

O presente capítulo da dissertação visa apresentar em detalhes a metodologia experimental e os materiais utilizados. Mediante o objetivo de investigar o FIV em cilindros com baixa razão de aspecto e com diferentes geometrias nas arestas, desenvolveu-se uma metodologia experimental detalhada nesta seção.

Ao que tange as técnicas e processos adotados nessa pesquisa, pode-se dividi-la de forma detalhada em: infraestrutura, modelos utilizados; aparato experimental elaborado para a execução dos ensaios; sistema de aquisição de dados; e, por fim, o método utilizado para a obtenção dos resultados.

\subsection{Tanque de reboque}

Os experimentos foram realizados no Laboratório de Engenharia Naval do Instituto de Pesquisas Tecnológicas do Estado de São Paulo, IPT.

Este laboratório conta com um tanque de reboque, que tem como característica principal um comprimento muito maior que a largura. Em termos dimensionais, portanto, o tanque de reboque do IPT tem 280 metros de comprimento, 6,6 metros de largura e lâmina d'água aproximada de 3,5 metros.

\subsubsection{Carros de reboque}

Este tanque possui um carro dinamométrico, em azul - vide foto 3.1, onde geralmente os modelos são conectados e rebocados de maneira a emular a velocidade de avanço ou a correnteza incidente.

Os ensaios de VIV foram realizados com uma base elástica, semelhante às utilizadas por KHALAK (1997) e GONÇALVES (2013c), projetada para cilindros com baixa razão massa e amortecimento.

Ao carro dinamométrico citado anteriormente, um carro auxiliar foi anexado, com o 
Figura 3.1: Foto do carro dinamométrico do tanque de reboque no IPT.

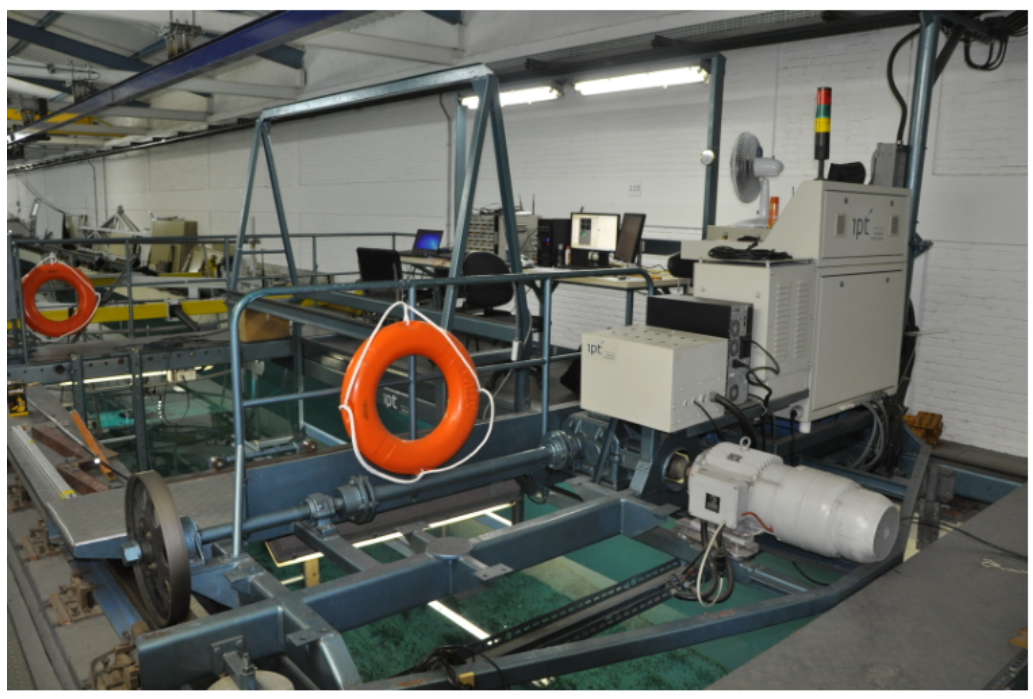

intuito de melhorar o posicionamento da estrutura no qual ocorreu a fixação do modelo. A Figura 3.2 mostra foto desta estrutura.

Figura 3.2: Foto carro secundário acoplado ao carro dinamométrico do tanque de reboque.

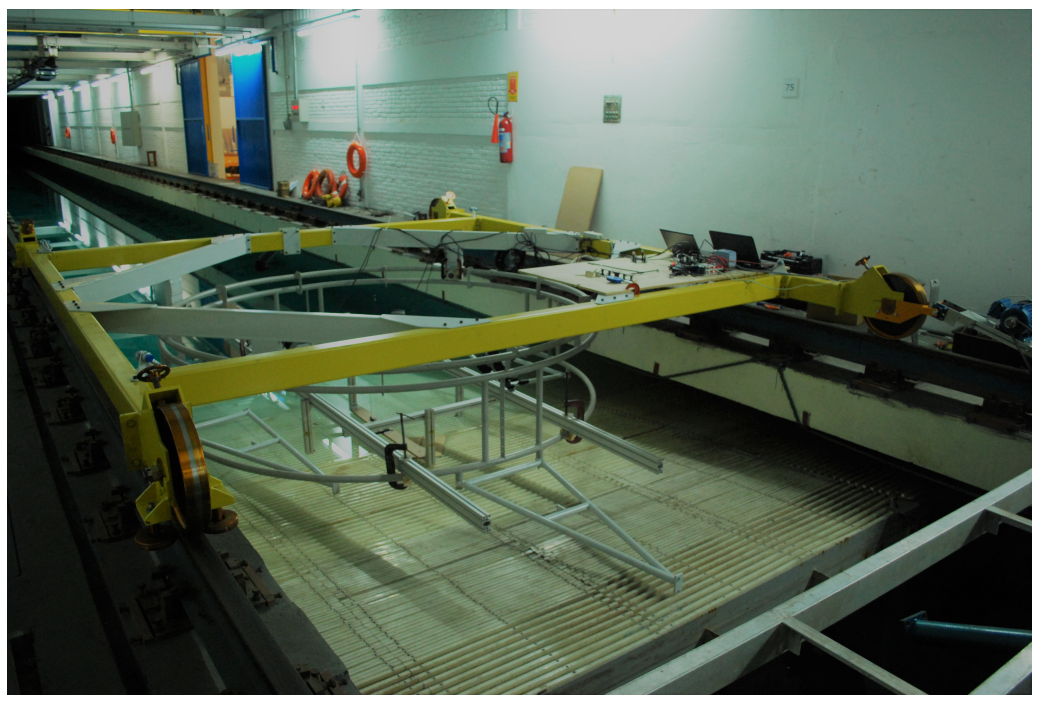

A principal característica que justifica sua utilização é a disponibilidade de um sistema rotatório que facilita a mudança do ângulo de incidência ao fluxo, além de facilitar a instalação das câmeras utilizadas para monitorar os movimentos dos modelos. 


\subsection{Sistema de Amarração}

O sistema de amarração está representado na Figura 3.3. Foram utilizadas quatro molas iguais, fabricadas de aço inox, de constante elástica $k=0,8 \mathrm{~N} / \mathrm{m}$.

Figura 3.3: Ilustração do aparato experimental montado no carro secundário. A esquerda: vista superior. A direita: vista lateral.
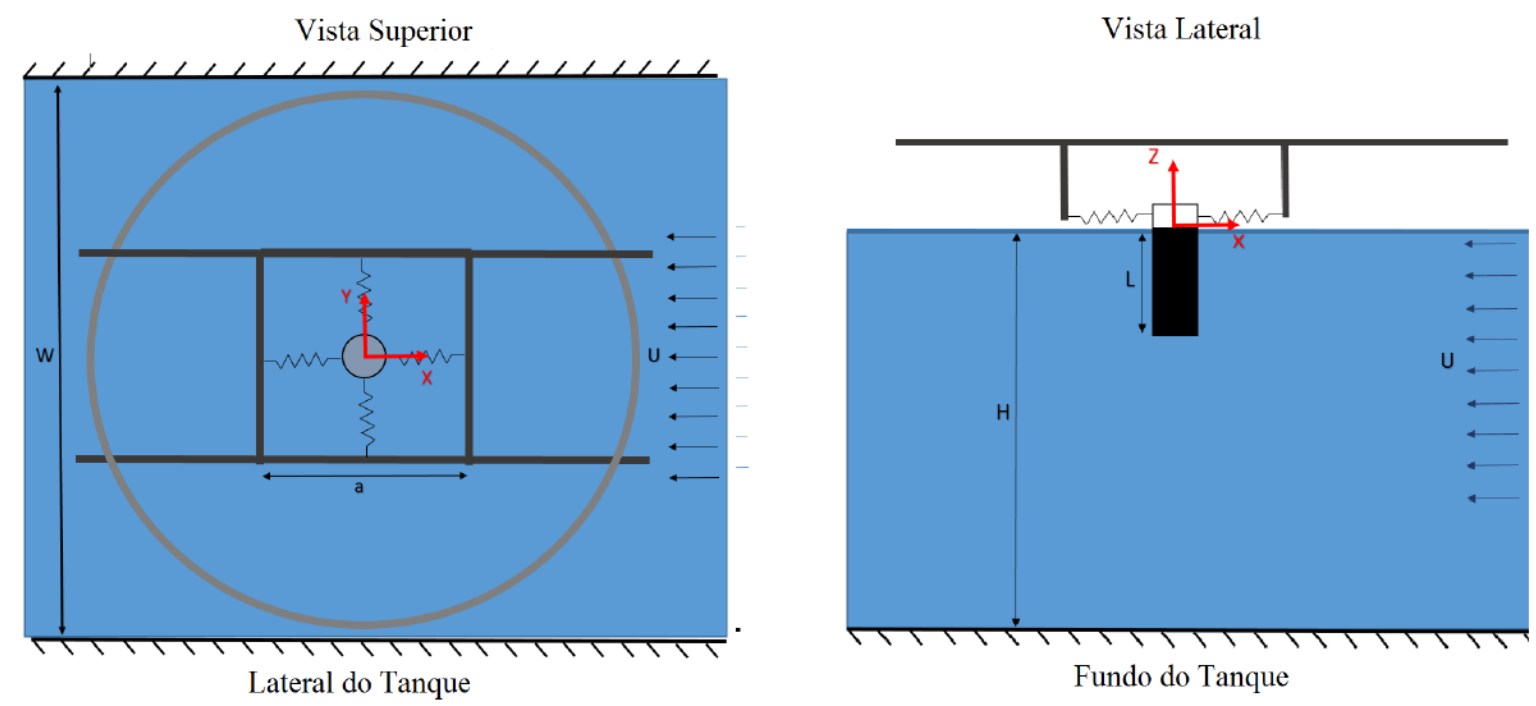

A fim de permitir a oscilação em seis graus de liberdade, os modelos foram montados em um quadro estrutural, feito de vigas de alumínio, responsável por mantê-los em equilíbrio o mais próximo possível da linha d'água.

A Tabela 3.1 mostra as características dimensionais das quatro molas utilizadas.

Table generated by Excel2LaTeX from sheet 'Plan1'

Tabela 3.1: Características geométricas das molas utilizadas.

\begin{tabular}{lc}
\hline Parâmetros & Dimensões [mm] \\
\hline$D_{0}$ & 8,50 \\
$d$ & 0,35 \\
$L_{0}$ & 191 \\
\hline
\end{tabular}




\subsection{Aquisição de Dados}

Para a monitoração e registro dos movimento dos modelos, foi adotado um sistema de rastreamento de alvos passivos por tratamento de imagens, fabricado pela Qualisys $\AA^{\circledR}$.

Este sistema consiste de câmeras com emissão e detecção infravermelha que capta o movimento do corpo por intermédio do rastreamento de alvos refletivos, conforme mostra a Figura 3.4. Desta forma, com a devida calibração, o sistema é capaz de monitorar os seis graus de liberdade dos modelos flutuantes. Para este estudo, foi utilizada três câmeras posicionadas e fixadas nas vigas de alumínio com o propósito de cobrir toda a área de oscilação dos modelos ensaiados separadamente.

Para registro das velocidades de reboque, que emulam a velocidade de escoamento $U$, é utilizado um sistema de sensoriamento (transdutor e condicionador) que monitora a velocidade em uma das rodas do carro dinamométrico.

A Tabela 3.2 apresenta as principais características das câmeras Qualisys®.

Figura 3.4: A esquerda, configuração das câmeras usadas no ensaio. A direita, detalhes de uma dessas câmeras.
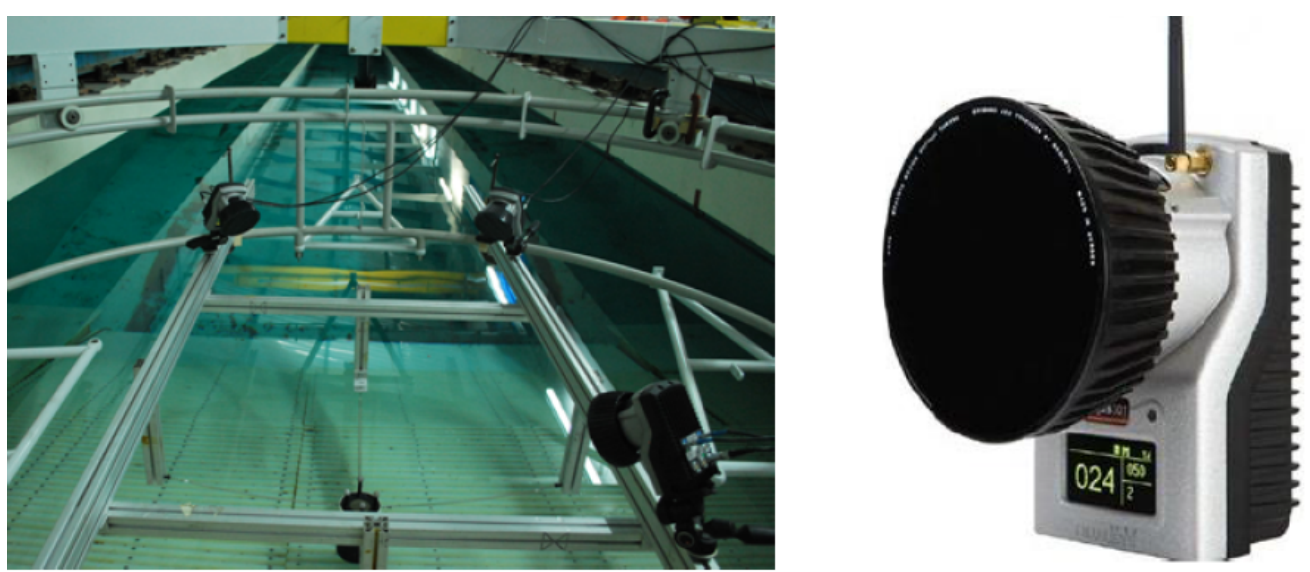

Table generated by Excel2LaTeX from sheet 'Plan1'

Tabela 3.2: Principais características das câmeras Qualisys ${ }^{\circledR}$.

\begin{tabular}{ll}
\hline Especificações & Descrição \\
\hline Dimensões & $(185 \times 110 \times 124)[\mathrm{mm}]$ \\
Ângulo de visão da lente & $40^{\circ}$ (padrão) \\
Faixa do espectro de luz & Infravermelho \\
Sensor CMOS (pixels) & 640 x 320 \\
Taxa de aquisição máxima (fps 10) & 250 na resolução máxima \\
Capacidade do buffer de vídeo & 380 frames na resolução máxima \\
\hline
\end{tabular}




\subsection{Modelos Experimentais}

Foram construídos quatro modelos, todos de seção quadrada, porém com diferença nas arestas, vivas ou arredondadas. Por simplicidade neste texto, os modelos com arestas vivas serão denominados pelo prefixo SSE e os modelos com arestas arredondas por SRE.

Os parâmetros dimensionais dos modelos seguiram a lógica de estudos anteriores, feitos pela equipe do Tanque de Provas Numérico - TPN - da Escola Politécnica da Universidade de São Paulo, particularmente aquelas destinadas à investigação dos fundamentos do VIV. O motivo por usar quatro cilindros se justifica apenas para igualar a dimensão projetada em relação ao escoamento incidente.

Figura 3.5: Foto dos cilindros utilizados para os experimentos estudado.

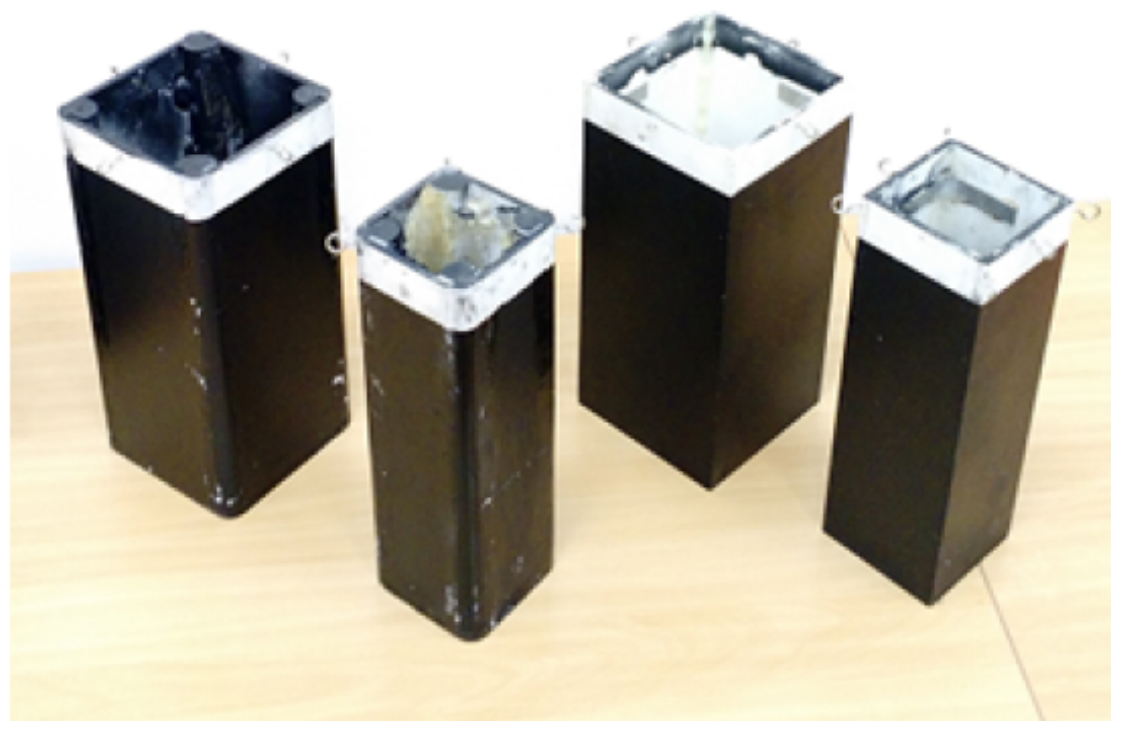

Tabela 3.3: Parâmetros dimensionais dos cilindros.

\begin{tabular}{lccccc}
\hline Cilindro & Ângulo de incidência [graus] & $\mathbf{D}[\mathrm{mm}]$ & $\mathbf{A}[\mathrm{mm}]$ & $\mathbf{L} / \mathbf{D}$ & $\mathbf{L} / \mathbf{A}$ \\
\hline SSE-00 & 0 & 125,0 & 125,0 & 2,0 & 2,0 \\
SSE-45 & 45 & 125,0 & 88,4 & 2,0 & 2,8 \\
\hline SRE-00 & 0 & 125,0 & 125,0 & 2,0 & 2,0 \\
SRE-45 & 45 & 125,0 & 88,4 & 2,0 & 2,8 \\
\hline
\end{tabular}

Com base na teoria apresentada na revisão bibliográfica, capítulo 2, pode-se ver que um cilindro com baixa razão de aspecto $L / D$ e baixa massa $m^{*}$ pode sofrer combinações de VIV e galloping. Sendo assim, a Figura 3.5 mostra os 4 cilindros com razão de aspecto $L / D=2$, dimensionalmente conseguida com base em cilindros com arestas $A=125 \mathrm{~mm}$ e $A=88,4 \mathrm{~mm}$, respectivamente para as incidências de $0^{\circ} \mathrm{e} 45^{\circ}$. Em todos os casos, $\mathrm{o}$ comprimento imerso foi sempre o mesmo, $L=250 \mathrm{~mm}$. A Tabela 3.3 sintetiza esse dimensional geométrico.

O material para fabricação dos modelos foi o Policloreto de Vinila (PVC). Uma mistura 
composta de areia e cola foi utilizada para preenchimento dos modelos, com o objetivo de lastreá-los.

A Figura 3.6 ilustra os cilindros com suas principais características geométricas.

Importante destacar que a razão de aspecto foi selecionada com base nos resultados obtidos em GONÇALVES (2013c), no qual os vórtices gerados pela alteração na geometria da aresta do cilindro pode ter influência no comportamento da esteira principal e, consequentemente, na resposta do VIV. Por sua vez, a definição das arestas dos cilindros arredondados foi feita com base nos trabalhos experimentais descritos em ZHAO (2014).

Figura 3.6: Principais parâmetros geométricos dos cilindros estudado.
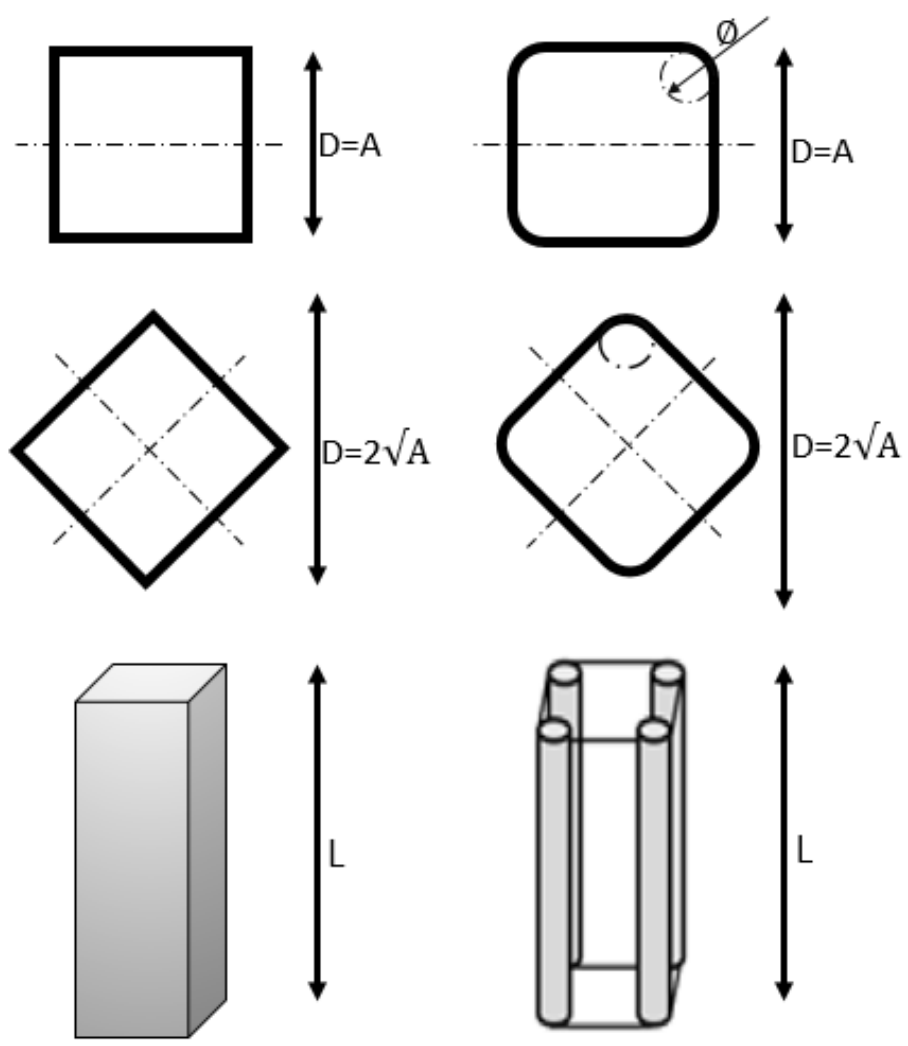

\subsection{Método Experimental}

Para a caracterização dos modelos elasticamente suportados na superfície livre, foram realizados ensaios de decaimento, que tiveram como objetivo principal a identificação das frequências naturais e estimativa linear do amortecimento envolvido nas oscilações em água.

É relevante informar que os valores das frequências naturais $f_{n x}, f_{n y}$ e $f_{n y a w}$, bem como os respectivos coeficientes de amortecimento $\zeta_{w}$ e as faixas de Reynolds dos cilindros foram todos obtidos/calculados em água. Tais informações estão na Tabela3.4.

Cerca de 40 condições de reboque (velocidades $U$ ) foram realizadas para cada cilindro estudado. Assim, os intervalos de velocidade reduzida estiveram na faixa $2<V_{r}<15$ e os 
Tabela 3.4: Parâmetros dos testes para cada condição.

\begin{tabular}{ccccccc}
\hline Cilindro & Incidência [graus] & $R e \times 10^{4}$ & $\zeta_{W}[\%]$ & $f_{n x}[H z]$ & $f_{n y}[H z]$ & $f_{n y a w}[H z]$ \\
\hline SSE-00 & 0 & $0,25-1,92$ & 7,54 & 0,126 & 0,122 & 0,277 \\
SSE-45 & 45 & $0,35-2,66$ & 7,89 & 0,125 & 0,123 & 0,245 \\
\hline SRE-00 & 0 & $0,34-2,59$ & 6,71 & 0,093 & 0,091 & 0,162 \\
SRE-45 & 45 & $0,37-2,80$ & 5,21 & 0,091 & 0,088 & 0,148 \\
\hline
\end{tabular}

intervalos de número de Reynolds em $2 \times 10^{3}<R e<3 \times 10^{4}$, o que correspondeu a velocidade dimensionais de $0,02 \mathrm{~m} / \mathrm{s}<U<0,23 \mathrm{~m} / \mathrm{s}$.

Os sinais das grandezas de interesse (deslocamentos nos seis graus de liberdade e velocidade) foram sempre registrados com a velocidade de reboque em regime, por um tempo suficientemente grande para o registro de um número adequado de ciclos e considerando uma frequência de aquisição de $f_{a q}=100 \mathrm{~Hz}$, bem acima das frequências de interessa para evitar o problema de aliasing.

Em termos de análise, rotinas construídas em Octave ${ }^{\circledR}$ foram construídas para a determinação das amplitudes adimensionais de resposta. Em virtude da característica tridimensional das emissões de vórtices, que se refletem em respostas não tão regulares, amplitudes calculadas a partir do valor quadrático médio ( $r m s$ - root mean square) se mostraram mais úteis para comparações entre resultados das diferentes condições de velocidade ensaiadas.

As velocidades reduzidas, por sua vez, foram calculadas com base no valor médio da velocidade de reboque, $U_{\text {med }}$, na dimensão característica $D=125 \mathrm{~mm}$ e sempre considerando a frequência natural de oscilação na direção transversal ao escoamento, $f_{n y}$, de acordo com valores da Tabela 3.4 .

Para a determinação das frequências de resposta, as mesmas rotinas em Octave ${ }^{\circledR}$ aplicam a análise de Fourier para a construção de espectros de potência ( $P S D$ - Power Spectrum Density), a partir dos quais é determinada a frequência dominante na vibração registrada, nesse estudo considerada aquela com a maior densidade espectral.

O próximo capítulo traz os resultados da aplicação desses materiais e método experimental. 


\section{Capítulo 4}

\section{RESULTADOS EXPERIMENTAIS}

A aplicação dos métodos descritos no capítulo anterior, resultou em gráficos como o exemplificando na Figura 4.1, onde os registos de deslocamento adimensional nas direções longitudinal (em azul), transversal (em vermelho) e vertical (em verde) são apresentados para o modelo de arestas arredondadas submetido à incidência $0^{\circ}$ ) do escoamento caracterizado por $V_{r}=7,34$.

Figura 4.1: Exemplos de registros temporais de deslocamento adimensional nas direções longitudinal, transversal e vertical do modelo SSE-00 (modelo com arestas vivas e incidência $0^{\circ}$ ) em $V_{r}=7,34$.
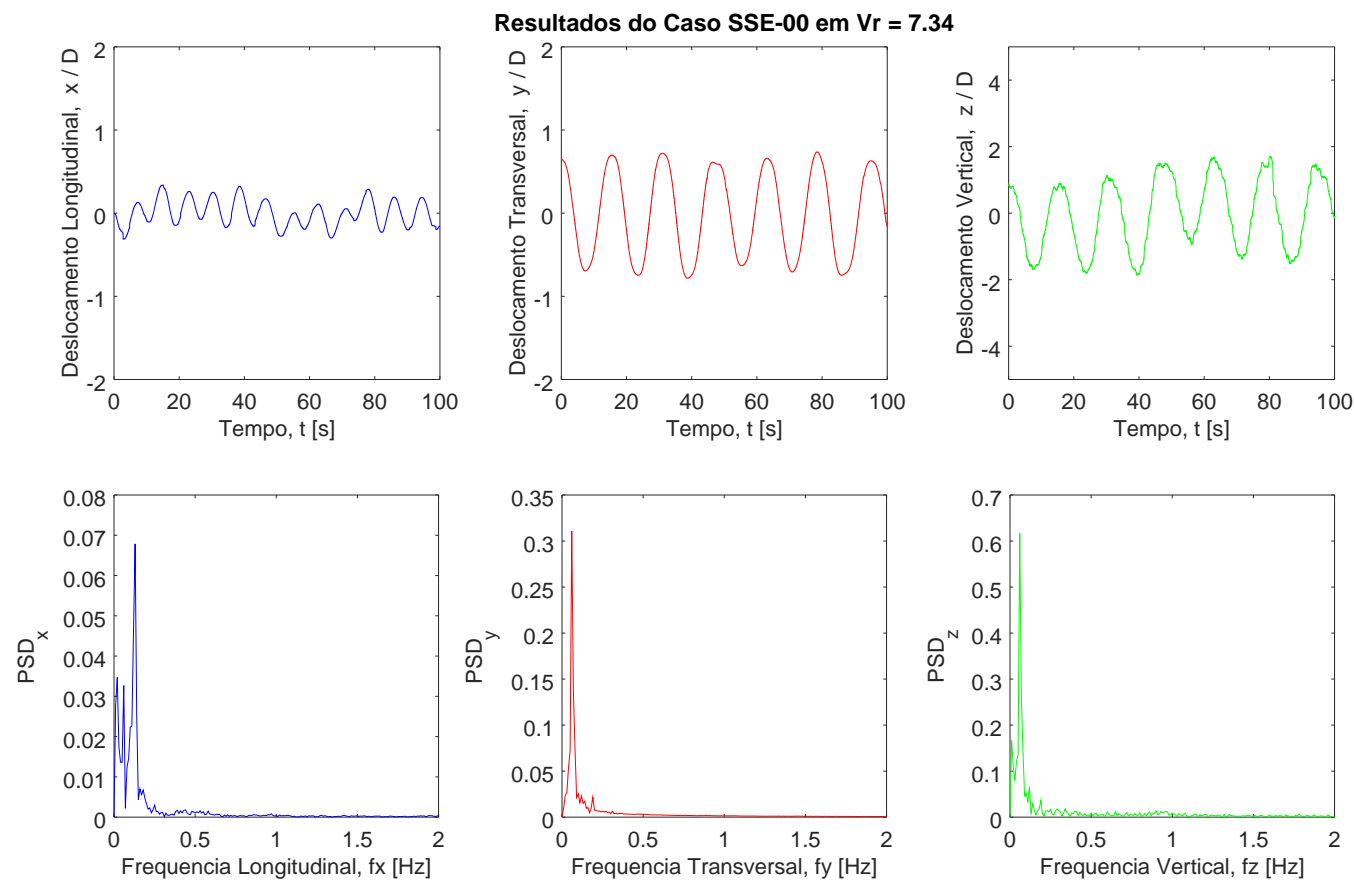

Seguindo o mesmo código de cores, os três gráficos inferiores na mesma Figura 4.1 exemplifica os respectivos espectros de potência dos registros de deslocamento.

Com base em análises desse tipo foram, então, obtidos os resultados de resposta apresentados, comparados e discutidos nas seção que se seguem. 


\subsection{Comparação direta entre respostas}

Os gráficos da Figura 4.2 comparam diretamente as amplitudes e frequências de resposta transversal exibida pelos quatro modelos ensaiados (por isso todos em cor vermelha). Importante destacar que:

- marcadores quadrados com interior preenchido dizem respeito ao modelo com arestas arredondadas e incidência de $0^{\circ}$ - SRE-00;

- losangos com interior preenchido dizem respeito ao modelo com arestas arredondadas e incidência de $45^{\circ}-\mathrm{SRE}-45$;

- marcadores quadrados com interior vazio dizem respeito ao modelo com arestas vivas e incidência de $0^{\circ}$ - SSE-00; e

- losangos com interior vazio dizem respeito ao modelo com arestas vivas e incidência de $45^{\circ}-$ SSE-45.

De acordo com essa figura, é possível verificar que as maiores amplitudes adimensionais de resposta transversal ao escoamento, $Y^{r m s} / D$ acontecem para a incidência de $0^{\circ}$, independente do tipo de aresta (viva ou arredondada).

Comparando os comportamentos dinâmicos para as duas incidências no modelo de arestas vivas, SSE-00 e SSE-45 (quadrados e losangos vazados, respectivamente), nota-se que no primeiro o comportamento se assemelha ao descrito por AMATO (2010), rever Figura 2.30, quando a velocidade de deflagração do gallpoing é próxima ou menor que a velocidade crítica do VIV, $V_{0} \lesssim V_{c r}$, ou seja, quando uma resposta combinada aparece e as amplitudes aumentam consideravelmente a partir da velocidade de início do VIV.

Já no segundo comportamento dinâmico, as respostas não crescem indefinidamente e, pelo contrário, parecem se manter em $Y^{r m s} / D \approx 0,4$ para as velocidades reduzidas mais altas.

Comparação análoga feita entre as duas incidências no modelo de arestas arredondadas, SRE-00 e SRE-45 (quadrados e losangos preenchidos, respectivamente), mostra que em ambas as geometrias o comportamento se assemelha ao do fenômeno de VIV típico, ou sejam com um decréscimo de amplitudes a partir de um valor mais alto de velocidade reduzida, no caso $V_{r} \approx 12$. No caso SRE-45, no entanto, o início da região de sincronização é mais suave que aquele exibido pela incidência de $0^{\circ}$.

Observando apenas as respostas transversais pode-se dizer, portanto, que a configuração SRE-45 é aquela que exibe as menores amplitudes adimensionais $Y^{r m s} / D$. Tal observação, porém, precisa ser analisada em conjunto com o que acontece nos demais graus de liberdade.

Em termos das razões de frequência transversal, nota-se que os modelos SSE-45 e SRE-00 respondem com $1,0 \lesssim f y / f_{n y} \lesssim 1,5$, enquanto que, curiosamente, os modelos SSE00 e SRE-45 respondem com $f y / f n y \approx 0,5$. 
Figura 4.2: Comparação entre as amplitudes e frequências de resposta transversal ao escoamento para os quatro modelos ensaiados: marcadores quadrados referem-se à incidência $0^{\circ}$ e, com o interior preenchido, aos modelos com arestas arredondadas SRE.
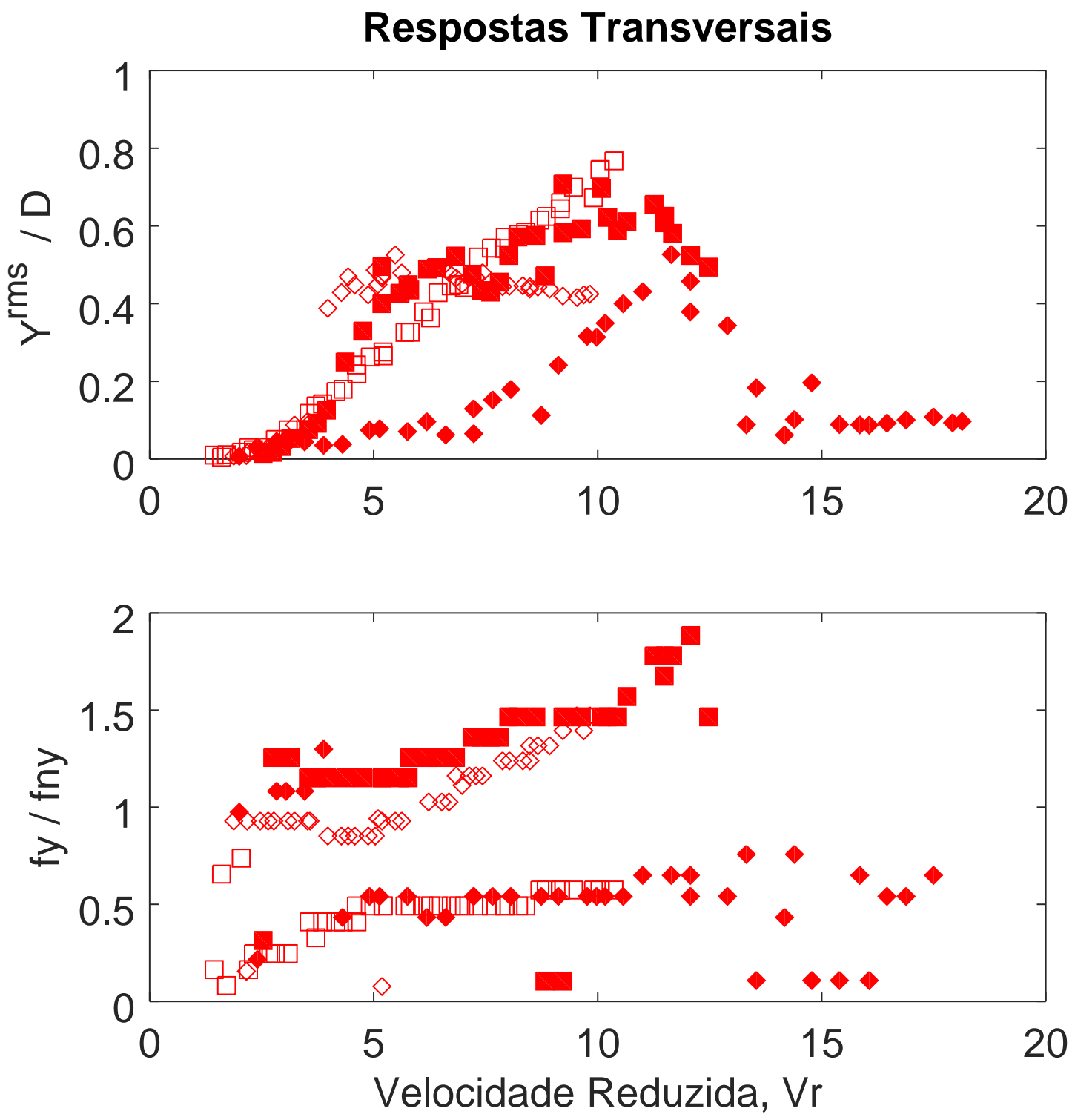

O gráfico inferior da Figura 4.3 comparam diretamente as frequências de resposta longitudinal para os quatro modelos ensaiados (todos agora em azul). De acordo com este gráfico, nota-se que, independente das relações $f y / f_{n y}$, para todos os cados $f x / f_{n y} \approx 2 f y / f_{n y}$.

A maior dispersão entre valores da relação $f x / f_{n y}$ está associada às baixas amplitudes de resposta longitudinal, que não ultrapassam $0,4 D$. Os maiores valores de $X^{r m s} / D$ são identificados para o caso SSE-00, em concordância com as maiores amplitudes $Y^{r m s} / D$ exibidas por esse caso.

Por sua vez, os gráficos da Figura 4.4 comparam diretamente as amplitudes e frequências de resposta em yaw (rotação $\Omega_{z}$ em torno da direção vertical) exibida pelos quatro modelos ensaiados (todos em cor verde: quadrados para $0^{\circ}$ e losangos para $45^{\circ}$ ). 
Figura 4.3: Comparação entre as amplitudes e frequências de resposta longitudinal ao escoamento para os quatro modelos ensaiados: marcadores quadrados referem-se à incidência $0^{\circ}$ e, com o interior preenchido, aos modelos com arestas arredondadas SRE.
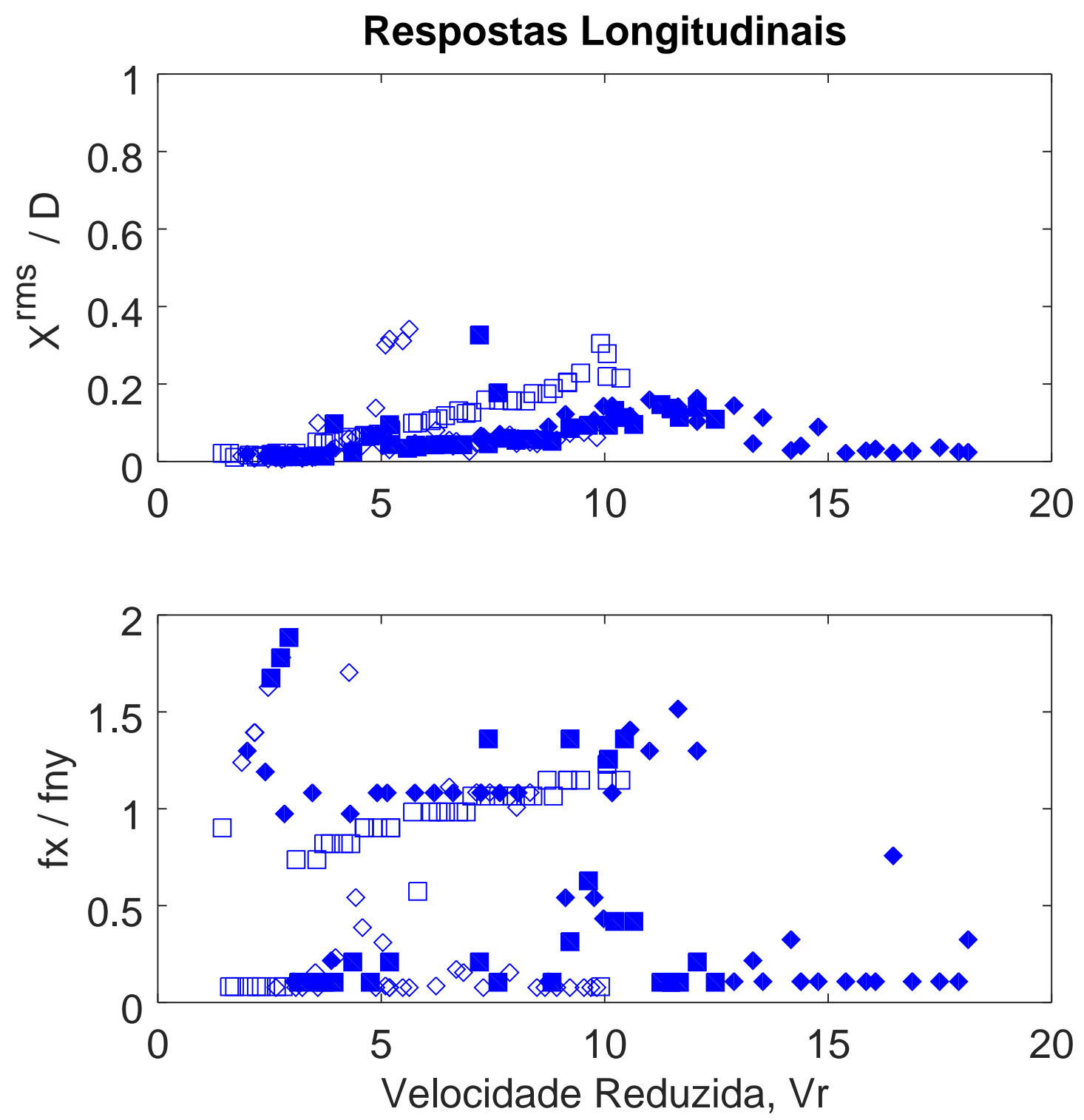

De maneira geral, nota-se que as rotações em yaw têm amplitudes angulares expressivas, com destaque para o modelo de arestas arredondadas sob incidência de escoamento a $45^{\circ}$ que chega a exibir valores de até $\Omega_{z}^{r m s}=9^{\circ}$. Em termos de frequência, as respostas parecem acompanhar aquelas dos deslocamentos transversais, porém com o comparecimento de outras componentes de valor mais alto, $f w \approx 4 f_{n y}, 5 f_{n y}$ e, em alguns casos, até maiores.

\subsection{Análise detalhada das respostas transversais}

A Figura 4.5 apresenta de maneira isolada as amplitudes e frequências de resposta transversal exibida pelo modelo SRE-00, ou seja, aquele de arestas arredondadas sob escoamento com 
Figura 4.4: Comparação entre as amplitudes e frequências de resposta em yaw para os quatro modelos ensaiados: marcadores quadrados referem-se à incidência $0^{\circ} \mathrm{e}$, com o interior preenchido, aos modelos com arestas arredondadas SRE.

\section{Respostas em Yaw}
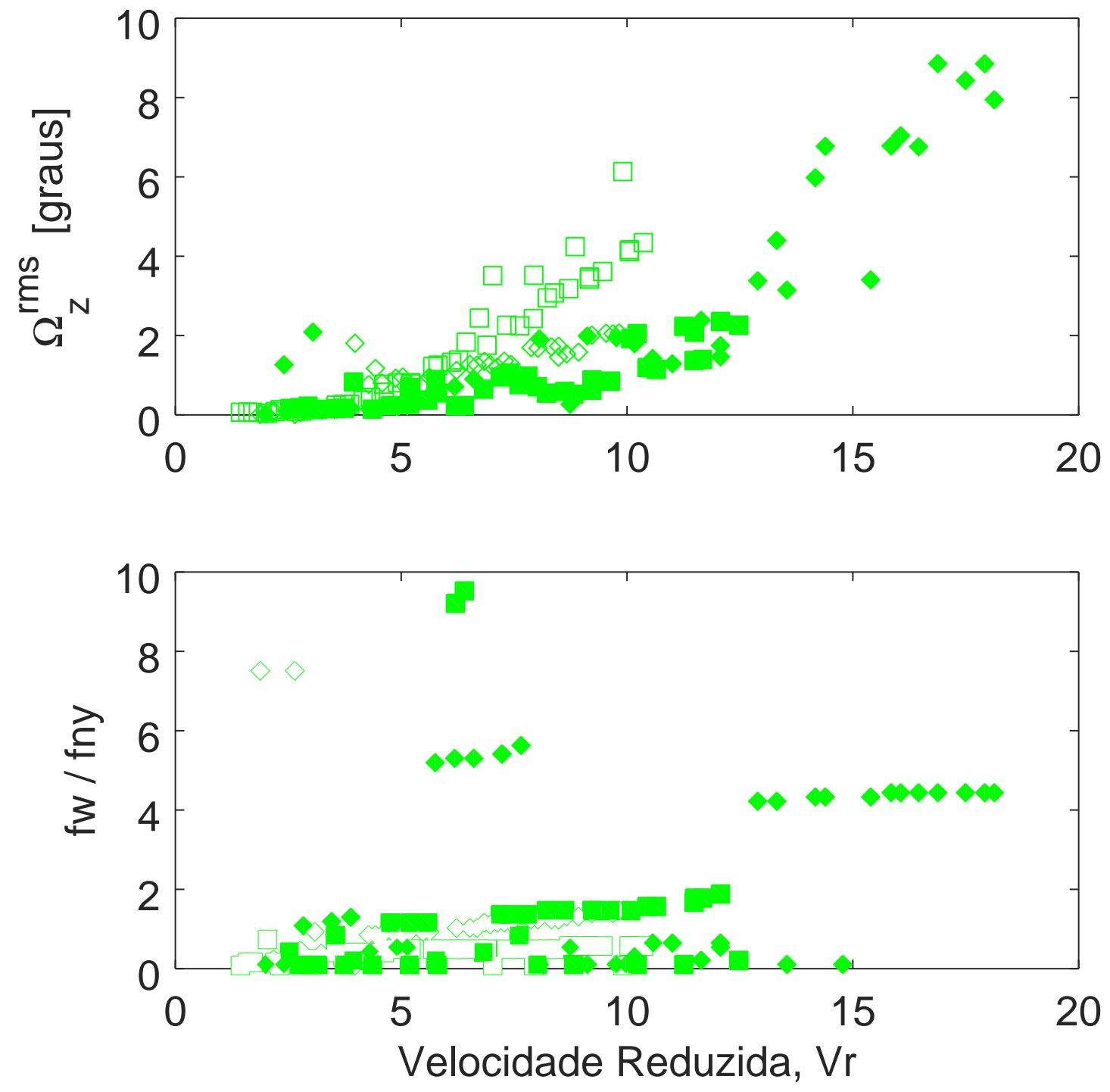

incidência de $0^{\circ}$.

De acordo com os gráficos da Figura 4.5, nota-se o início de sincronização em $V_{r} \approx 4$ e um término aparentemente iniciado em $V_{r} \approx 12$. Note também que $1,0 \lesssim f y / f_{n y} \lesssim 1,5$.

No caso do modelo com arestas arredondadas e incidência de $45^{\circ}$, SRE-45 na Figura 4.6, início e término de uma faixa de sincronização ficam ainda mais evidentes em termos da curva de amplitude de resposta. Embora tenha uma restauração idêntica àquela usada para o caso SRE-00, a incidência de $45^{\circ}$ exibe frequências $f y / f_{n y} \approx 0,5$.

Conforme descrito, o caso SSE-00, modelo com arestas vivas e incidência de escoamento a $0^{\circ}$ é aquele que exibe as maiores amplitudes, crescente para a toda a faixa de velocidades reduzidas testada. Em termos das relações de frequência, também neste caso 
Figura 4.5: Amplitudes e frequências adimensionais de resposta na direção transversal ao escoamento para o modelo SRE-00, arestas arredondadas e incidência $0^{\circ}$.

\section{Respostas Transversais do Caso SRE-00}
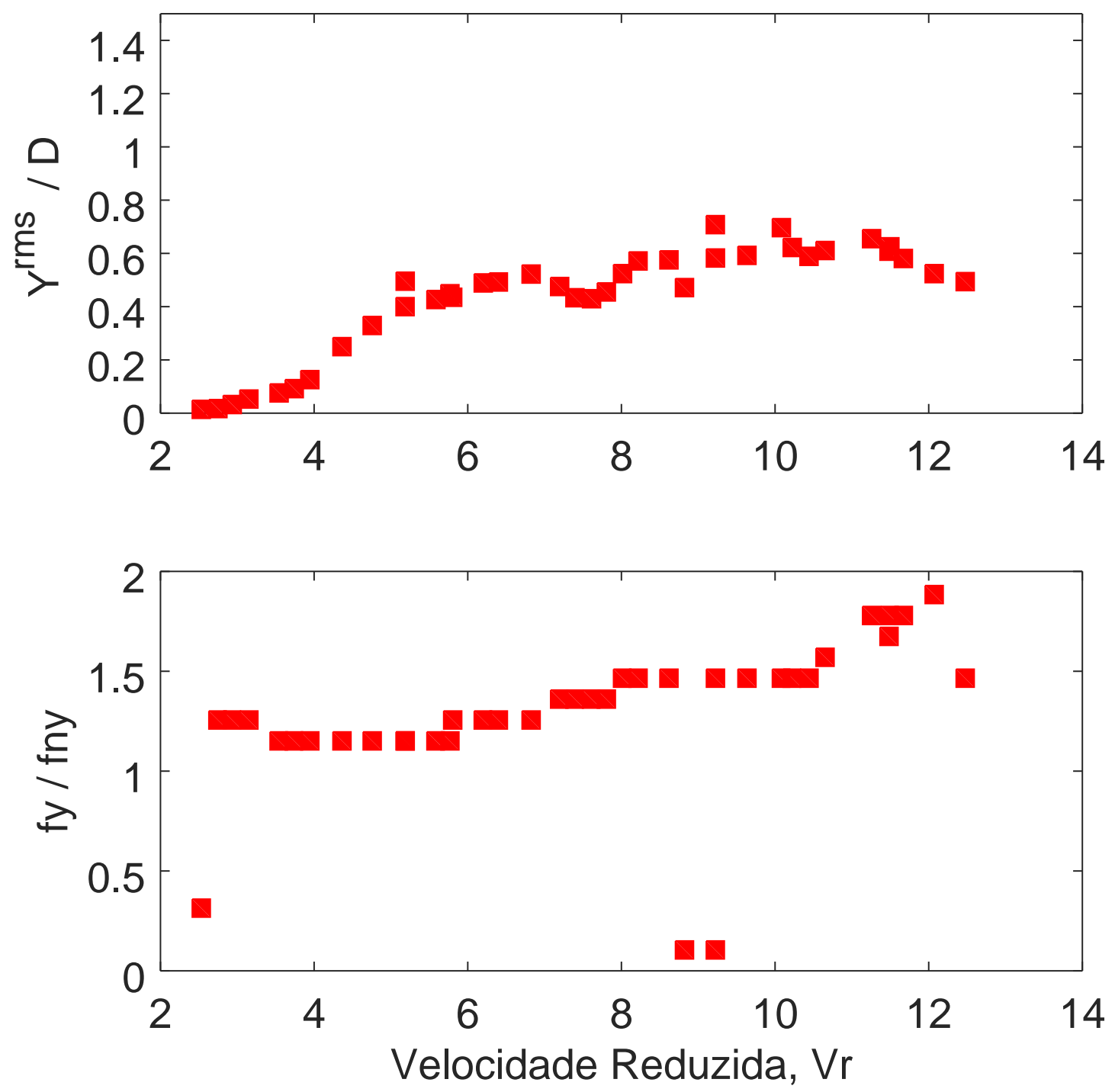

$f y / f_{n y} \approx 0,5$.

Então, a Figura 4.8 apresenta de maneira isolada as amplitudes e frequências de resposta transversal para o modelo SSE-45, aquele de arestas vivas sob escoamento com incidência de $45^{\circ}$.

Conforme mencionado, fica clara a manutenção de amplitudes $Y^{r m s} / D \approx 0,4$ na medida em que as velocidades reduzida aumentam, associas a $1,0 \lesssim f y / f_{n y} \lesssim 1,5$.

Note que para $V_{r} \lesssim 6$ a razão $f y / f_{n y}$ é bem próxima do valor unitário e acima desta velocidade, coincidindo com a manutenção do " patamar " em $Y^{r m s} / D \approx 0,4$, a razão entre frequências começa a gradativamente crescer até o valor de 1,5 . 
Figura 4.6: Amplitudes e frequências adimensionais de resposta na direção transversal ao escoamento para o modelo SRE-45, arestas arredondadas e incidência $45^{\circ}$.

\section{Respostas Transversais do Caso SRE-45}
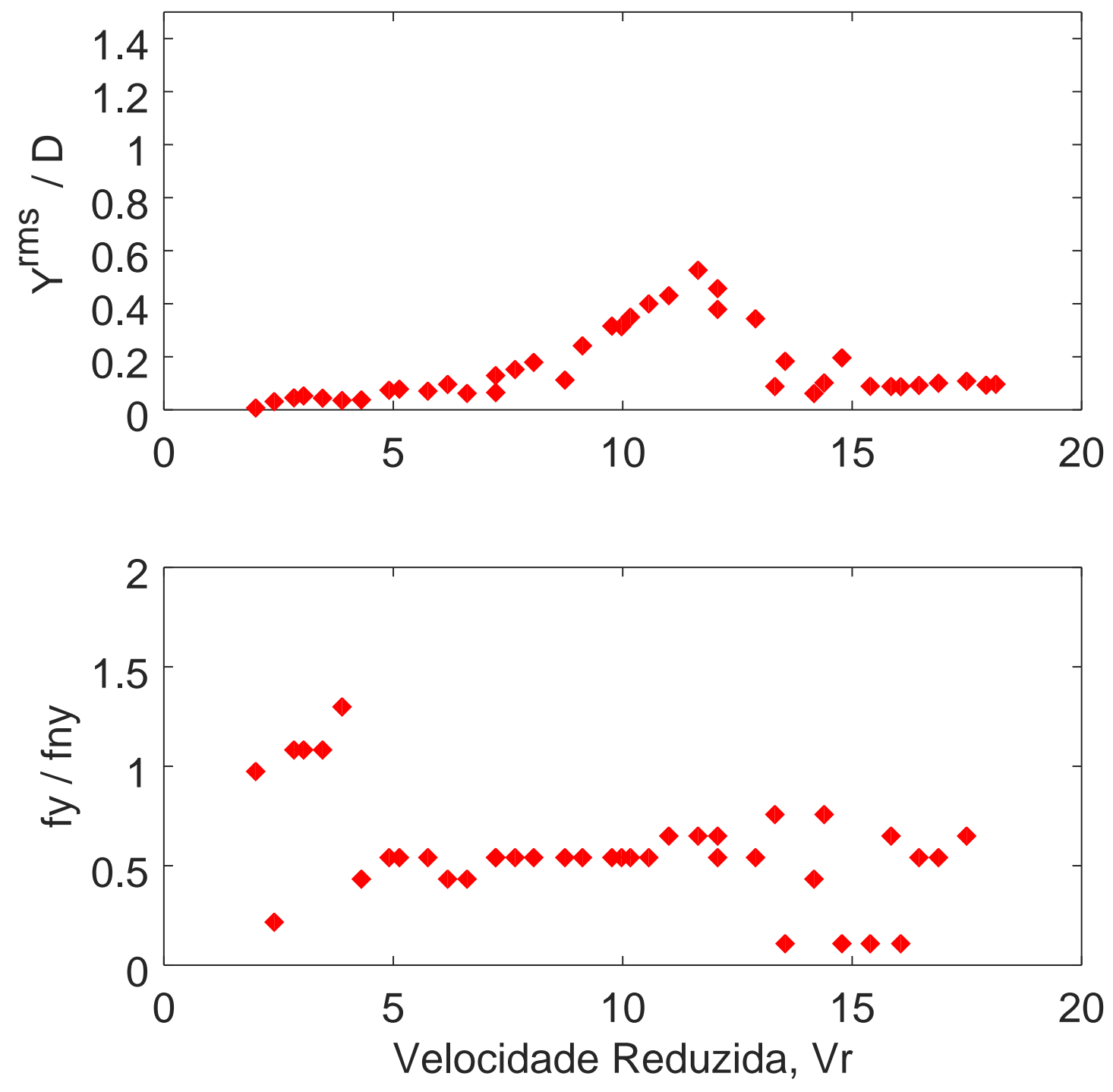
Figura 4.7: Amplitudes e frequências adimensionais de resposta na direção transversal ao escoamento para o modelo SSE-00, arestas vivas e incidência $0^{\circ}$.

Respostas Transversais do Caso SSE-00
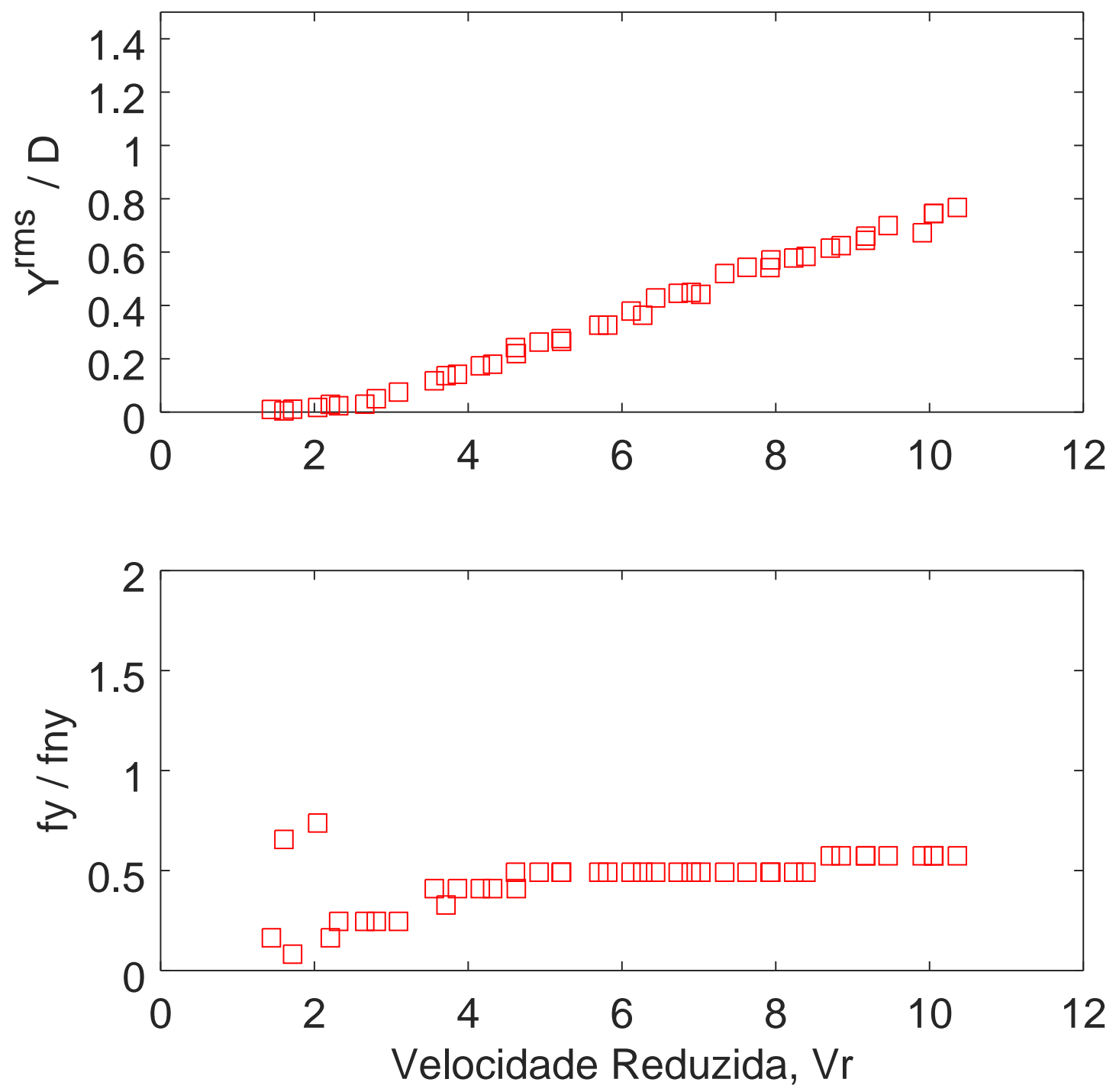
Figura 4.8: Amplitudes e frequências adimensionais de resposta na direção transversal ao escoamento para o modelo SSE-45, arestas vivas e incidência $45^{\circ}$.

\section{Respostas Transversais do Caso SSE-45}
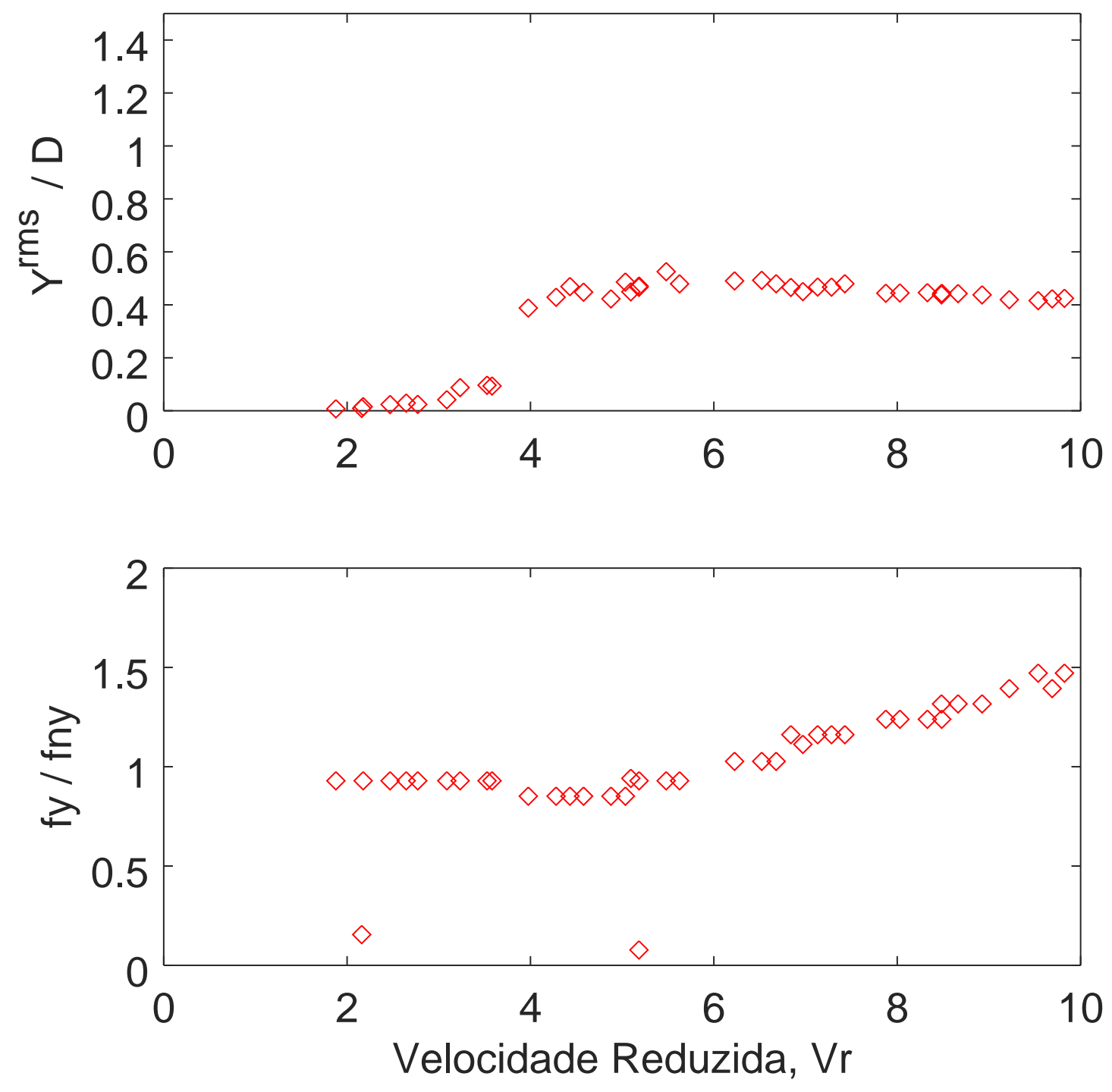


\subsection{Análise detalhada das respostas longitudinais}

As Figuras 4.9, 4.10, 4.11 e 4.12 ilustram isoladamente as amplitudes e frequências de respostas para os quatro modelos ensaiados, respectivamente SRE-00, SRE-45, SSE-00 e SSE-45.

Em termos das amplitudes, de uma maneira geral, estas não ultrapassam $X^{r m s} / D=$ 0,4 . São progressivamente crescentes com o aumento da velocidade reduzida nos casos de escoamento incidindo a $0^{\circ}$, SRE-00 e SSE-00, enquanto exibem regiões com início e término no caso SRE-45, ver $5 \lesssim V_{r} \lesssim 14$ na Figura 4.10 , e no caso SSE-45, ver $5 \lesssim V_{r} \lesssim 6$ na Figura 4.12 .

Figura 4.9: Amplitudes e frequências adimensionais de resposta na direção longitudinal ao escoamento para o modelo SRE-00, arestas arredondadas e incidência $0^{\circ}$.

\section{Respostas Longitudinais do Caso SRE-00}
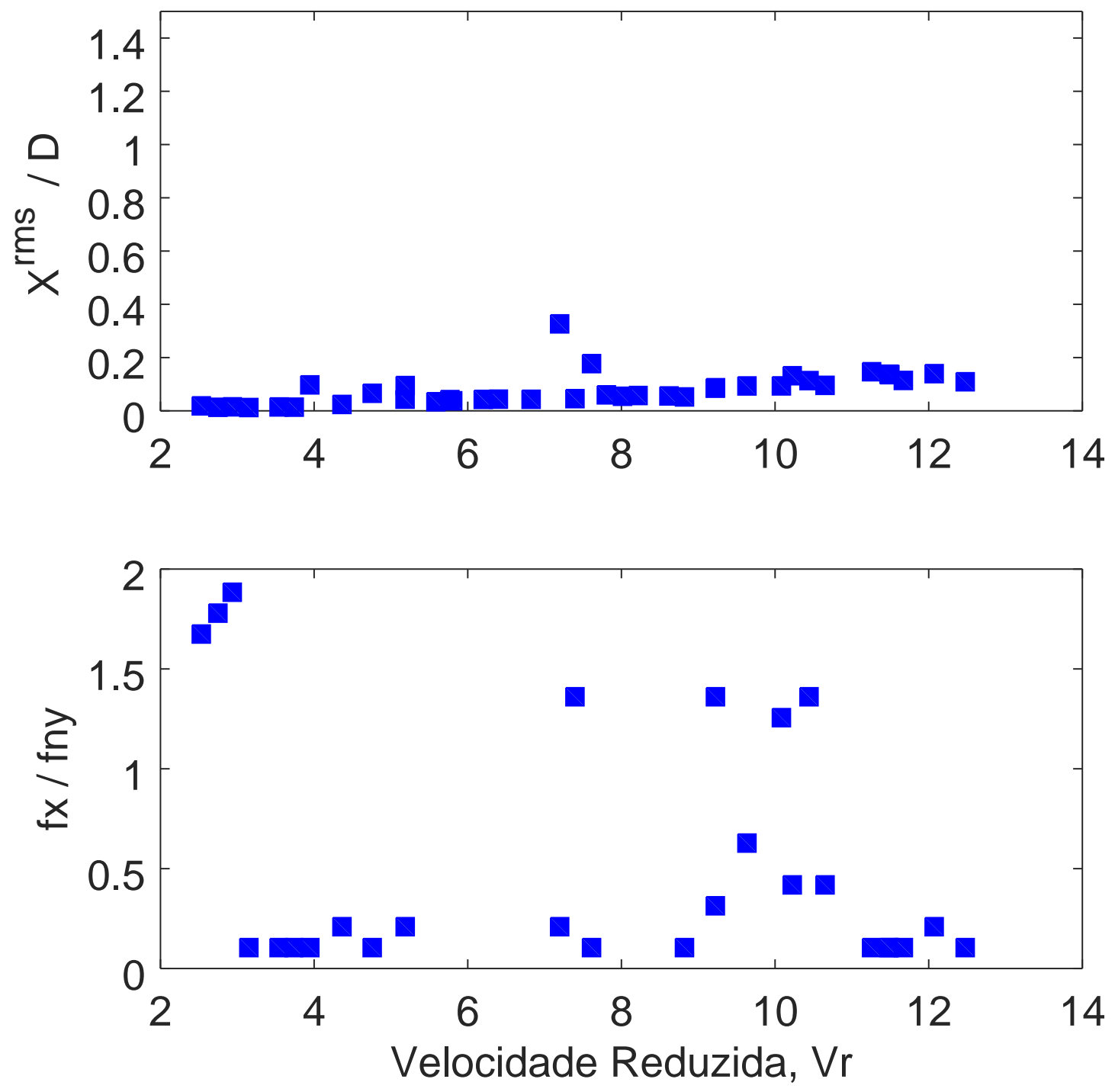

No que se refere às frequências de resposta longitudinal, independente do caso, observase que sempre $f x \approx 2 f y$, de acordo com o que foi colhido com a revisão bibliográfica realizada. 
Note que no caso SSE-00, aquele com as maiores amplitudes transversais $Y^{r m s} / D$ associadas ao crescente valor das $X^{r m s} / D$, a razão entre frequências $f x / f_{n y}$ se dispersa pouco no entorno do valor unitário. Desta forma, entende-se que grandes amplitudes de movimento acoplado tornam a caracterização em frequência bem definida.

Figura 4.10: Amplitudes e frequências adimensionais de resposta na direção longitudinal ao escoamento para o modelo SRE-45, arestas arredondadas e incidência $45^{\circ}$.
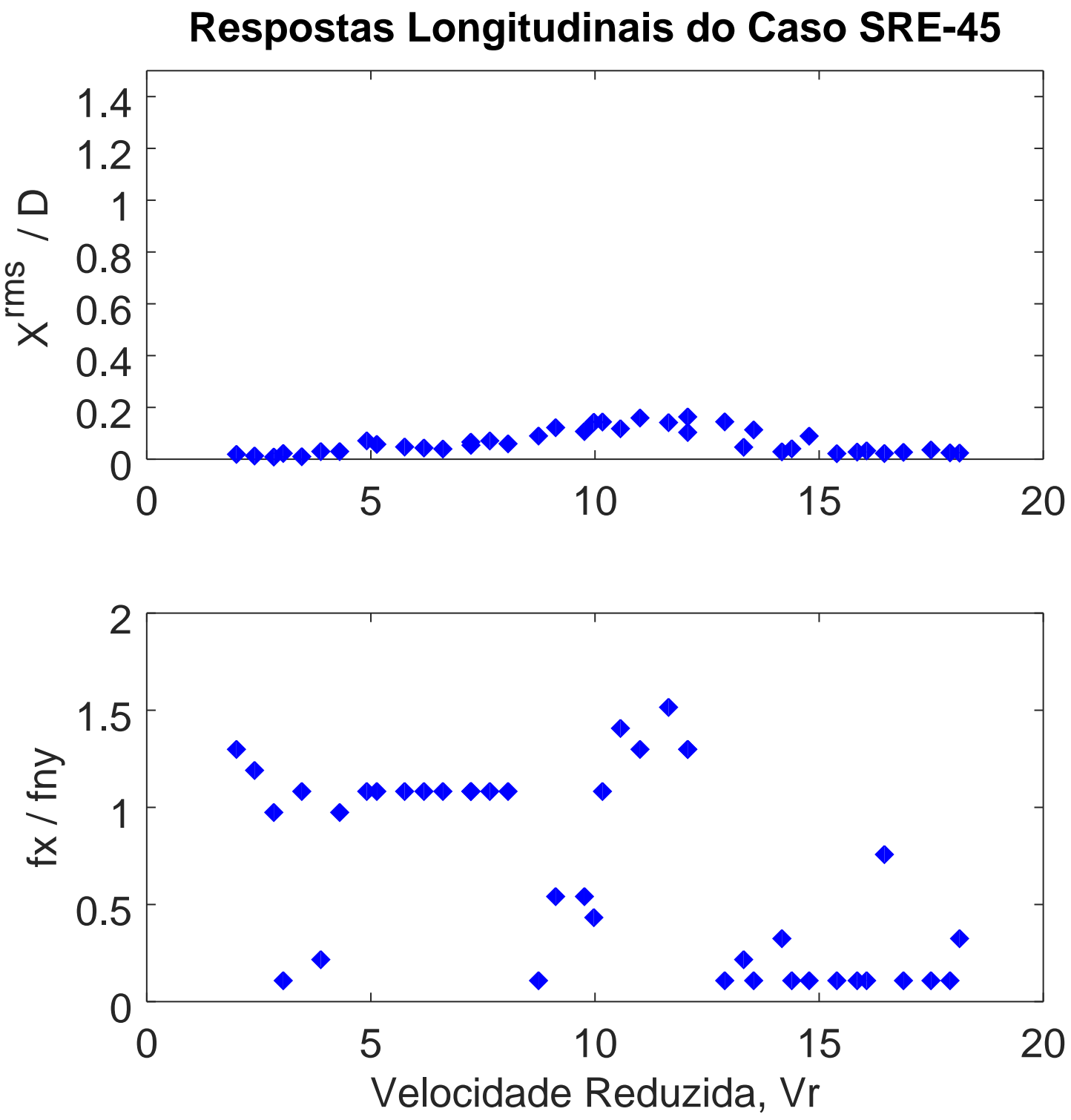

Importante relembrar que as frequências aqui apresentadas são aquelas referentes às maiores densidades espectrais obtidas com as análises de Fourier dos registros que Ihes deram origem. Isto não significa que outras frequências estejam ausentes do conteúdo da análise e nos demais valores proporcionais a $f_{n y}$.

Para efeitos de uma caracterização mais aprofundada das demais frequências, técnicas mais elaboradas como a análise de Hilbert-Huang podem ser aplicadas aos registros temporais de deslocamento. Esta estratégia, no entanto, ficará como perspectiva para traba- 
Figura 4.11: Amplitudes e frequências adimensionais de resposta na direção longitudinal ao escoamento para o modelo SSE-00, arestas vivas e incidência $0^{\circ}$.
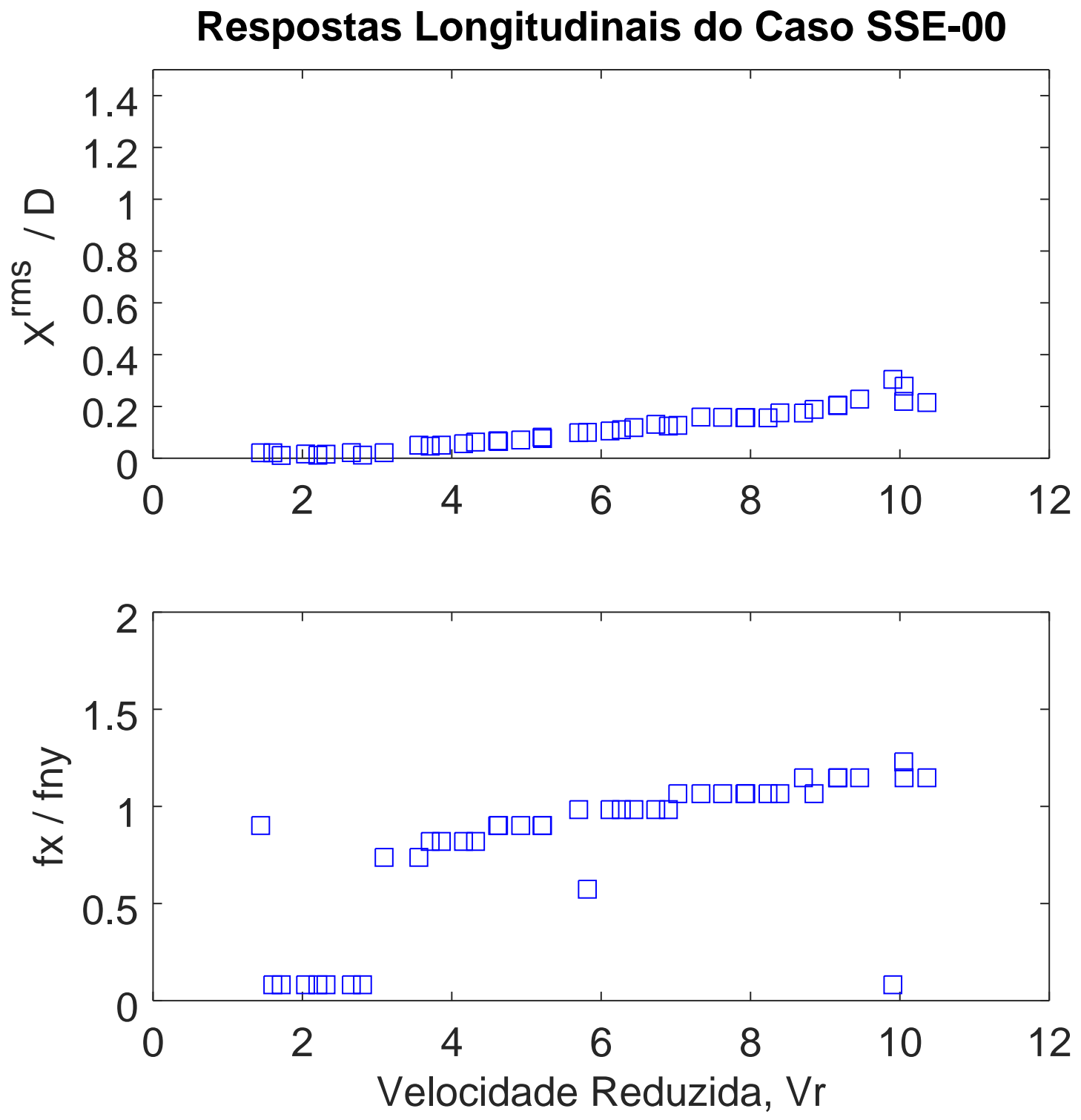

Ihos futuros, inclusive com eventual respaldo de simulados numéricas. 
Figura 4.12: Amplitudes e frequências adimensionais de resposta na direção longitudinal ao escoamento para o modelo SSE-45, arestas vivas e incidência $45^{\circ}$.

\section{Respostas Longitudinais do Caso SSE-45}
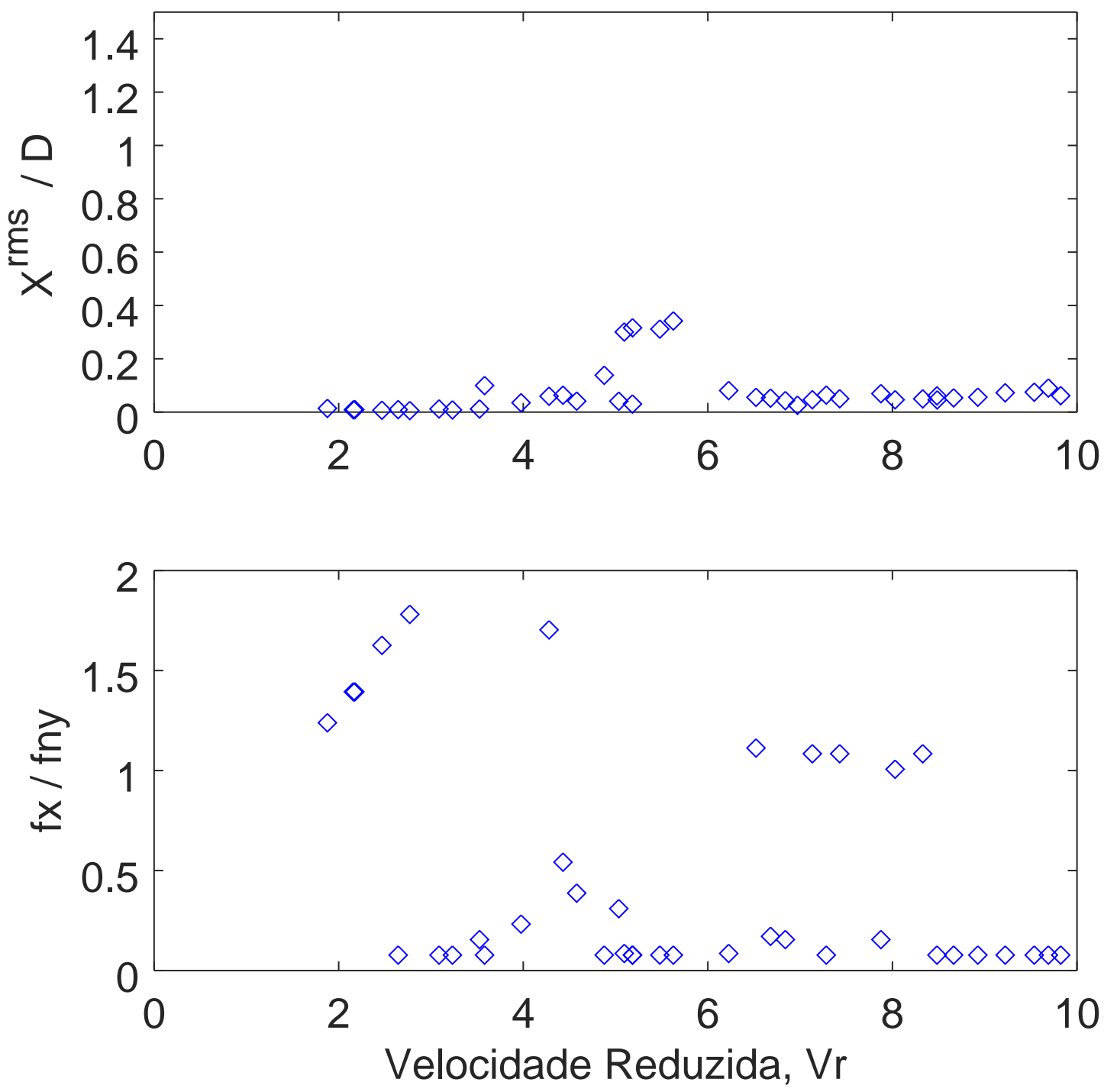


\subsection{Análise detalhada das respostas em yaw}

Para finalizar o conjunto de análises deste texto, as Figuras 4.13, 4.14, 4.15 e 4.17, apresentam de maneira isolada as amplitudes e frequências do ângulo de rotação entorno da direção vertical, ou seja, do movimento de yaw.

De uma maneira geral, nota-se que as rotações em yaw têm magnitude considerável, que não pode ser negligencias.

Figura 4.13: Amplitudes e frequências adimensionais de resposta em yaw para o modelo SRE-00, arestas arredondadas e incidência $0^{\circ}$.
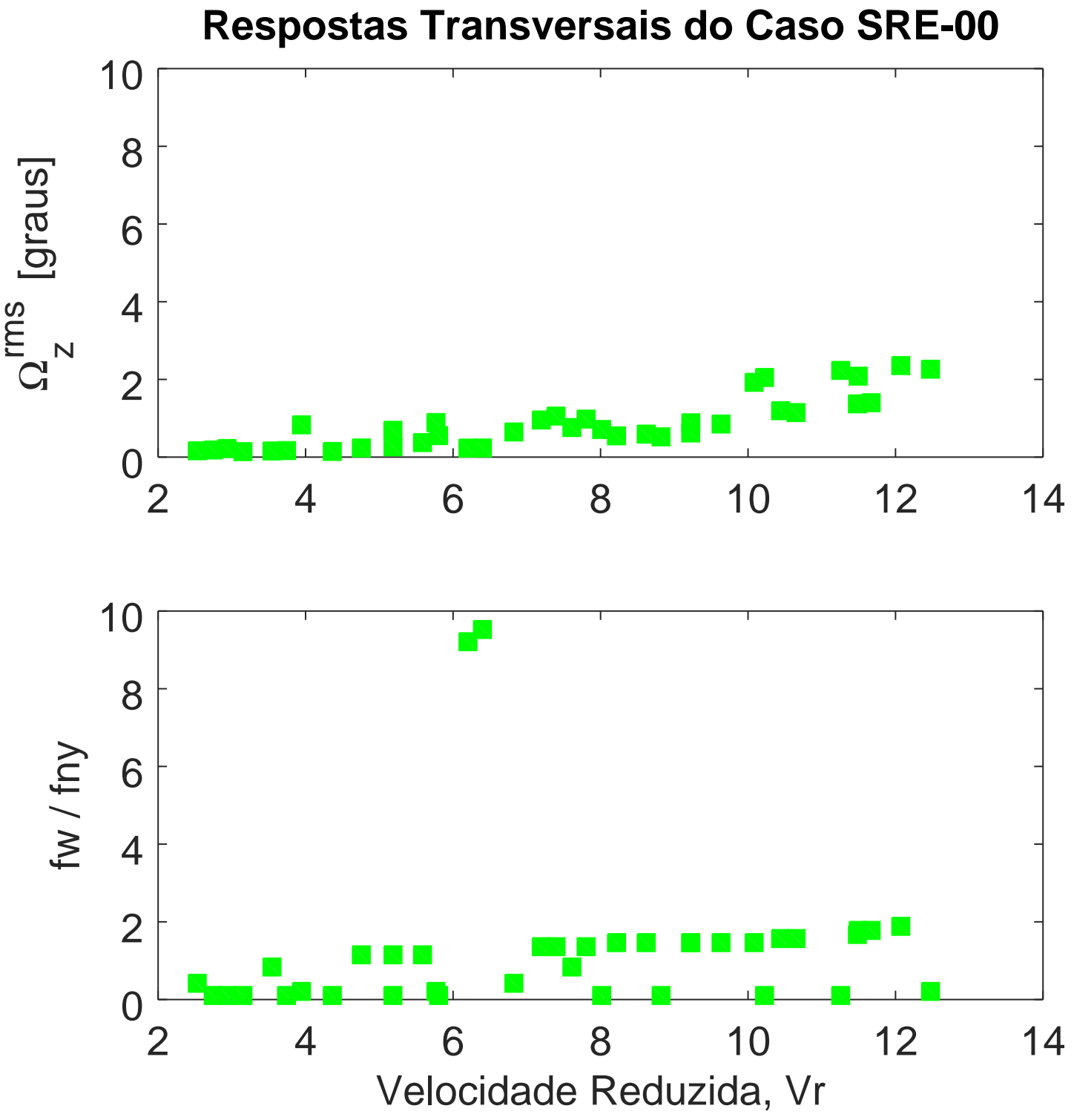

Importante destacar que embora o caso SRE-45 seja aquele com as menores amplitudes de resposta transversal, em termos da rotação, esse é justamente o caso que apresentou as maiores rotações em yaw.

Considerando que os movimentos de yaw geralmente acompanham as frequências 
$f y$, mas que isso, no entanto, não acontece no caso SRE-45, ponderações sobre qual seria a pior combinação de movimentos para o sistema de amarração não seriam nada fáceis.

Figura 4.14: Amplitudes e frequências adimensionais de resposta em yaw para o modelo SRE-45, arestas arredondadas e incidência $45^{\circ}$.
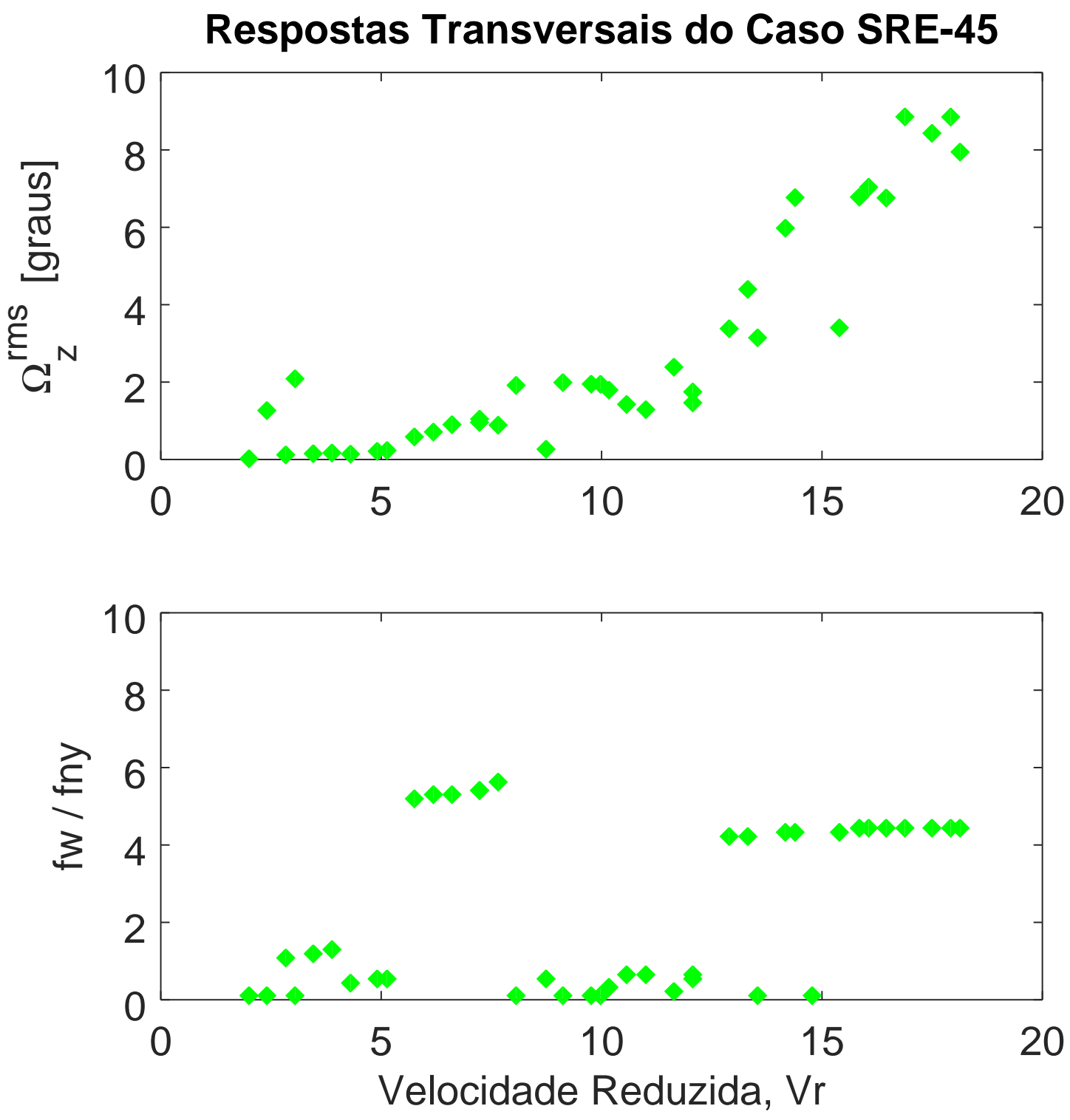

Por justiça, no entanto, há que se considerar que o caso foi o único onde se conseguiram testar velocidades reduzidas bem altas, onde justamente foram identificadas as maiores amplitudes angulares. Se consideradas $V_{r}<12$ os ângulos de yaw no caso SRE-45 não ultrapassa os $3^{\circ}$. Abaixo deste valor de velocidade reduzida, então, o caso SSE-00, aquele com as maiores amplitudes transversais associadas ao concomitante crescimento de amplitudes longitudinais é, também, o caso com as maiores amplitudes de rotação em yaw, chegando até $6^{\circ}$ em $V_{r} \approx 10$, ver Figura 4.15.

A Figura 4.16 dá exemplo dos registros de rotação no entorno das direções $x$ (roll), y (pitch) e z (yaw), bem como os respectivos espectros de potência obtidos com base nas 
Figura 4.15: Amplitudes e frequências adimensionais de resposta em yaw para o modelo SSE00 , arestas vivas e incidência $0^{\circ}$.
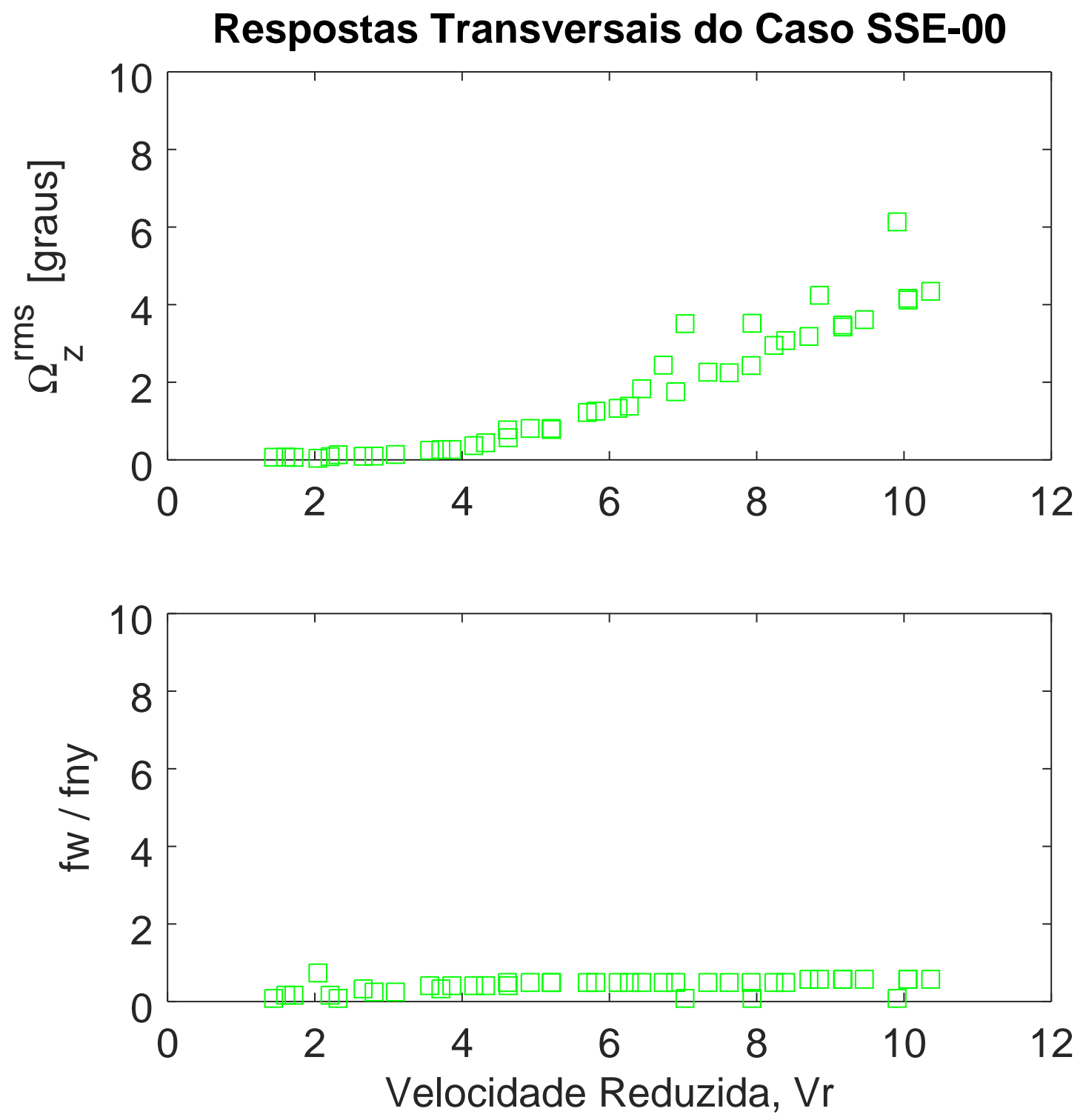

análises de Fourier.

De acordo com essa figura, percebe-se que as rotações em yaw são as mais expressivas, mas que, além delas, também são identificas rotações no entorno das direções $x$ e y, como era de se esperar já que se tratam de modelos flutuantes, ou seja, dotados de seis graus de liberdade na superfície livre (interface ar-água).

Embora de menor monta, é possível depreender das análise, pela própria natureza da restauração adotada que as rotações entorno da direção x (roll) têm relação com as translações na direção y, enquanto as rotações entorno da direção y (pitch) se associam às translações longitudinais.

Análises mais aprofundadas a esse respeito são deixadas como sugestão para traba- 
Ihos futuros.

Figura 4.16: Exemplos de registros temporais de rotação (roll, pitch e yaw) do modelo SSE-00 (modelo com arestas vivas e incidência $0^{\circ}$ ) em $V_{r}=7,34$.
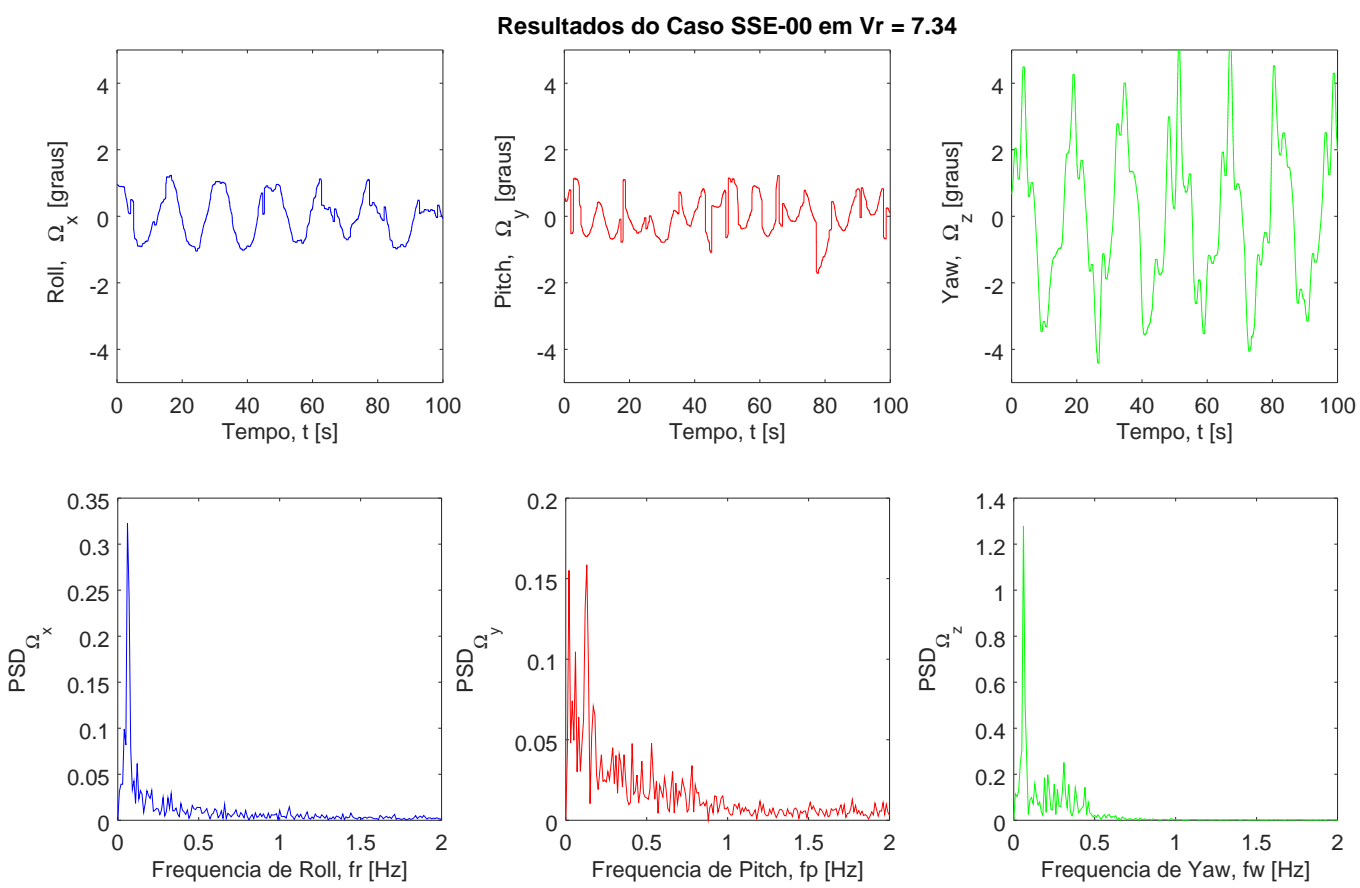

Esta última discussão coloca a esse capítulo de resultados que permite, então, a composição de um novo capítulo, onde os avanços conseguidos são sintetizados e perspectivas de desdobramentos são apresentadas. 
Figura 4.17: Amplitudes e frequências adimensionais de resposta em yaw para o modelo SSE45 , arestas vivas e incidência $45^{\circ}$.
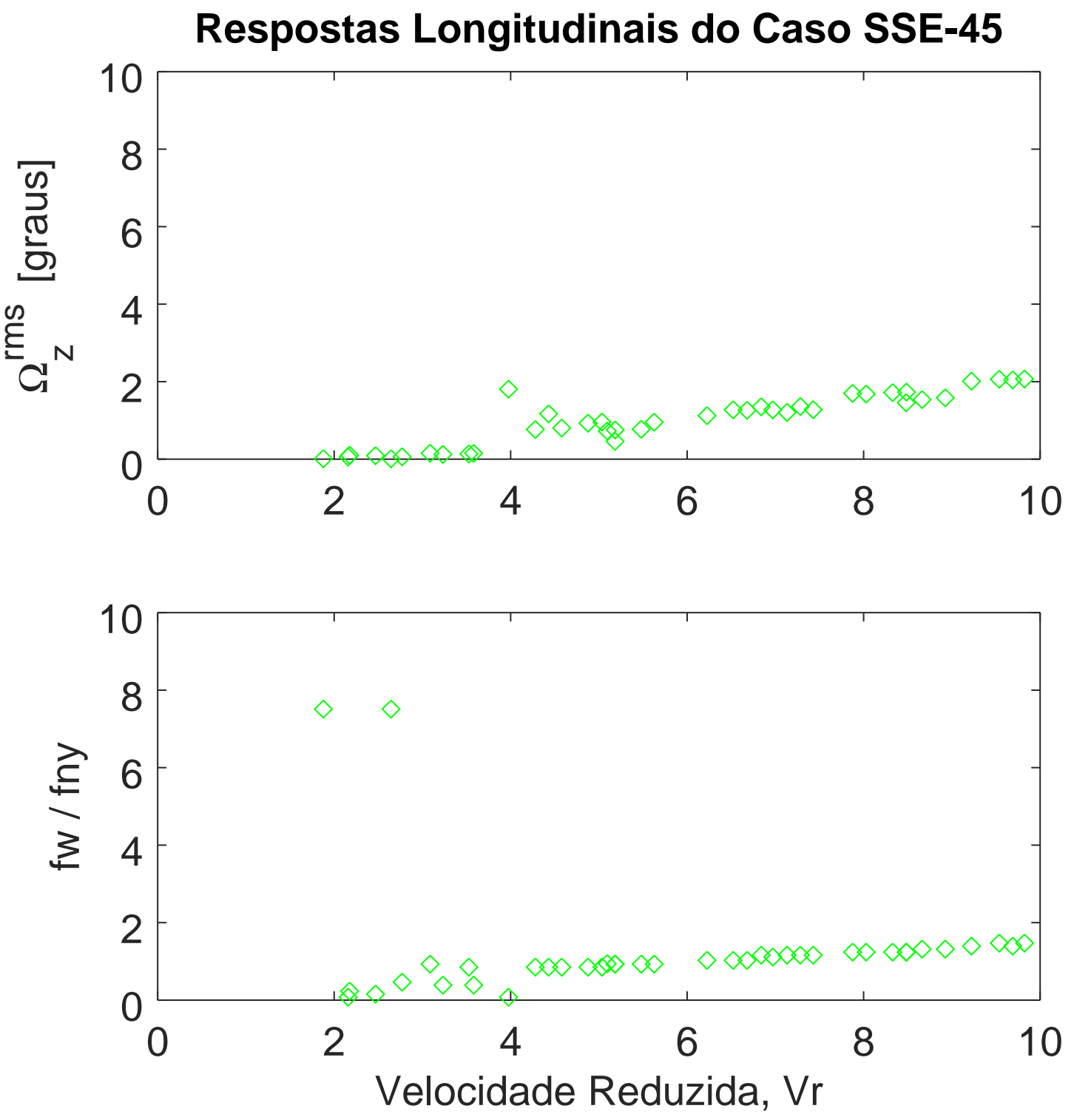


\section{Capítulo 5}

\section{CONCLUSÕES e PERSPECTIVAS}

Neste trabalho, duas geometrias na aresta de cilindros flutuantes de baixa razão de aspecto $(L / D)$ e seção quadrada foram investigadas experimentalmente: uma considerando arestas vivas (SSE) e outra arredondadas (SRE). Para cada umas dessas geometrias, duas incidências de escoamento foram consideradas, $0^{\circ}$ e $45^{\circ}$. Os testes aconteceram no tanque de reboque do IPT e ocorreram em velocidade reduzidas na faixa $2<V_{r}<15$, o que corresponde a números de Reynolds no intervalo $2 \times 10^{3}<R e<3 \times 10^{4}$.

Movimentos nos seis graus de liberdade de cada cilindro flutuante (SSE-00; SSE-45, SRE-00 e SRE-45) foram registrados para as diferentes velocidades testadas. A partir desses registros, estatística das amplitudes e análise de Fourier para determinação das frequências de resposta foram realizadas, permitindo a construção de gráficos de deslocamento rms adimensional nas direções longitudinal e transversal ao escoamento, bem como gráficos da rotação rms em yaw, todos como função da velocidade reduzida. Respectivamente, também foram montados gráficos das razões de frequência dominante nesses três graus de liberdade. Com base nesse gráficos foram obtidas as seguintes conclusões.

As maiores amplitudes adimensionais de resposta transversal ao escoamento, $Y^{r m s} / D$ acontecem para a incidência de $0^{\circ}$, independente do tipo de aresta (viva ou arredondada).

O caso SSE-00, modelo com arestas vivas submetido a escoamento com incidência a $0^{\circ}$, exibiu as maiores oscilações transversais, associadas à concomitantes oscilações longitudinais. Esse comportamento como um todo se assemelha àquele descrito em AMATO (2010), quando VIV e galloping parecem acontecer simultaneamente.

O caso SSE-45, modelo com arestas vivas submetido a escoamento com incidência a $45^{\circ}$, apresentou menores amplitudes, mas um "patamar" em $Y^{r m s} / D \approx 0,4$ para as velocidades reduzidas mais altas.

O arredondamento das arestas, casos SRE-00 e SRE-45, levou a um comportamento dinâmico típico do VIV, com uma região de sincronização no intervalo $4 \lesssim V_{r} \lesssim 12$. No caso SRE-45, no entanto, o início da região de sincronização é mais suave que aquele exibido pela incidência de $0^{\circ}$.

No que se refere às razões de frequência transversal, verificou-se que os modelos 
SSE-45 e SRE-00 respondem com $1,0 \lesssim f y / f_{n y} \lesssim 1,5$, enquanto os modelos SSE-00 e SRE45 respondem com $f y / f_{n y} \approx 0,5$. Este último resultado, apesar de aparentemente estranho, é corroborado por uma excitação das oscilações longitudinais em frequência que mantem a relação usualmente conhecida, $f x \approx 2 f y$.

De uma maneira geral, as rotações em yaw se mostraram importantes, com amplitudes angulares expressivas. Destaque para o caso SRE-45, que apresentou $\Omega_{z}^{r m s}=9^{\circ}$ em $V_{r} \approx 18$ (mas $\Omega_{z}^{r m s}=2^{\circ}$ em $V_{r} \approx 12$ ), e para o caso SSE-00, que apresentou $\Omega_{z}^{r m s}=6^{\circ}$ em $V_{r} \approx 10$.

Segundo esses resultados, o arredondamento das aresta, de uma maneira geral, meIhora o comportamento dinâmico, diminuindo as amplitudes de resposta devido aos fenômenos de vibração induzida pelo escoamento.

Tal conclusão, no entanto, precisa de análises mais aprofundas que, por ora, suscitam as seguintes perspectivas para trabalhos futuros.

Realização de análises mais aprofundadas dos demais graus de liberdade envolvidos na dinâmica dos cilindros flutuantes excitados pelo VIV e/ou pelo galloping. Essas análises devem incluir a aplicação de técnicas de processamento de sinais mais versáteis, particularmente aquelas que permitem uma compreensão melhor das frequências de resposta, ao mesmo tempo que aumentam a precisão da determinação estatística das amplitudes. Exemplo desta técnica é a Transformada de Hilbert-Huang.

Realização de investigações para a definição do mecanismo exato responsável pelos fenômenos de VIV e/ou galloping atuante nos cilindros com baixa razão de aspecto e seção quadrada, a partir da visualização do escoamento próximo (com a utilização de câmeras capazes de captar o movimento das partículas no entorno do cilindro - técnicas de PIV) e, portanto, permitir a medição do campo de pressões nessa mesma região.

Realização de análises da dinâmica dos fluidos computacional (Computational Fluid Dynamics - CFD) para a identificação dos modelos fluidos de geração e desprendimento de vórtices nos cilindros flutuantes de baixa ração de aspecto com alterações na arestas imersas. Essas análises, em conjunto com as visualizações de escoamento devem mostrar as causas fluidas para muito dos comportamentos dinâmicos como os apontados neste texto.

Finalmente, independente dessas perspectivas de trabalhos que ainda precisam ser realizados para um maior compreensão, acredita-se que este trabalho atingiu seus objetivos, mostrando que movimentos induzidos pelo escoamento são alterados por modificações na geometria da extremidade livre de cilindros flutuantes com baixa razão de aspecto. Há que se destacar que por se tratar de um cilindro com baixa razão de aspecto, a extremidade livre analisada neste trabalho foi a geometria da aresta. 


\section{Bibliografia}

AMATO, R. (2010). Sulla risposta dinamica ed aeroelastica all'azione eolica di una torre a sezione rettangolare. PhD thesis, Politecnico de Milano - Facoltà di Ingegneria Industriale.

ASSI, G. R. S. (2005). Estudo experimental do efeito de interferência no escoamento ao redor de cilindros alinhados. Master's thesis, Univerisade de São Paulo - Dissertação de mestrado.

ASSI, G. R. S. e. a. (2010). On the wake-induced vibration of tandem circular cylinders: the vortex interaction excitation mechanism. Journal of Fluid Mechanics, v661, p. 365-401.

BEARMAN, P. W. (1984). Vortex shedding from oscillating bluff bodies. Ann. Rev. Fluid Mech, v. 16, pp. 195-222., 16:195-222.

BLEVINS, R. D. (2001). Flow-induced vibrations. 2nd edition, 2 ed edition.

CLAUSS, G. (2007). The conquest of the inner space. Marine Stystems and Ocean Engineering.

FUJARRA, A. L. C. (2013). O fenômeno de vim em plataformas oceânicas. (tese de livre docência). Technical report, Universidade de São Paulo.

FUJARRA, A. L. C. e. a. (2012). State-of art on vortex-induced motion: a comprehensive survey after more than onde decade of experimental investigation. Proceedings of the 31th International Conference on Ocean, Offshore and Arctic Engineering.

GERRAD, J. H. (1966). The mechanics of the formation region of the vortices behind bluff bodies. Journal of Fluid Mechanics, v. 25, n. Part 2, pp. 401-413., v.25(n.2):p.401-413.

GONÇALVES, R. T.; ROSETTI, e. a. (2013a). Experimental study on vortex-induced motions of a semi-submersible platform with four square columns, part ii: effects of surface waves, external damping and draft condition. Ocean Engineering, 62, pp, 10-24.

GONÇALVES, R. e. a. (2013b). Two-degree-of-freedom vortex-induced vibration of circular cylinders with very low aspect ratio and small mass ratio. Journal of Fluids and Structures, $v$. 39, pp. 237-257.

GONÇALVES, R. T. (2013c). Vibrações Induzidas pela Emissão de Vórtices em Cilindros com Baixa Razão de Aspecto. PhD thesis, Tese (doutorado) - Universidade de São Paulo. 
GONÇALVES, R. T. e. a. (2012). Experimental study on vortex-induced motions of a semisubmersible platform with four square columns, part $\mathrm{i}$ : Effects of current incidence angle and hull appendages. Ocean Engineering, 54, pp, 150-169.

GONÇALVES, R. T. e. a. (2015). Flow arround circular cylinders with very low aspect ratio. Journal of Fluid and Structures, v. 54, pp. 122-141.

GOVARDHAN, R.; WILLIAMSON, C. H. K. (2000). Modes of vortex formation and frequency response a frfree vibrating cylinder. Journal of Fluid Mechanics, v.420.

JAUVITIS, N.; WILLIAMSON, C. (2004). The effect of two degrees od frefree on vortex-induced vibration at low mass and damping. Journal of Fluid Mechanics, v. 509, pp. 23-62.

KAWAMURA, T. e. a. (1984). Flow around a finite circular cylinder on a flat plate : cylinder height greater than turbulent boundary layer thickness. Bulletin of the Japan Society of Mechanical Engineers, pp. 2142-2151.

KHALAK, A.; WILLIAMSON, C. (1997). Fluid forces and dynamics of a hydroelastic structure with very low mass and damping. Journal of Fluid and Structures, v. 11, pp. 973-982., (n. 11).

KHALAK, A.; WILLIAMSON, C. (1999). Motions forces and mode transitions in vortex-induced vibration at low mass-damping. Journal of Fluids and Structures, v. 13, pp. 813-851., (n.13):p.813-851.

KORKISCHKO, I. (2011). Investigação experimental e analítica do escoamento ao redor de cilindro circular com supressores de VIV. PhD thesis, Tese (doutorado) - Universidade de São Paulo.

MENEGHINI, J.R.; BEARMAN, P. (1993). Numerical simulationof high amplitude oscillatory flow about a circular cylinder using a discrete vortex method. In Tese de Doutorado - Imperial College.

NEMES, A. e. a. (2012). The interaction between flow-induced vibration mechanims of a square cylinder with varying aangle of attack. Journal of Fluid Mechanics, v. 710, pp. 102-130., 710:102-130.

NORBERG, C. (2000). Flow around a circular cylinder: aspects of fluctuating lift. Journal of Fluids and Structures, p. 459-469.

PARK, C. W.; LEE, S. (2004). Effects of free-end corner shape on flow structure around a finite cylinder. Journal of Fluids and Structures v. 19, pp. 141-158.

ROSHKO, A. (1954). On the drag and shedding frequency of bluff cylinders. Nut. Adv. Comm. Aero., Wash., Tech. Note 3169.

SARPKAYA, T. (1979). Vortex-induced oscillating - a selective rewiew. Journal of Applied Mechanics, v. 46, pp. 241-258. 
SARPKAYA, T. (2004). A critical review of the intrinsic nature of vortex-induced vibrations. Journal of Fluids and Structures, v. 19, n. 4, pp. 389-447.

SLAOUTI, A.; GERRARD, J. H. (1981). An experimental investigation of the end effects on the wake of a circular cylinder towed through water at low reynolds numbers. Journal of Fluid Mechanics, v, 112, pp. 297-314.

SOMEYA, S. e. a. (2010). Experimental investigation of a flow-induced oscillating cylinder with two-degree-of-freedom. Nuclear Engineering and Design, pp. 4001-4007.

WILLIAMSON, C. H. K.; ROSHKO, A. (1988). Vortex formation in the wake of an oscillating cylinder. Journal of Fluids and Structures, v. 2, pp. 355-381., v. 2.

WILLIAMSON, C. H. K. (1996). Vortexdynamics in the cylinder wake. Annual Review of Fluid Mechanics, v. 28, pp. 477-539.

WILLIAMSON, C. H. K.; GOVARDHAN, R. (2004). Vortex-induced vibrations. Annual Review of Fluid Mechanics, v. 36, n. 1, p. 413-455.

ZDRAVOVICH, M. (1987). The effects of interface between circular cylinders in cross-flow. Journal of Fluids and Structures; v1,pp. 239-261.

ZHAO, J. e. a. (2014). Fluid-structure interaction of a square cylinder at different aangle of attack. Journal Fluid Mechanics, v. 747, pp. 688-721. 
